\author{
Universidade de São Paulo \\ Instituto de Astronomia, Geofísica e Ciências Atmosféricas \\ Departamento de Astronomia
}

Natália Fernanda de Souza Andrade

\title{
Aquecimento Alfvênico em discos de acreção protoestelares: efeito na redução da zona
} morta

São Paulo 



\section{Aquecimento Alfvênico em discos de acreção protoestelares: efeito na redução da zona}

\section{morta}

Dissertação apresentada ao Departamento de Astronomia do Instituto de Astronomia, Geofísica

e Ciências Atmosféricas da Universidade de São Paulo como requisito parcial para a obtenção do título de Mestre em Ciências.

Área de Concentração: Astronomia

Orientadora: Prof. ${ }^{a}$ Dr. ${ }^{a}$ Vera Jatenco Silva Pereira

Versão corrigida. O original encontrase disponível na unidade.

São Paulo 

À minha família 



\section{Agradecimentos}

À minha família pelo apoio e amor, sem os quais esse trabalho não seria possível. Em especial, aos meus pais, pelos esforços e sacrifícios constantes que me propiciaram seguir em frente com o sonho da vida acadêmica e à minha irmã, pelo orgulho e alegria que sempre me deu. O caminho adiante é sempre mais fácil quando sabemos que temos para onde voltar.

Aos amigos de Ribeirão, pelo companheirismo e confiança de tantos anos, em especial ao meu melhor amigo (e primo!) Rafa, à Sabrina, Ane, Victoria, João, Matt e tantos mais. A vida sempre foi mais gostosa ao lado de vocês.

Aos amigos e colegas do IAG, em especial à Stela, Thayse, Cadu, André, Luisa, Erik, Andrés, Pablo, Marcelo, Stephan, Lilianne, Rafa e tantos outros que tornaram meu tempo na USP e em São Paulo muito mais alegre.

À minha família de São Paulo, seu Giuseppe, dona Marlene, Amanda, Geisy e todas as pessoas que passaram pela república, por fazerem da nossa casa um lar, de uma maneira que só uma família consegue fazer.

À minha orientadora, Professora Vera Jatenco-Pereira, que me acompanha desde meu primeiro ano de graduação, pela orientação e disponibilidade, sempre alegre, que me concedeu.

Aos professores do departamento de Astronomia do IAG pelas discussões e ensinamentos, tanto dentro quanto fora da sala de aula. Gostaria de agradecer especialmente à Professora Jane Gregorio-Hetem e ao meu relator, Professor Alex Carciofi, pelos conselhos e conversas, importantes tanto para o meu crescimento acadêmico quanto pessoal.

À Fundação de Amparo à Pesquisa do Estado de São Paulo (FAPESP) e à Coordenação de Aperfeiçoamento de Pessoal de Nível Superior (CAPES), pelo apoio financeiro, sob o 
processo FAPESP número 2017/26042-2, concedido através do convênio FAPESP/CAPES para a concessão de bolsas de pesquisas de ensino superior no estado de São Paulo. As opiniões, hipóteses e conclusões ou recomendações expressas neste material são de responsabilidade dos autores e não necessariamente refletem a visão da FAPESP e da CAPES.

À Universidade São Paulo e ao IAG, por proporcionarem toda a estrutura necessária para a realização desse Mestrado, especialmente aos funcionários do IAG, por fazerem o ambiente de trabalho o mais leve e aconchegante possível.

Aos que ficam. 


\section{Resumo}

Discos de acreção são observados em torno de estrelas jovens, como estrelas T Tauri. Para que haja transporte do material do disco para a estrela é necessário que as partículas do disco percam um pouco de sua energia de rotação e caiam em direção ao objeto central. O mecanismo de transporte de momento angular mais promissor é a Instabilidade MagnetoRotacional (IMR). No entanto, esta instabilidade requer que as partículas do gás estejam acopladas às linhas de campo magnético. Para que isso ocorra, uma fração das partículas deve estar carregada. Como a temperatura do disco é muito baixa, as partículas apresentam baixos graus de ionização. Assim, para que a IMR possa atuar em todo o disco, são necessárias temperaturas mais altas. Há vários trabalhos na literatura que utilizam o amortecimento de ondas Alfvén como mecanismo extra de fonte de energia em discos. Os mecanismos estudados foram: o amortecimento não-linear e o turbulento. Neste trabalho, estudamos em 2D os amortecimentos não-linear e turbulento e introduzimos um novo mecanismo, ainda não aplicado à este ambiente, a absorção ressonante de ondas Alfvén de superfície, e analisamos como cada um desses mecanismos pode aquecer o disco. Propomos também que a absorção ressonante pode ser acoplada ao amortecimento turbulento, através do desenvolvimento da Instabilidade Kelvin-Helmholtz. Nossos resultados mostram que a absorção ressonante, por não promover nenhum aquecimento expressivo, não gera nenhum tipo de mudança na estrutura do disco, enquanto o amortecimento não-linear torna-se significativo apenas para grandes fluxos de onda. O amortecimento acoplado, por outro lado, apesar de aquecer o disco significativamente, sendo na maioria das vezes mais efetivo que os mecanismos não-linear e ressonante, gera temperaturas inferiores àquelas associadas ao amortecimento turbulento, mecanismo mais eficiente dentre os considerados neste trabalho. 



\section{Abstract}

Accretion disks are commonly observed around young stars, such as T Tauri stars. In order for the accretion to happen, the disk particles must lose their rotational energy and fall towards the central object. The most promising mechanism for angular momentum transport in accretion disks is the Magnetorotational Instability (MRI). This instability, however, requires that the gas particles be coupled to the magnetic field lines. Thus, a fraction of the particles must be charged. As the disk temperatures are too low, the particles exhibit a low ionization fraction. Therefore, to assure the occurrence of the MRI in the whole disk, higher temperatures are required. Many works in the literature have proposed the damping of Alfvén waves as an extra energy source in disks. The considered mechanisms were: the nonlinear damping and the turbulent damping. In this work, we have studied, in 2D, the nonlinear and turbulent dampings and introduce a new mechanism, not yet applied to this environment, the resonant absorption of surface Alfvén waves, and analyse how each of these mechanisms can heat the disk. We also propose that the resonant absorption can be coupled to the turbulent damping, through the Kelvin-Helmholtz Instability. Our results show that, since the resonant absorption does not provoke any expressive heating in the disk, changes in the disk structure associated with this mechanism are inexistent, while the nonlinear damping is significant only for very high Alfvén wave fluxes. The coupled mechanism, on the other hand, despite significantly heat the disk, being more effective than the nonlinear and resonant mechanisms in most cases, generates smaller temperatures than the turbulent damping, the most effective mechanism among those considered in this work. 



\section{Lista de Figuras}

1.1 Imageamento de discos associados à estrelas $\mathrm{T}$ Tauri, realizado com a banda H do instrumento SPHERE/IRDIS. Figura retirada de Avenhaus et al. (2018). 21

1.2 Representação dos diferentes estágios evolutivos de uma estrela de tipo solar (i.e. de baixa massa). Figura retirada de André (1994) . . . . . . . . . . . .

1.3 Representação esquemática de uma estrela $\mathrm{T}$ Tauri. Figura retirada de Hartmann (2005) . . . . . . . . . . . . . . . . . .

1.4 Representação do modelo de acreção em camadas proposto por Gammie (1996), aplicado à estrelas T Tauri. Figura retirada de Gammie (1996) . . . 27

1.5 Representação esquemática da atuação da IMR . . . . . . . . . . . . . . . .

2.1 Representação esquemática da difusão de matéria associada à atuação da viscosidade. Figura extraída de Hartmann $(2009)$. . . . . . . . . . . . . . .

3.1 Esquema da geometria adotada para a aplicação da absorção ressonante no disco e dos processos que levam à dissipação da onda de superfície. . . . . . .

3.2 Representação esquemática do desenvolvimento da Instabilidade KelvinHelmholtz. Figura retirada de Murcia (2018). . . . . . . . . . . . . 599

3.3 Representação esquemática da geometria adotada para o disco. . . . . . . . 61

3.4 Representação esquemática do mecanismo proposto para unificar os amortecimentos turbulento e ressonante. . . . . . . . . . . . . . . . .

4.1 Fluxograma do método utilizado para obter a estrutura do disco quando apenas a dissipação viscosa é atuante. . . . . . . . . . . . . . . . . .

4.2 Fluxograma do procedimento utilizado para obter a fração de ionização no disco e estimar a extensão da zona morta. . . . . . . . . . . . . . . . 91 
5.1 Perfil radial das temperaturas central (traço-ponto) e efetiva (linha cheia) para um disco de acreção ao redor de uma estrela $\mathrm{T}$ Tauri de massa $M_{*}=$ $0.7 M_{\odot}$, quando apenas a dissipação viscosa é atuante. . . . . . . . . . . .

5.2 Perfil radial da densidade superficial para um disco de acreção ao redor de uma estrela $\mathrm{T}$ Tauri de massa $M_{*}=0.7 M_{\odot}$, quando apenas a dissipação viscosa é atuante. . . . . . . . . . . . . . . . . . . . . . . .

5.3 Perfil da variação da densidade volumétrica do disco de acreção ao redor uma estrela T Tauri de massa $M_{*}=0.7 M_{\odot}$, nas direções radial e vertical, quando apenas a dissipação viscosa é atuante. . . . . . . . . . . . . . . 96

5.4 Perfil da variação da densidade superficial do disco de acreção ao redor uma estrela T Tauri de massa $M_{*}=0.7 M_{\odot}$, nas direções radial e vertical, quando apenas a dissipação viscosa é atuante. . . . . . . . . . . . . . . . . . .

5.5 Perfil da densidade de coluna $\left(\mathrm{em}^{-2}\right.$ ) para um disco de acreção, que segue o modelo $\alpha$ padrão e o modelo de camadas, ao redor de uma estrela $\mathrm{T}$ Tauri de massa $M_{*}=0.7 M_{\odot}$, quando apenas a dissipação viscosa é atuante. 98

5.6 Perfil radial da temperatura central do disco considerado para um parâmetro de fluxo de ondas $f=0.01$ e número azimutal $m=40000$. . . . . . . 100

5.7 Extensão da zona morta após a atuação da absorção ressonante de ondas Alfvén de superfície (painel (a)) e do amortecimento não-linear de ondas Alfvén (painel (b)) para $f=0.01$ e $m=40000$.

5.8 Extensão da zona morta após a atuação do mecanismo acoplado (painel (a)) e do amortecimento turbulento de ondas Alfvén (painel (b)) para $f=0.01$ e $m=40000$.

5.9 O mesmo que a Figura 5.6, mas para $f=0.02$ e $m=40000 \ldots$. . . . . 103

5.10 O mesmo que a Figura 5.7, mas para $f=0.02$ e $m=40000$. . . . . . . 104

5.11 O mesmo que a Figura 5.8, mas para $f=0.02$ e $m=40000 . \ldots$. . . . 105

5.12 O mesmo que a Figura 5.8, mas para $f=0.02$ e $m=4000$. . . . . . . . 106

5.13 O mesmo que a Figura 5.6, mas para $f=0.1$ e $m=400 . \ldots$. . . . . 107

5.14 O mesmo que a Figura 5.7, mas para $f=0.1$ e $m=400 . \ldots$. . . . . 109

5.15 O mesmo que a Figura 5.8 , mas para $f=0.1$ e $m=400$. . . . . . . . 110

5.16 O mesmo que a Figura 5.6, mas para $f=0.2$ e $m=400$. . . . . . . . 111

5.17 O mesmo que a Figura 5.7, mas para $f=0.2$ e $m=400 . \ldots$. . . . . 112 
5.18 O mesmo que a Figura 5.8 , mas para $f=0.2$ e $m=400 . \ldots$. . . . 113

5.19 O mesmo que a Figura 5.8 , mas para $f=0.2$ e $m=100$. . . . . . . . 114

5.20 variação radial das escalas de tempo atuantes no disco. . . . . . . . . . . 119 



\section{Lista de Tabelas}

5.1 Tabela com o resumo dos resultados obtidos para cada um dos mecanismos. 116 



\section{Sumário}

1. Introdução . . . . . . . . . . . . . . . . . . . . . . . 19

1.1 Discos de acreção no processo de formação estelar . . . . . . . . . . . . . . 21

1.2 Ondas Alfvén como mecanismo extra de aquecimento . . . . . . . . . . 28

2. A teoria de discos de acreção . . . . . . . . . . . . . . . . . . . . . 31

2.1 As equações que regem o disco . . . . . . . . . . . . . . . . . . 31

2.2 A aproximação de disco geometricamento fino . . . . . . . . . . . . . 33

2.3 A aproximação de disco geometricamento fino, opticamente espesso e esta-

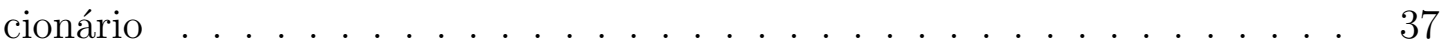

3. O amortecimento de ondas Alfvén como fonte extra de aquecimento . . . . . . 43 43

3.1 Ondas Alfvén . . . . . . . . . . . . . . . . . . . . 43

3.2 O amortecimento não-linear de ondas Alfvén . . . . . . . . . . . . . . 46

$3.3 \mathrm{O}$ amortecimento turbulento de ondas Alfvén . . . . . . . . . . . . 48

3.4 A absorção ressonante de ondas Alfvén de superfície . . . . . . . . . . . . . 51

3.5 A unificação dos mecanismos turbulento e ressonante . . . . . . . . . . 56

3.5.1 Condições iniciais e as equações-base para o disco . . . . . . . 58

3.5.2 A forma da perturbação . . . . . . . . . . . . . . . . 62 62

3.5.3 A prescrição para a Instabilidade Kelvin-Helmholtz . . . . . . . . . 65

3.5.4 A Instabilidade Kelvin-Helmholtz como um mecanismo de acoplamento entre o amortecimento turbulento e a absorção ressonante de ondas Alfvén de superfície . . . . . . . . . . . . . . . . . . . . 68

4. O código numérico . . . . . . . . . . . . . . . . . . . . . . . . . . 75 
4.1 Código-base: simulação de um disco geometricamente fino, opticamente espesso no regime estacionário . . . . . . . . . . . . . . 75

4.1.1 Obtenção das propriedades no plano médio do disco . . . . . . . 78

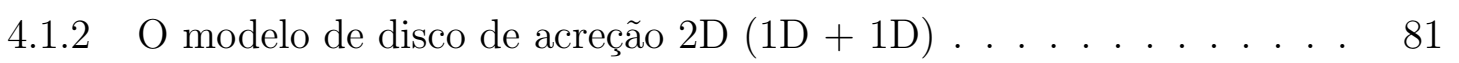

4.2 Inclusão dos mecanismos de amortecimento de ondas Alfvén . . . . . . . . 84

4.3 Código responsável por obter a fração eletrônica no disco de acreção e simular a extensão da zona morta . . . . . . . . . . . . . . . 86

4.3 .1 Ionização térmica . . . . . . . . . . . . . . . 86

4.3.2 Ionização por raios-X . . . . . . . . . . . . . . . . 87

4.3.3 Ionização por raios cósmicos . . . . . . . . . . . . . 88

4.3.4 Recombinação . . . . . . . . . . . . . . . . 88

4.4 Procedimento adotado . . . . . . . . . . . . . . . . . . . . . . . 89

5. Simulações e Resultados . . . . . . . . . . . . . . . . . . . . . . 93

5.1 Simulações referentes ao disco-base . . . . . . . . . . . . . . . 93

5.2 Simulações após a atuação dos mecanismos de amortecimento . . . . . 98

5.2.1 Simulações com parâmetro de fluxo de ondas $\mathrm{f}=0.01 \ldots$. . . . 99

5.2.2 Simulações com parâmetro de fluxo de ondas $\mathrm{f}=0.02 \ldots$. . . . . 99

5.2.3 Simulações com parâmetro de fluxo de ondas $\mathrm{f}=0.1 \ldots$. . . . . 107

5.2.4 Simulações com parâmetro de fluxo de ondas $\mathrm{f}=0.2 \ldots \ldots$

6. Conclusões . . . . . . . . . . . . . . . . . . . . . . . . 121

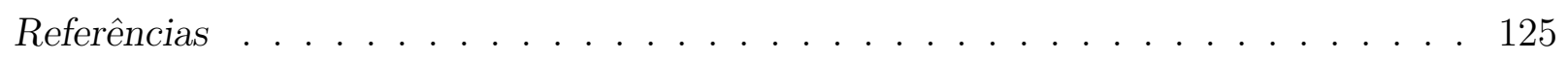

Apêndice 137

A. As equações que regem o disco . . . . . . . . . . . . . . . . . . . . . . 139

A.1 A equação de conservação de momento angular . . . . . . . . . . . . . . 139

A.2 O tensor de stress viscoso f . . . . . . . . . . . . . . . 141

A.3 A aproximação de disco geometricamente fino . . . . . . . . . . . . . 142

A.4 A aproximação do disco geometricamente fino, opticamente espesso e estacionário . . . . . . . . . . . . . . . . . . . . . . 145 
Capítulo 1

\section{Introdução}

A formação estelar permanece sendo um tema de grande interesse para as mais diversas áreas da Astronomia e Astrofísica. Sendo as estrelas os principais componentes bariônicos das galáxias, os processos envolvidos em sua formação podem ser utilizados para investigar as estruturas presentes no Universo, desde pequenas (e.g. sistemas planetários) à grandes escalas (e.g. galáxias).

A ideia de que o nascimento de uma estrela esteja relacionado à presença de uma grande nuvem de gás e poeira não é recente. De fato, já no século XVIII, Laplace e Kant afirmavam que o sistema solar nasceu de uma nebulosa em rotação. Mais recentemente, tais nebulosas foram rebatizadas de nuvens moleculares e reconhecidas como sendo berçários estelares. Esses sítios de formação estelar possuem características singulares necessárias à formação estelar: suas temperaturas são extremamente baixas, variando de 10-20 K, suas densidades são extremamente altas, são compostas, basicamente, de hidrogênio na sua forma molecular $\left(H_{2}\right)$ e apresentam movimentos turbulentos supersônicos Hartmann, 2009). A gravidade dessas nuvens é, a priori, contrabalançeada pela pressão térmica do gás, pela pressão magnética e por movimentos turbulentos. De fato, a turbulência supersônica observada nesses objetos é uma componente importante no balanceamento de energia, de forma que o colapso tende a ocorrer em regiões da nuvem que apresentam movimentos turbulentos reduzidos (e.g. Larson 1981; Hartmann 2009).

Conforme o colapso ocorre, algumas propriedades da nuvem se tranformam: há um aumento na temperatura da nuvem, uma vez que ocorre a transformação da energia potencial gravitacional em energia cinética; a velocidade de rotação aumenta significativamente devido à conservação de momento angular e ocorre ainda o achatamento da nuvem, formando um disco. Por fim, ocorre um aumento da pressão da nuvem, devido ao aumento observado 
na temperatura e densidade, de forma que a pressão volta a se tornar comparável à força gravitacional, desacelerando o colapso e originando, assim, uma protoestrela, i.e., uma estrela, nos estágios iniciais de sua evolução, que ainda não iniciou a fusão de Hidrogênio em seu núcleo. Dessa forma, o sistema final será formado por uma protoestrela na região central, circundada por um disco, o qual será responsável por promover a acreção observada nos estágios evolutivos mais avançados.

Apesar de, atualmente, haver um consenso a respeito do papel das nuvens moleculares na formação estelar de forma geral, a evolução pós-colapso varia enormemente de acordo com a massa da estrela: estrelas da pré-sequência principal (PMS, do inglês pre-mainsequence) de baixa massa $\left(M_{*} \lesssim 2 M_{\odot}\right)$, de tipos espectral F-M, são denominadas estrelas T Tauri, enquanto estrelas da PMS de massa intermediária, $M_{*} \sim 2-10 M_{\odot}$, são chamadas de estrelas Herbig Ae/Be (e.g. Hartmann, 2009). Estrelas de mais alta massa evoluem tão rapidamente que não há uma fase de PMS observável. Nos últimos anos, o desenvolvimento de técnicas e equipamentos de observação mais sofisticados possibilitaram um estudo mais aprofundado sobre a estrutura desses objetos, uma vez que agora é possível resolver esses sistemas. A observação de discos associados à estrelas T Tauri vem sendo particularmente beneficiado devido aos avanços associados à astronomia observacional de comprimentos de onda longos (e.g. comprimentos de onda submilimétricos e em rádio). Ademais, devido ao fato desses discos emitirem luz polarizada, técnicas polarimétricas também constituem-se como uma ótima ferramenta no imageamento dessas estruturas. Na Figura 1.1, são mostradas imagens de discos, associados à diferentes estrelas T Tauri, obtidas utilizando o imageamento por polarimetria do SPHERE/IRDIS, na banda H. Note que há uma grande variedade na estrutura desses discos, inclusive no tamanho (na direção radial) desses objetos. De fato, a extensão radial configura-se como uma importante propriedade na caracterização desses discos, apesar de sua definição ainda não ser uma tarefa trivial. Existem diversas evidências, entretanto, que apontam que a escala de tamanho típica desses objetos é da ordem de centenas de unidades astronômicas (UA, e.g. Andrews e Williams 2007; Maucó et al. 2016, Najita e Bergin 2018). É importante frisar, porém, que tais medidas levam em consideração o raio externo do gás que compõe o disco, uma vez que, devido ao fato de grãos de poeira sofrerem uma 'arrasto' radial para as regiões mais internas do disco, a utilização da poeira para a determinação da extensão dessas estruturas pode resultar em uma subestimação do tamanho desses objetos (e.g. Ansdell et al. 2018; 

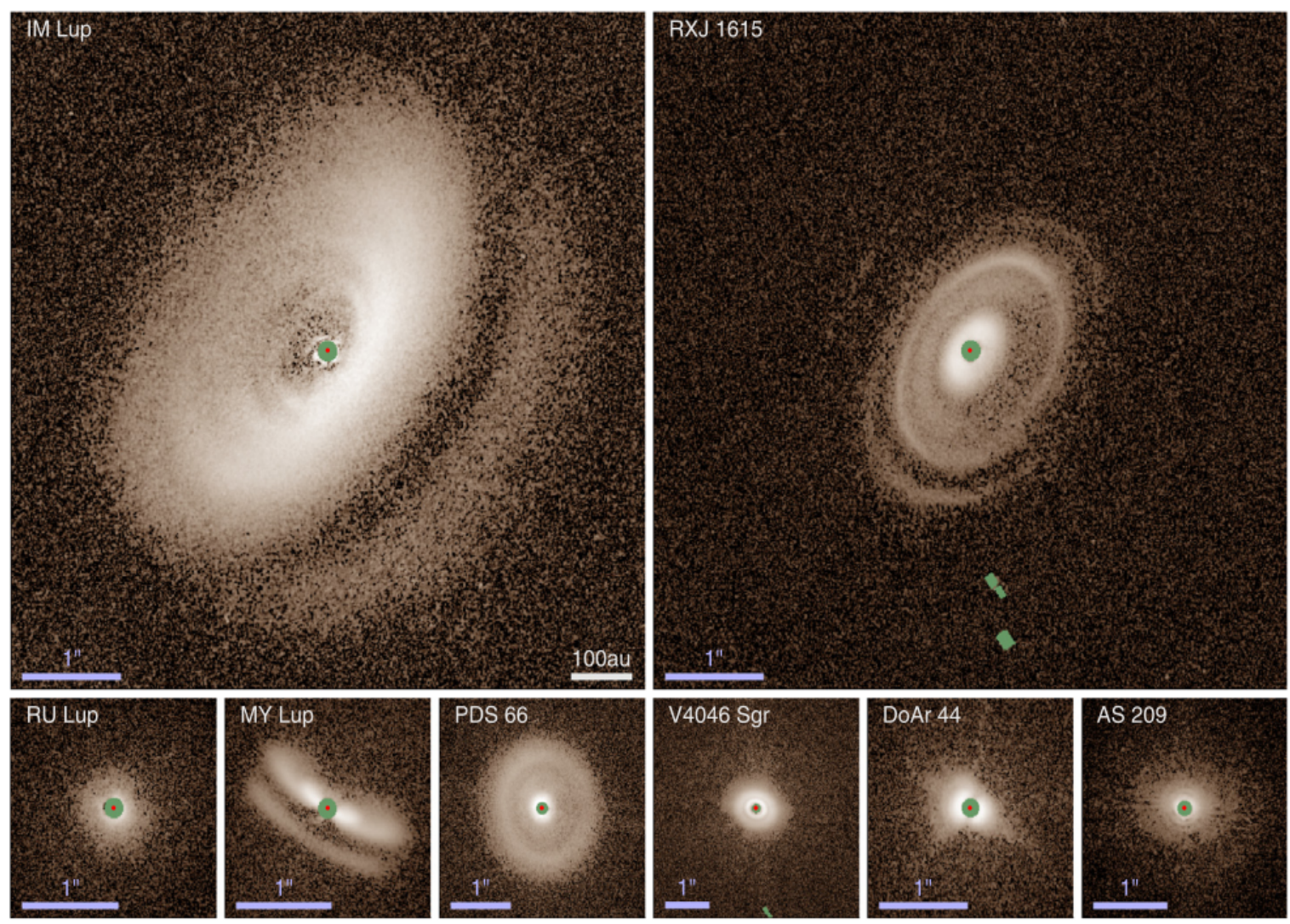

Figura 1.1: Imageamento de discos associados à estrelas $\mathrm{T}$ Tauri, realizado com a banda $\mathrm{H}$ do instrumento SPHERE/IRDIS. Todas as imagens representam o mesmo tamanho físico. Os pontos vermelhos representam a posição da estrela, enquanto os círculos verdes denotam as regiões onde não há informações. Figura retirada de Avenhaus et al. (2018).

Najita e Bergin 2018). Nesta dissertação, focaremos apenas nos processos relacionados à formação de estrelas de baixa massa, i.e., estudaremos os mecanismos associados à evolução das estrelas T Tauri.

\subsection{Discos de acreção no processo de formação estelar}

Durante o colapso da nuvem molecular, a sua velocidade de rotação aumenta, de forma que parte da matéria das regiões mais periféricas da nuvem concentra-se em um disco, cujo plano é perpendicular ao eixo de rotação, formando um sistema composto por esse disco associado a um objeto central (a protoestrela). Nessa nova configuração (objeto central + disco), o sistema passa por quatro grandes estágios evolutivos, apresentados na Figura 1.2. retirada de André (1994), conforme proposto por Lada (1987) e André et al. (1993). Os índices 0-III representam os estágios evolutivos de menos para o mais avançado, respectivamente. No topo, apresentamos o estágio imediatamente seguinte à contração da 
nuvem: o processo de contração cessa e o objeto central torna-se uma protoestrela (classe 0). Devido à alta opacidade do sistema resultante (protoestrela + disco) não é possível observar a radiação proveniente do objeto central, sendo visível apenas a radiação associada aos grãos de poeira presentes no envelope que o circunda. As fontes de classe 0 caracterizam-se por serem extremamente vermelhas e apresentarem emissões substanciais no regime submilimétrico (sub-mm), comparativamente à sua luminosidade total (Hartmann, 2009). O espectro esperado de tais objetos encontra-se representado no gráfico à esquerda no topo da Figura 1.2. O estágio imediatamente posterior corresponde à uma protoestrela de classe I (segundo painel, de cima para baixo, da Figura 1.2). Nesta fase, o objeto central já se encontra mais evoluído, tendo acretado uma grande quantidade de matéria da nuvem circunstelar. Dessa forma, a quantidade de gás e poeira que envolvem a estrela é inferior à presente em protoestrelas de classe 0, de forma que a emissão no submm passa a ser menos significativa, enquanto a emissão no infra-vermelho (IR, do inglês infrared) (médio à distante) torna-se bastante evidente.

Os dois últimos painéis da Figura 1.2, por sua vez, representam objetos estelares jovens (YSOs, do inglês Young Stellar Objects) em estágios mais avançados. Nesses casos, a radiação da fotosfera estelar já pode ser observada. Objetos de classe II - também denominados T Tauris clássicas - são compostos por um objeto central em avançado estágio evolutivo acompanhado por um disco circunstelar opticamente espesso. Essa configuração faz com que a distribuição de energia espectral (SED, do inglês Spectral Energy Distribution) do objeto tome a forma de um corpo negro deformado para comprimentos de onda maiores, conforme pode ser visto na Figura 1.2. Tal deformação está associada à um excesso de emissão no IR provocado pelas partículas de poeira presentes no disco, as quais absorvem a emissão em frequências mais altas, advindas da estrela, e a reemite em menores frequências. Finalmente, os objetos de classe III são aqueles onde boa parte do disco já foi dissipada, de forma que sua SED assemelha-se à um espectro de corpo negro, típico da emissão fotosférica de uma estrela PMS de baixa massa, tendo baixa contribuição da emissão associada ao disco (Hartmann, 2009).

O paradigma atual para as estrelas T Tauri clássicas é de que o efeito do campo magnético proveniente do objeto central trunca o disco em um dado raio interno, $R_{i}$, de forma que a acreção ocorre através de um processo denominado acreção magnetosférica (e.g. Ostriker e Shu, 1995; Hartmann, 2009): as partículas são transferidas do disco para a 

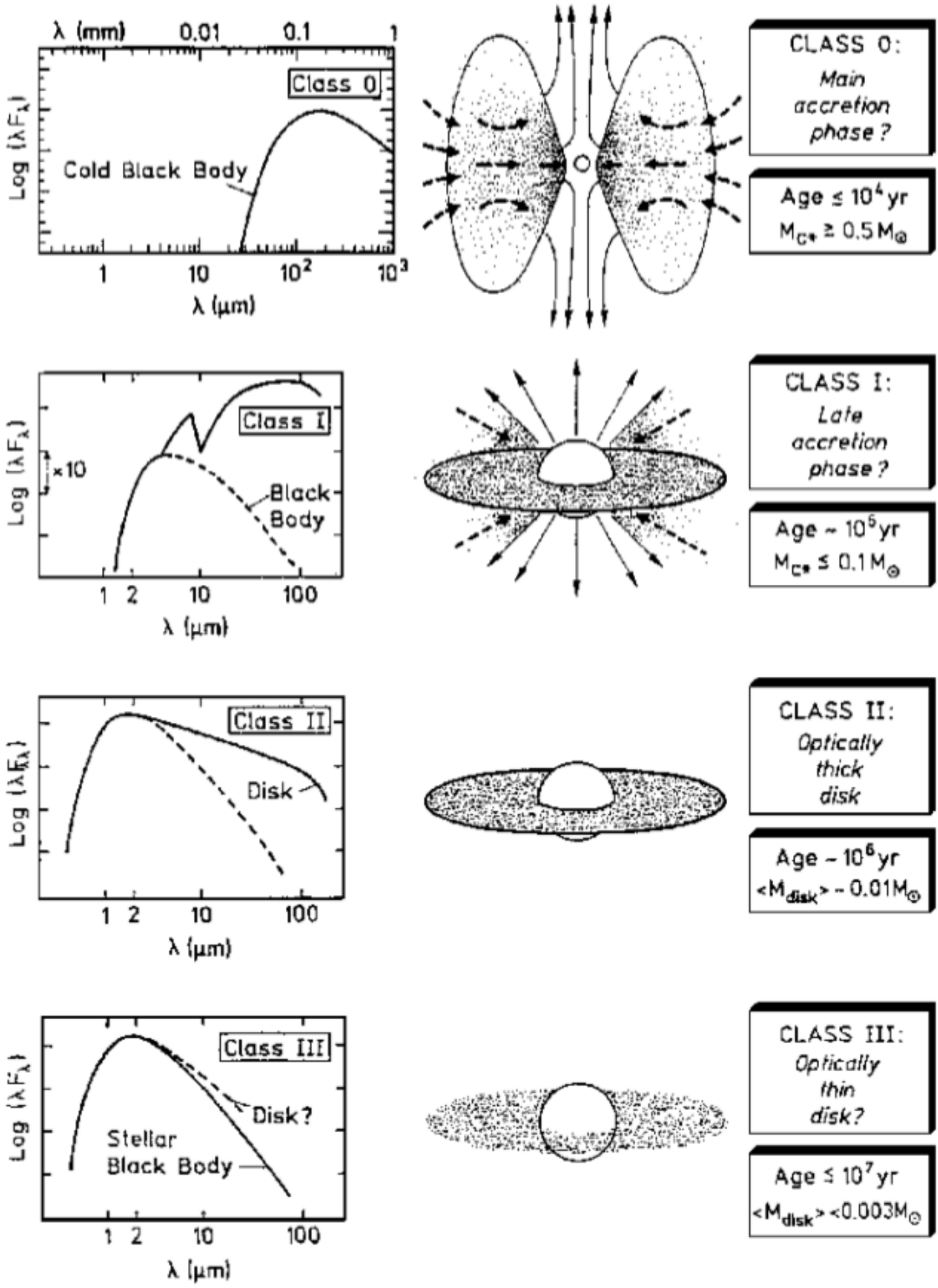

Figura 1.2: Representação dos diferentes estágios evolutivos de uma estrela de tipo solar (i.e. de baixa massa). Apresentamos, além de uma representação esquemática do objeto, um exemplo do espectro esperado de acordo com os diferentes estágios evolutivos. Figura retirada de André (1994). 
protoestrela por colunas de acreção magnéticas que ligam o disco à superfície estelar. Esse fluxo de matéria atinge velocidades próximas à velocidade de queda livre, de forma que, ao atingir o objeto central, originam um excesso de emissão nas regiões mais quentes do espectro, como no óptico e ultravioleta. Ademais, essas altas velocidades, adquiridas nesses funis, também explicam a presença de linhas de emissão largas, características das estrelas T Tauri clássicas. O raio de trancamento (i.e. raio interno do disco) é definido através da equiparação entre a tensão magnética associada à magnetosfera estelar e a tensão da matéria do disco, i.e., nas regiões internas ao raio de truncamento a pressão magnética é dominante sobre a pressão do gás (e.g. Romanova e Owocki 2015). Uma ilustração dessa configuração é dada na Figura 1.3 . O processo de acreção é intrinsicamente relacionado ao transporte de momento angular nesses discos protoestelares. Diversos mecanismos já foram propostos como sendo responsáveis por promover esse transporte de momento angular nesses objetos, como, por exemplo, ventos que possam atuar sobre o sistema estreladisco e a Instabilidade Magnetorotacional (IMR, Balbus e Hawley, 1991). Nos últimos anos, os efeitos associados à presença de ventos vêm sendo intensamente explorados na extração de momento angular desses discos. De fato, Bai (2011) e Perez-Becker e Chiang (2011) mostraram que, devido à baixa fração de ionização, nas regiões mais internas do disco $(r<10 \mathrm{UA})$ a IMR não é suficiente para explicar as taxas de acreção observadas, de forma que mecanismos extras de ionização e/ou de trasporte de momento angular deveriam ser atuantes. Assim, ventos magnetizados originários no disco foram propostos como um possível mecanismo associado à extração de momento angular, principalmente nas regiões mais próximas ao objeto central (e.g. Bai 2011; Bai e Stone 2013; Gressel et al. 2015 e Bai et al. 2016). Ventos de origem térmica também podem aparecer nesses discos, devido ao aquecimento das suas camadas mais superficiais por radiação externa como, por exemplo, radiação por raios-X e ultravioleta (e.g. Gorti et al. 2009, 2015. É importante frisar, entretanto, que ventos de origem estelar também impactam de maneira significativa a evolução do sistema estrela-disco. Esses ventos são especialmente relevantes pois sua presença é fundamental para explicar a aparente conservação de momento angular em estrelas da PMS, uma vez que tais ventos conseguem extrair o momento angular extra, advindo da acreção, diretamente da estrela (e.g. Matt e Pudritz 2005; Gallet e

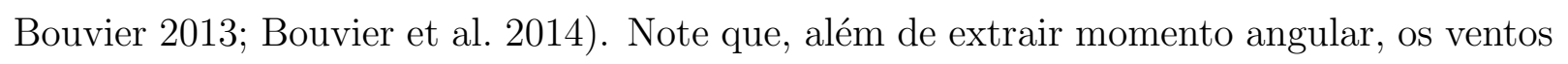
(tanto estelares quanto aqueles originários do disco) também removem matéria do disco, 

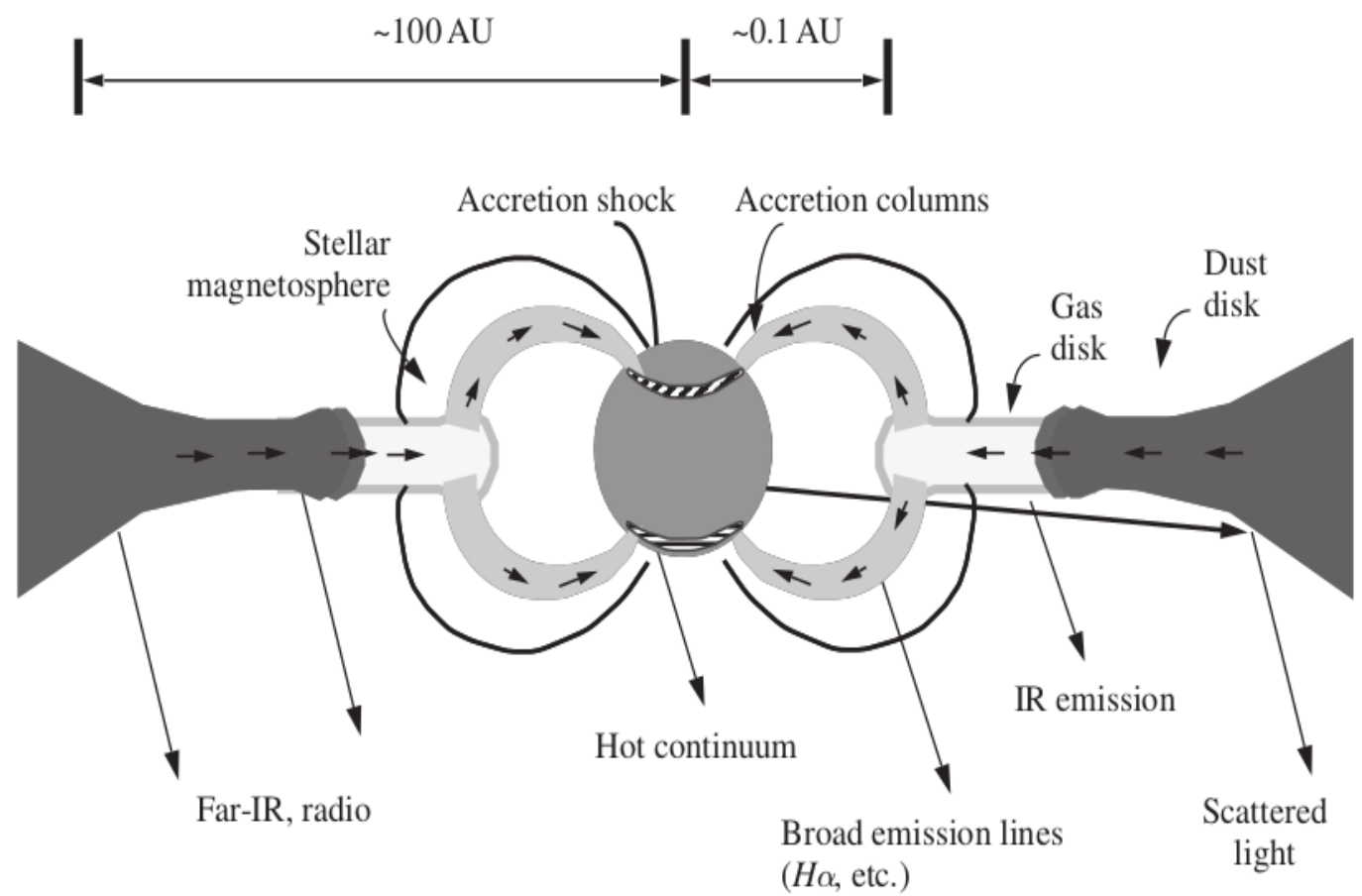

Figura 1.3: Representação esquemática de uma estrela T Tauri. O disco é truncado em um dado raio interno devido à atuação da magnetosfera da protoestrela, de forma que a acreção ocorre através das colunas de acreção que conectam o disco à superfície estelar. O disco emite em comprimentos de onda maiores, como o IR e rádio, enquanto a estrela emite no contínuo para altas frequências. Os funis de acreção são associados à presença das linhas largas observadas nesses objetos. Figura retirada de Hartmann (2005).

principalmente das regiões mais superficiais desse objeto (i.e. das regiões a várias escalas de altura do plano médio). Essa propriedade pode impactar significativamente a evolução desses sistemas, uma vez que expõe as regiões mais internas (próximas ao plano médio do disco). Em realidade, Bai et al. (2016) sugeriu que tais outflows deveriam afetar, positivamente, a formação de planetesimais, uma vez que, devido ao fato dos grãos de poeira se concentrarem, principalmente, nas regiões mais próximas ao plano médio, essa extração da matéria, nas porções mais externas do disco, auxiliaria no aumento da razão poeira-gás desses meios.

Devido ao fato de discos de acreção protoestelares serem meios magnetizados, instabilidades de origem magnetohidrodinâmicas (MHD) podem se tornar importantes, como a IMR. Essa instabilidade é responsável por originar viscosidade em discos onde a velocidade angular diminui de acordo com o aumento da distância ao centro, de forma a promover o transporte de momento angular para as periferias do disco, possibilitando a ocorrência do processo de acreção (e.g. Schulz, 2005; Hartmann, 2009). Essa instabilidade é, ainda, responsável por instaurar um regime turbulento em um fluido Kepleriano, a priori, laminar 
(e.g. Hawley et al., 1995, Hawley, 2000). A IMR, entretanto, necessita que as partículas do disco estejam congeladas às linhas de campo magnético para ser efetiva. Devido à essa exigência, Gammie (1996), utilizando o modelo padrão de Shakura e Sunyaev (1973), o qual assume a viscosidade como sendo resultante da interação de redemoinhos turbulentos e parametriza-a em função do parâmetro livre, $\alpha$, demonstrou que a IMR não atua em toda a extensão do disco. De fato, nas regiões mais próximas ao plano médio, a atuação da IMR é inexpressiva e a acreção deixa de ocorrer. Dessa maneira, Gammie (1996) introduziu o conceito de acreção em camadas: o disco poderia ser dividido em duas regiões, as zonas ativas e a zona morta. As zonas ativas seriam aquelas onde as partículas estão suficientemente ionizadas e a IMR é atuante. Elas estariam localizadas nas regiões mais externas do disco, onde efeitos de ionização externos (tais como ionização por raios-X e raios cósmicos) são relevantes. Nessas regiões, portanto, o processo de acreção seria eficiente. A região mais interna do disco, onde a IMR é incapaz de agir, foi denominada, então, a zona morta, conforme apresentado na Figura 1.4. Desde esse trabalho pioneiro por Gammie (1996), diversos outros autores debruçaram-se sobre o estudo das propriedades da zona morta, obtendo que a sua extensão é definida pelas propriedades do disco, como, por exemplo, a sua densidade de coluna (e.g. Fromang et al., 2002; Ilgner e Nelson, 2006; Martin et al., 2012; Dzyurkevich et al., 2013).

O modo de atuação da IMR é ilustrado na Figura 1.5: imagine que uma pequena perturbação na velocidade radial perturbe o campo, de modo que, duas partículas que, a priori, estavam associadas à uma mesma linha sejam reposicionadas: a partícula 1 é deslocada para uma órbita ligeiramente mais interna, enquanto a partícula 2 é colocada em uma órbita mais externa. Consequentemente, a partícula 1 será forçada a aumentar sua velocidade angular, por estar em uma órbita mais interna, enquanto a partícula 2 será forçada a diminuir sua velocidade. Da mesma forma, esse reposicionamento fará as linhas de campo serem esticadas, de forma que uma tensão magnética será instaurada e culminará na aceleração e desaceleração das partículas 2 e 1, respectivamente (Mignone, 2016). Logo, a partícula 1 perderá momento angular, sendo movida para órbitas cada vez mais internas, enquanto a partícula 2 ocupará órbitas mais e mais externas. Eventualmente, um ponto de ruptura será atingido, onde a tensão magnética não será mais suficiente, e momento angular será então transferido das regiões mais internas para as regiões mais externas do disco. 


\section{Layered Accretion in a T Tauri Disk}

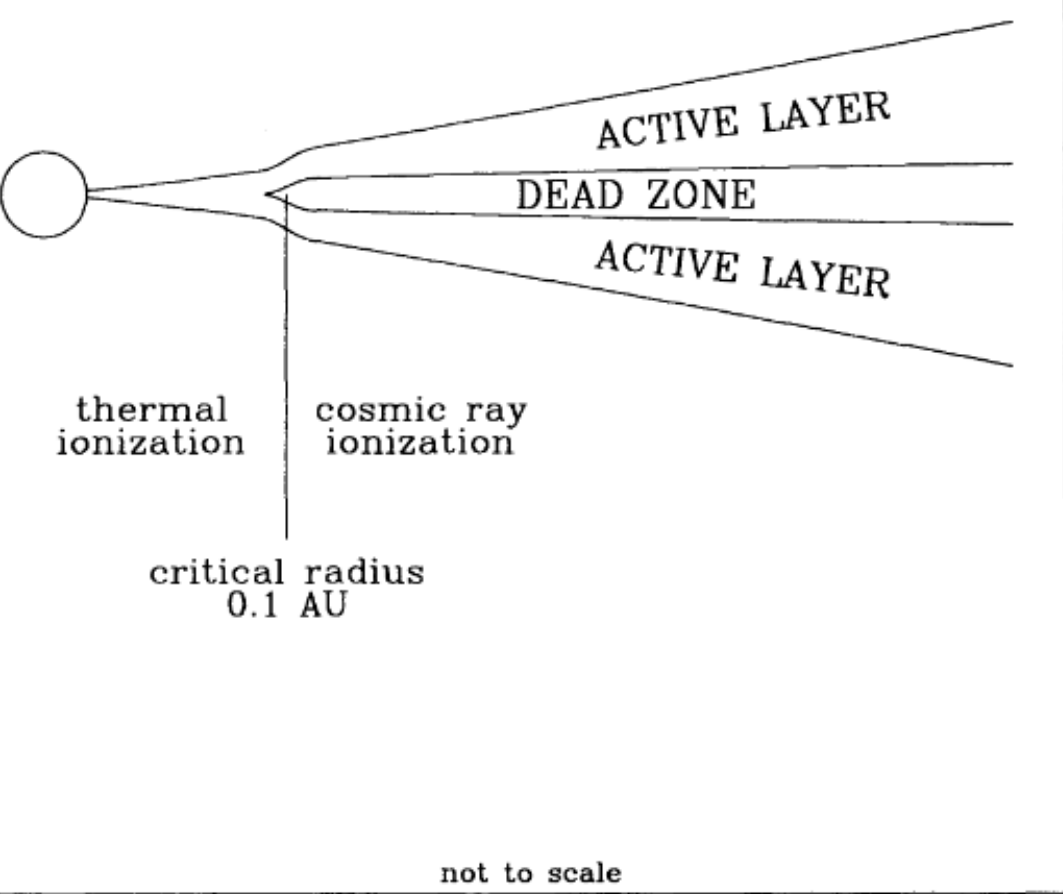

Figura 1.4: Representação do modelo de acreção em camadas proposto por Gammie (1996), aplicado às estrelas T Tauri. As regiões próximas (radialmente) do objeto central estão submetidas à ionização térmica devido às suas altas temperaturas $\left(T>10^{3} \mathrm{~K}\right)$. Já na superfície do disco, a ionização por fontes externas é efetiva devido à baixa densidade de coluna nessas regiões. Essas porções do disco onde a fração de ionização é elevada, denominadas zonas ativas, possibilitam a atuação da IMR e, consequentemente, o processo de acreção. Já nas regiões a distâncias radiais intermediárias, e localizadas próximas ao plano médio do disco, as temperaturas são insuficientes para assegurar a ocorrência da ionização térmica, ao mesmo tempo em que, devido à alta densidade de coluna, raios cósmicos e outras fontes de ionização externas não conseguem penetrar. Dessa forma, nessa porção do disco, chamada zona morta, a fração de ionização é insuficiente para assegurar a existência da IMR, tornando o processo de acreção ineficiente. Figura retirada de Gammie (1996). 


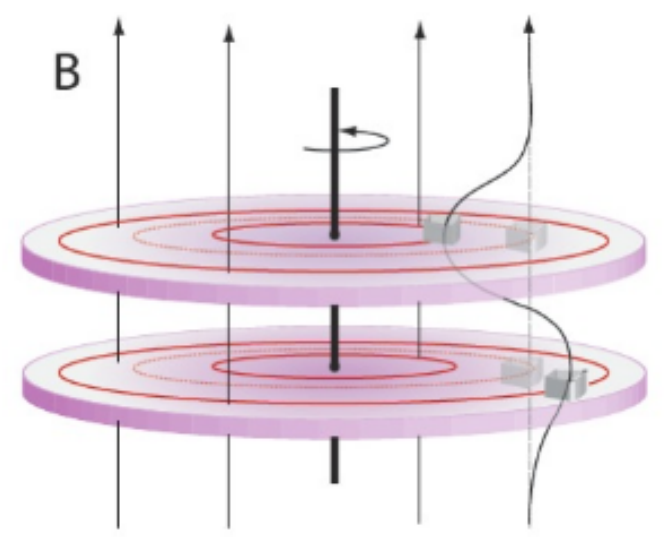

Figura 1.5: Representação esquemática de como a IMR atua em um disco de acreção. Figura retirada de uma apresentação de 2014 de Ryan Murphy para a disciplina Plasma Astrophysics ministrada no Harvard-Smithsonian Center for Astrophysics. Link da apresentação: https://www.cfa.harvard.edu/ namurphy/Lectures/Ay253_07_MHDinstabilities2.pdf.

Durante os anos, diversas fontes de ionização foram consideradas atuantes no disco. Nas regiões do disco próximas à protoestrela, onde as temperaturas ultrapassam os $1000 \mathrm{~K}$, a ionização térmica ${ }^{1}$ por íons alcalinos torna-se um processo importante (e.g. Umebayashi e Nakano, 1988; Balbus e Hawley, 2000), enquanto nas demais regiões do disco processos de ionização não-térmicos devem ser levados em consideração. Dentre esses processos não-térmicos, ionização por raios cósmicos (e.g. Gammie, 1996; Fleming e Stone, 2003; Turner et al., 2007; Martin et al., 2012 ) e por raios-X provenientes do objeto central (e.g. Glassgold et al., 1997; Igea e Glassgold, 1999; Fromang et al., 2002; Turner e Sano, 2008) já foram extensivamente estudados na literatura. Por outro lado, a presença de ondas Alfvén nesses objetos também passou a ser considerada como uma possível fonte extra de ionização não-térmica no disco (e.g. Vasconcelos et al., 2000).

\subsection{Ondas Alfvén como mecanismo extra de aquecimento}

Turner et al. (2007) e Turner e Sano (2008) demonstraram que tensões magnéticas podem ocorrer na zona morta e que as partículas dessa região ainda mantêm, mesmo que fracamente, um acoplamento com as linhas de campo magnético. Dessa forma, o aparecimento de ondas Alfvén nessas regiões é esperado. Entretanto, devido ao fato do

\footnotetext{
${ }^{1}$ Considera-se ionização térmica os casos onde a temperatura do meio é suficientemente alta, de forma a propiciar altas frações de ionização colisional.
} 
fluido constituinte da zona morta possuir conduvitividade finita, além de exibir colisões entre as partículas, essas ondas são amortecidas ao se propagarem pelo disco (veja, por exemplo, Hasegawa e Uberoi 1982), transferindo, dessa maneira, energia para o meio. Atentanto-se à isso, Vasconcelos et al. (2000) estudou os efeitos do amortecimento de ondas Alfvén em aquecer o plano médio, demonstrando a importância desse mecanismo extra no aquecimento do disco. Mais recentemente, Jatenco-Pereira (2013, 2015), ao estudar o amortecimento de ondas Alfvén em discos empoeirados, também apontou a eficiência do amortecimento de ondas MHD em aquecer esses objetos. Dessa forma, no presente trabalho, iremos dar continuidade a esses estudos, analisando a influência do amortecimento de ondas Alfvén, em especial dos amortecimentos não-linear, turbulento e da absorção ressonante de ondas Alfvén de superfície, no aumento da fração de ionização do disco, a fim de propiciar a ocorrência da IMR em uma maior região desse objeto. Além de analisar qual dos três mecanismos supracitados é o mais eficiente em aquecer o disco, quando agindo independentemente, também propomos um quarto mecanismo que acopla os efeitos da absorção ressonante de ondas de superfície e do amortecimento turbulento.

Essa dissertação estrutura-se da seguinte maneira: no Capítulo 2, apresentamos a teoria física de discos de acreção, assim como as simplificações de disco geometricamente fino, opticamente espesso e estacionário. Além disso, nesse mesmo capítulo, introduzimos a prescrição $\alpha$ de Shakura e Sunyaev (1973); no Capítulo 3, introduzimos os mecanismos de amortecimento de ondas Alfvén estudados no presente trabalho; no Capítulo 4, damos uma breve descrição do método numérico utilizado para simular o disco protoestelar sob consideração, enquanto no Capítulo 5 mostramos os resultados obtidos. Finalmente, no Capítulo 6, explicitamos as principais conclusões desse trabalho, além das perspectivas futuras. 


\section{A teoria de discos de acreção}

Neste capítulo, versaremos sobre a teoria de discos de acreção e deduziremos as equações relevantes para um disco dominado pela viscosidade, conforme proposto por Shakura e Sunyaev (1973), no limite geometricamente fino e estacionário.

\subsection{As equações que regem o disco}

Discos de acreção, assim como todos os demais fluidos, são completamente descritos através das três equações da hidrodinâmica: as equações para a conservação de massa, de momento angular e de energia. Nesta seção, apresentamos tais equações em coordenadas cilíndricas. As deduções aqui mostradas também podem ser encontradas em Pringle (1981), Vasconcelos (2000), Frank et al. (2002) e Hartmann (2009).

\section{(i) Equação de conservação de massa}

Para um gás de velocidade $\vec{v}$, densidade $\rho$ e temperatura $T$, definidos em função da posição e do tempo e, assumindo que não há geração nem desaparecimento de energia, a equação de conservação de massa pode ser definida por:

$$
\frac{\partial \rho}{\partial t}+\nabla \cdot(\rho \vec{v})=0
$$

Sendo o divergente em coordenadas cilíndricas definido como:

$$
\nabla \cdot \vec{A}=\frac{1}{r} \frac{\partial}{\partial r}\left(r A_{r}\right)+\frac{1}{r} \frac{\partial A_{\phi}}{\partial \phi}+\frac{\partial A_{z}}{\partial z},
$$


a Equação 2.1 torna-se:

$$
\frac{\partial \rho}{\partial t}+\frac{1}{r} \frac{\partial}{\partial r}\left(\rho r v_{r}\right)+\frac{1}{r} \frac{\partial}{\partial \phi}\left(\rho v_{\phi}\right)+\frac{\partial}{\partial z}\left(\rho v_{z}\right)=0
$$

(ii) Equação de conservação de momento angular

A equação de conservação de momento angular, por sua vez, pode ser escrita como:

$$
\rho \frac{D \vec{v}}{D t}=-\rho \vec{\nabla} \Phi-\vec{\nabla} P+\vec{\nabla} \cdot \vec{\Pi}
$$

onde $\nabla \Phi$ representa o potencial gravitacional, $P$ denota a pressão total, $\frac{D}{D t}=\frac{\partial}{\partial t}+$ $(\vec{u} . \vec{\nabla})$ indica que refere-se à uma derivada material, sendo $\vec{u}$ a velocidade do fluído, e $\vec{\Pi}$ é o tensor de stress viscoso, definido por:

$$
\Pi_{i k}=\mu\left[\frac{\partial w_{i}}{\partial x_{k}}+\frac{\partial w_{k}}{\partial x_{i}}-\frac{2}{3}(\vec{\nabla} \cdot \vec{v}) \delta_{i k}\right]+\zeta \frac{\partial w_{j}}{\partial x_{j}} \delta_{i k}
$$

onde $\mu$ é o coeficiente de viscosidade dinâmica e $\zeta$ é o coeficiente de viscosidade de volume. Note que, nesse caso, $\frac{\partial w_{i}}{\partial x_{k}}$ são as componentes do tensor gradiente de velocidade, $\nabla w$. As componentes da equação de conservação de momento angular são, portanto (veja nas Seções A.1 e A.2 do Apêndice A uma dedução detalhada):

(a) Componente radial da equação de conservação de momento

$$
\frac{\partial v_{r}}{\partial t}+v_{r} \frac{\partial v_{r}}{\partial r}+\frac{v_{\phi}}{r} \frac{\partial v_{r}}{\partial \phi}-\frac{v_{\phi}^{2}}{r}+v_{z} \frac{\partial v_{r}}{\partial z}=-g_{R}-\frac{1}{\rho} \frac{\partial P}{\partial r}+\frac{1}{\rho}(\nabla \cdot \vec{\Pi})_{r}
$$

\section{(b) Componente azimutal da equação de momento}

$$
\frac{\partial v_{\phi}}{\partial t}+v_{r} \frac{\partial v_{\phi}}{\partial r}+\frac{v_{\phi}}{r} v_{r}+\frac{v_{\phi}}{r} \frac{\partial v_{\phi}}{\partial \phi}+v_{z} \frac{\partial v_{\phi}}{\partial z}=-\frac{1}{r} \frac{\partial \Phi}{\partial \phi}-\frac{1}{\rho r} \frac{\partial P}{\partial \phi}+\frac{1}{\rho}(\nabla \cdot \vec{\Pi})_{\phi}
$$




\section{(c) Componente vertical da equação de momento}

$$
\frac{\partial v_{z}}{\partial t}+v_{r} \frac{\partial v_{z}}{\partial r}+\frac{v_{\phi}}{r} \frac{\partial v_{z}}{\partial \phi}+v_{z} \frac{\partial v_{z}}{\partial z}=-\frac{\partial \Phi}{\partial z}-\frac{1}{\rho} \frac{\partial P}{\partial z}+\frac{1}{\rho}(\nabla \cdot \vec{\Pi})_{z}
$$

\section{(iii) Equação de conservação de energia}

A equação que descreve a conservação de energia interna pode ser escrita como:

$$
\rho \frac{\partial \epsilon}{\partial t}=-P \vec{\nabla} \cdot \vec{v}-\vec{\nabla} \cdot \vec{F}+\Psi
$$

onde $\rho \epsilon$ representa a densidade de energia interna, $P$ novamente denota a pressão, $\vec{F}$ refere-se ao fluxo total e $\Psi$ é a taxa de dissipação viscosa, definida por:

$$
\Psi=\Pi_{i k} \frac{\partial v_{i}}{\partial x_{k}}
$$

As equações acima são aplicáveis para descrever qualquer tipo de disco de acreção. Entretanto, para um disco geometricamente fino, i.e., um disco onde a dimensão vertical é muito menor que a extensão radial do disco, algumas aproximações podem ser feitas que simplificam, significativamente, o problema.

\subsection{A aproximação de disco geometricamento fino}

Em teoria de discos de acreção, uma das hipóteses adotadas é de que o objeto de estudo configura-se como um disco geometricamente fino, i.e., a sua escala de altura na direção z é muito menor que a extensão radial do disco, e que possui simetria axial, de forma que as derivadas na direção azimutal se anulam $\left(\frac{\partial}{\partial \phi}=0\right)$. Além disso, podemos confinar o movimento das partículas constituintes do disco no plano $r-\phi$, de forma que a velocidade na direção- $z$ torna-se desprezível $\left(v_{z}=0\right)$, assim como as derivadas da velocidade em $z$ $\left(\partial v_{i} / \partial z=0\right)$.

Aplicando as condições acima na equação de continuidade (Equação 2.3) e integrando a equação resultante em $z$, obtemos: 


$$
\int_{-\infty}^{\infty}\left(\frac{\partial \rho}{\partial t}+\frac{1}{r} \frac{\partial}{\partial r}\left(\rho r v_{r}\right)\right) d z=0
$$

Sendo a densidade superficial, $\Sigma$, definida como a integral da densidade volumétrica na altura,

$$
\Sigma=\int_{\infty}^{-\infty} \rho d z
$$

a equação de conservação de massa, para um disco geometricamente fino, passa a ser escrita como:

$$
\frac{\partial \Sigma}{\partial t}+\frac{1}{r} \frac{\partial}{\partial r}\left(r v_{r} \Sigma\right)=0
$$

De forma análoga, a componente azimutal da equação de momento, aplicada ao limite geometricamente fino, torna-se (na Seção A.3 do Apêndice A encontra-se a dedução completa):

$$
\rho\left(\frac{\partial v_{\phi}}{\partial t}+v_{r} \frac{\partial v_{\phi}}{\partial r}+\frac{v_{\phi}}{r} v_{r}\right)=\frac{\partial}{\partial r}\left[\mu r \frac{\partial \Omega}{\partial r}\right]+2 \mu \frac{\partial \Omega}{\partial r}
$$

Tomando $v_{\phi}=\Omega r$, onde $\Omega$ denota a velocidade angular de rotação do disco, $\mu=\nu \rho$, sendo $\nu$ a viscosidade cinemática, e multiplicando a equação acima por $r$, obtemos:

$$
r \frac{\partial(\Sigma \Omega r)}{\partial t}+r \frac{\partial\left(\Omega r \Sigma v_{r}\right)}{\partial r}+r \Sigma \Omega v_{r}=r \frac{\partial}{\partial r}\left[\nu \Sigma r \frac{\partial \Omega}{\partial r}\right]+2 r \nu \Sigma \frac{\partial \Omega}{\partial r}
$$

onde uma integração em $z$ foi feita, de forma análoga à realizada na Equação 2.11.

Realizando as derivadas parciais e tomando a derivada temporal de $\Omega$ igual à zero, dado que estamos considerando um potencial gravitacional fixo, a Equação 2.15 pode ser escrita, de forma mais compacta, como:

$$
\frac{\partial \Sigma}{\partial t} \Omega r^{2}+\frac{1}{r} \frac{\partial}{\partial r}\left(\Sigma \Omega r^{3} v_{r}\right)=\frac{1}{r} \frac{\partial}{\partial r}\left(\nu \Sigma r^{3} \frac{\partial \Omega}{\partial r}\right)
$$


Substituindo a Equação 2.13 na Equação 2.16, obtemos o seguinte resultado:

$$
-\frac{\Omega r^{2}}{r} \frac{\partial}{\partial r}\left(r v_{r} \Sigma\right)+\frac{1}{r} \frac{\partial}{\partial r}\left(\Sigma \Omega r^{3} v_{r}\right)=\frac{1}{r} \frac{\partial G}{\partial r}
$$

o qual reduz-se, após alguns cálculos, a:

$$
\Sigma v_{r} r \frac{\partial}{\partial r}\left(\Omega r^{2}\right)=\frac{\partial G}{\partial r}
$$

onde $G=\nu \Sigma r^{3} \partial \Omega / \partial r$ representa o torque atuando sobre o disco.

Isolando $v_{r}$ da Equação 2.18 e substituindo em 2.13, obtemos uma prescrição para a evolução temporal da densidade superficial do disco:

$$
\frac{\partial \Sigma}{\partial t}=\frac{1}{r} \frac{\partial}{\partial r}\left[\frac{\partial G / \partial r}{\partial\left(\Omega r^{2}\right) / \partial r}\right]
$$

Para discos cujas trajetórias das partículas podem ser bem aproximadas por uma órbita Kepleriana, a velocidade angular passa a ser descrita pela velocidade Kepleriana, $\Omega=$ $\left(G M / r^{3}\right)^{1 / 2}$, e a dependência temporal da densidade superficial passa a ser descrita por (Pringle, 1981; Frank et al., 2002; Hartmann, 2009):

$$
\frac{\partial \Sigma}{\partial t}=\frac{3}{r} \frac{\partial}{\partial r}\left[r^{1 / 2} \frac{\partial}{\partial r}\left(\nu \Sigma r^{1 / 2}\right)\right]
$$

De forma geral, a equação de difusão de $\Sigma$ é não-linear, uma vez que a viscosidade pode ser dependente dos parâmetros do disco, como a distância radial, o tempo e a própria densidade superficial. Supondo uma distribuição inicial para a densidade superficial, em um dado anel de raio $R_{1}$, dada por:

$$
\Sigma(r, t=0)=\frac{\delta\left(r-R_{1}\right)}{2 \pi R_{1}}
$$

Lynden-Bell e Pringle (1974) mostraram que a solução para a Equação 2.20 pode ser escrita como: 


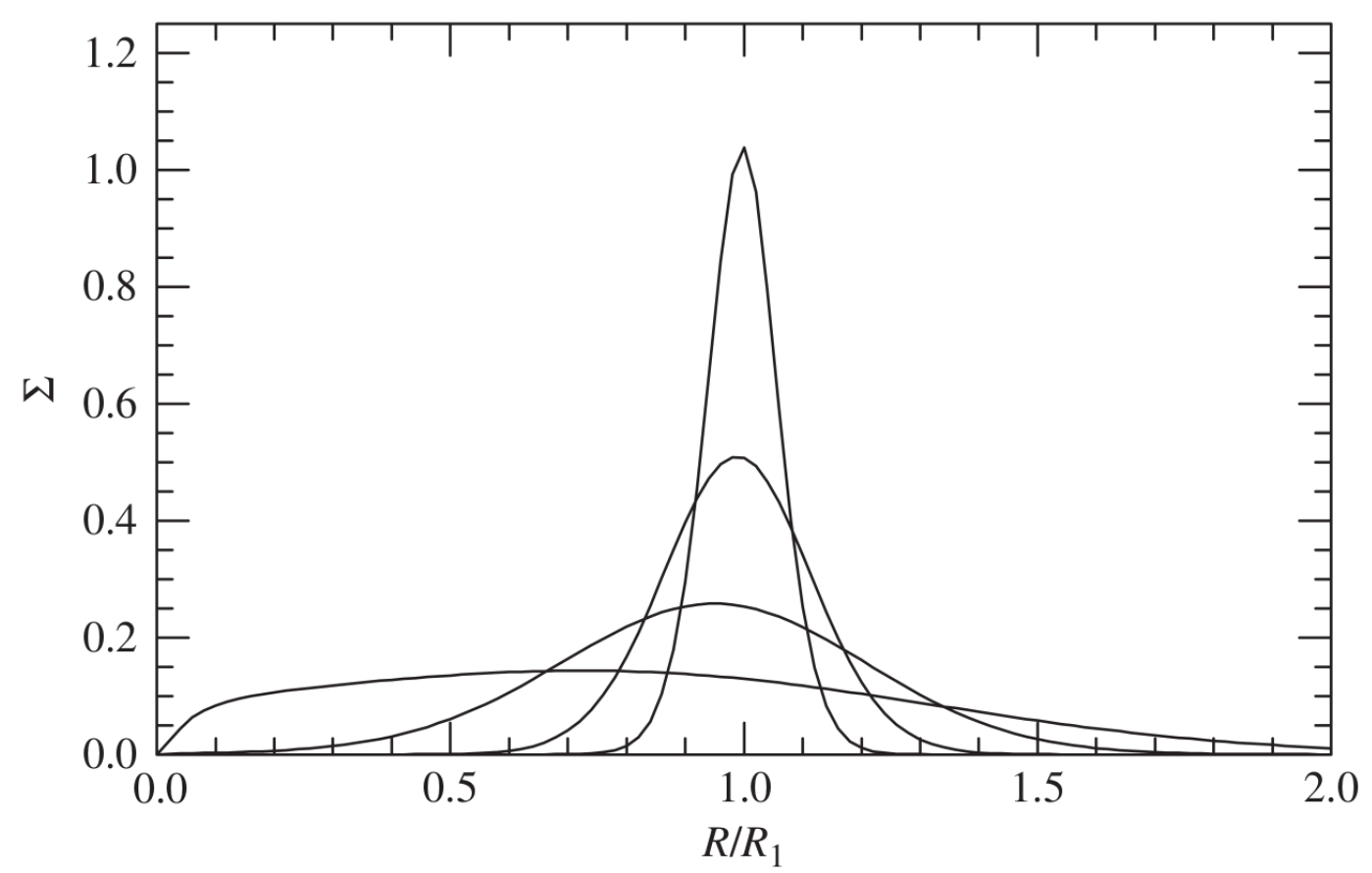

Figura 2.1: Representação esquemática da difusão de matéria associada à atuação da viscosidade. Notase que, com o passar do tempo, a matéria, inicialmente concentrada em um anel, vai sendo espalhada. Ainda assim, a maior parte da matéria fica contida próximo à origem do sistema, apesar de uma pequena quantidade, devido à conservação do momento angular, ocupar raios maiores. As linhas mostradas correspondem à tempos adimensionais, $t_{d}$, de cima para baixo, de $0.004,0.016,0.064$ e 0.256 . Figura extraída de Hartmann (2009).

$$
\Sigma\left(x, t_{d}\right)=\frac{x^{-1 / 4} t_{d}^{-1}}{2 \pi R_{1}^{2}} \exp \left[\frac{-\left(1+x^{2}\right)}{2 t_{d}}\right] I_{1 / 4}\left(\frac{x}{t_{d}}\right)
$$

onde $I_{1 / 4}$ representa a função de Bessel modificada de primeira espécie de ordem 1/4, $x=r / R_{1}$ denota a escala de distância adimensional e $t_{d}=6 \nu t / R_{1}^{2}$ corresponde ao tempo adimensional. Uma representação esquemática do comportamento contido na Equação 2.22 é mostrada na Figura 2.1. Nota-se que o efeito da viscosidade é espalhar a matéria, a priori contida no anel, culminando em uma distribuição onde a matéria é mais concentrada em raios pequenos (i.e., mais próximos do raio de origem $R_{1}$ ), enquanto uma pequena quantidade é transferida para raios maiores, conservando, assim, o momento angular (Hartmann. 2009). 


\subsection{A aproximação de disco geometricamento fino, opticamente espesso e estacionário}

Devido às grandes incertezas na prescrição da viscosidade em discos de acreção e na compreensão do transporte de momento angular, é importante desenvolver métodos para a resolução da estrutura do disco que não dependam de $\nu$. Se considerarmos um disco no estado estacionário e opticamente espesso, sua emissão pode ser descrita independente da viscosidade (Hartmann, 2009). Tal aproximação é justificável, uma vez que, em várias situações, algumas propriedades do disco, como a taxa de transferência de matéria, mantém-se constante por períodos maiores que a escala de tempo para mudanças na estrutura do disco, dada pela escala de tempo viscosa (Frank et al., 2002). Neste caso, é possível estudar a estrutura do disco através da imposição de $\partial / \partial t=0$, além das condições relacionadas ao fato do disco ser considerado geometricamente fino, citadas na Seção 2.2 .

Utilizando a aproximação de disco fino e estacionário, obtém-se que a componente radial do tensor de stress viscoso passa a ser dada por:

$$
(\vec{\nabla} \cdot \vec{\Pi})_{r}=\frac{4}{3} \frac{\partial \mu}{\partial r} \frac{\partial v_{r}}{\partial r}+\frac{4}{3} \mu \frac{\partial}{\partial r} \frac{\partial v_{r}}{\partial r}-\frac{2}{3} \frac{\partial \mu}{\partial r} \frac{v_{r}}{r}-\frac{4}{3} \frac{\mu}{r^{2}} v_{r}+\frac{4}{3} \frac{\mu}{r} \frac{\partial v_{r}}{\partial r}
$$

de forma que a componente radial da equação de conservação do momento angular assume a forma:

$$
\begin{aligned}
v_{r} \frac{\partial v_{r}}{\partial r}-\frac{v_{\phi}^{2}}{r}=-g_{R}- & \frac{1}{\rho} \frac{\partial P}{\partial r}+\frac{4}{3 \rho} \frac{\partial \mu}{\partial r} \frac{\partial v_{r}}{\partial r}+\frac{4}{3 \rho} \mu \frac{\partial}{\partial r} \frac{\partial v_{r}}{\partial r} \\
& -\frac{2}{3 \rho} \frac{\partial \mu}{\partial r} \frac{v_{r}}{r}-\frac{4}{3 \rho} \frac{\mu}{r^{2}} v_{r}+\frac{4}{3 \rho} \frac{\mu}{r} \frac{\partial v_{r}}{\partial r} .
\end{aligned}
$$

Aproximando a derivada parcial radial como $\partial / \partial r \sim 1 / r$ e assumindo que a velocidade radial é muito menor que a velocidade de rotação do discd ${ }^{1}$ (Vasconcelos, 2000), a Equação 2.24 reduz-se à:

$$
\frac{v_{r}^{2}}{r}-\frac{v_{\phi}^{2}}{r}=-g_{r}-\frac{1}{\rho} \frac{P}{r}+2 \frac{\mu v_{r}}{\rho r^{2}}
$$

Como a massa de discos associados às estrelas T Tauri é uma baixa fração das massas das protoestrelas centrais (e.g. Andrews e Williams, 2005; McKee e Ostriker, 2007), é possível

\footnotetext{
${ }^{1}$ A velocidade de acreção é subsônica, enquanto a velocidade de rotação é supersônica.
} 
aproximar o termo $g_{r}$ como sendo definido pela gravidade proveniente da estrela apenas. Ademais, é possível definir a pressão do gás como:

$$
P=c_{s}^{2} \rho
$$

onde $c_{s}$ representa a velocidade do som isotérmica, e a viscosidade como sendo descrita pela prescrição $\alpha$, na forma:

$$
\nu=\alpha c_{s} H
$$

com $H$ caracterizando a escala de altura do disco. Note que a definição apresentada na Equação 2.27 foi proposta, inicialmente, por Shakura e Sunyaev (1973), e descreve a viscosidade observada como sendo advinda dos efeitos associados à turbulência presente no meio. Assim, supondo a turbulência atuante no disco subsônica e, tomando a escala de altura do disco, $H$, como o limite superior para o tamanho desses vórtices turbulentos, é possível descrever a viscosidade nesses objetos em função da velocidade do som, $c_{s}$ (onde postula-se a velocidade turbulenta como sendo definida por $v_{t u r b}=\alpha c_{s}$, sendo $\alpha$ limitado entre 0 e 1), e de $H$. Logo, com o auxílio da Equação 2.27, a Equação 2.25 pode ser reescrita como:

$$
\frac{v_{r}^{2}}{r}-\frac{v_{\phi}^{2}}{r}=-g_{r}-\frac{c_{s}^{2}}{r}+\frac{2 \alpha c_{s} H v_{r}}{r^{2}}
$$

Agora, aplicando novamente $v_{r}<c_{s}<v_{\phi}$, chegamos que:

$$
\frac{v_{\phi}^{2}}{r^{2}}=g_{r}
$$

Dessa forma, obtemos que a velocidade de rotação do disco pode ser escrita como:

$$
v_{\phi}^{2}=\frac{G M_{*}}{r},
$$


dado que a autogravidade do disco é desprezível em relação à gravidade do objeto central. Sabendo ainda que a velocidade de rotação relaciona-se à velocidade angular através de $v_{\phi}=\Omega r$, conclui-se que a velocidade angular do disco é:

$$
\Omega=\sqrt{\frac{G M_{*}}{r^{3}}} \equiv \Omega_{K}
$$

Ou seja, para um disco geometricamente fino e em regime estacionário a sua velocidade angular é descrita pela velocidade Kepleriana, $\Omega_{K}$.

Utilizando a equação de conservação de massa para um disco geometricamente fino (Equação 2.13) e integrando-a sobre a área diferencial do disco, $2 \pi r d r$,

$$
\frac{\partial}{\partial t} \int_{r_{i n}}^{r_{e x t}} \Sigma 2 \pi r d r=-\int_{r_{i n}}^{r_{e x t}} \frac{1}{r}\left\{\frac{\partial}{\partial r}\left(r v_{r} \Sigma\right)\right\} 2 \pi r d r
$$

obtemos:

$$
2 \pi \frac{\partial}{\partial t} \int_{r_{i n}}^{r_{e x t}} \Sigma r d r=-2 \pi r v_{r} \Sigma
$$

de forma que a taxa de acreção do disco, sob as hipóteses consideradas, é definida como:

$$
\dot{M}=2 \pi r \Sigma\left(-v_{r}\right)
$$

onde define-se $\dot{M}=\frac{\partial M}{\partial t}$, sendo a massa do disco, $M$, dada por $M=2 \pi \int_{r_{i n}}^{r_{e x t}} \Sigma r d r$.

Agora, se considerarmos a componente azimutal da equação de conservação de momento angular (Equação 2.16) e substituírmos a prescrição para a taxa de acreção, associada à restrição imposta pelo regime estacionário $(\partial / \partial t=0)$, a Equação 2.16 torna-se:

$$
\frac{\partial}{\partial r}\left(-\Omega r^{2} \dot{M}\right)=2 \pi \frac{\partial}{\partial r}\left(\nu \Sigma r^{3} \frac{\partial \Omega}{\partial r}\right)
$$

Integrando a equação acima, obtemos:

$$
\Omega r^{2} \dot{M}=-2 \pi r\left(\nu \Sigma r^{2} \frac{\partial \Omega}{\partial r}\right)+J
$$


onde $J$ corresponde à uma constante de integração definida por Vasconcelos (2000):

$$
J \sim \dot{M} R_{*}^{2} \Omega\left(R_{*}\right)
$$

Dessa forma, a Equação 2.34 torna-se:

$$
\Omega r^{2} \dot{M}-\dot{M} R_{*}^{2} \Omega\left(R_{*}\right)=-2 \pi r\left(\nu \Sigma r^{2} \frac{\partial \Omega}{\partial r}\right) .
$$

Substituindo as prescrições para as velocidades Kepleriana $\left(\Omega_{K}\right.$ e $\left.\Omega_{K}\left(R_{*}\right)\right)$ na Equação 2.35, chegamos à forma da evolução radial da densidade superficial do disco:

$$
\nu \Sigma=\frac{\dot{M}}{3 \pi}\left[1-\left(\frac{R_{*}}{r}\right)^{1 / 2}\right]
$$

A componente vertical da equação de conservação de momento angular (Equação 2.8), sob as aproximações de disco geometricamente fino e estacionário, por sua vez, reduz-se à:

$$
\frac{1}{\rho} \frac{\partial P}{\partial z}=-\frac{\partial \Phi}{\partial z}
$$

Sendo o potencial gravitacional definido por:

$$
\Phi=\frac{G M_{*}}{\left(r^{2}+z^{2}\right)^{1 / 2}}
$$

é possível escrever o gradiente vertical da pressão como:

$$
\frac{\partial P}{\partial z}=\rho \frac{z G M_{*}}{\left(r^{2}+z^{2}\right)^{3 / 2}}
$$

Fazendo uso de que o disco sob consideração é geometricamente fino $(z / r \ll 1)$, reescrevemos a equação acima da seguinte maneira: 


$$
\frac{\partial P}{\partial z}=\rho \frac{z G M_{*}}{r^{3}}
$$

Agora, mantendo em mente que a escala de comprimento típica na direção vertical é a escala de altura, $H$, podemos escrever $\frac{\partial P}{\partial z} \sim P / H$ e $z \sim H$. Ademais, se definirmos a pressão conforme a prescrição dada pela Equação 2.26, obtemos:

$$
\frac{\rho c_{s}^{2}}{H}=\rho H \Omega_{K}^{2}
$$

de forma que é possível escrever a escala de altura do disco simplesmente como a razão entre a velocidade do som e a velocidade Kepleriana, na forma:

$$
H=\frac{c_{s}}{\Omega_{K}}
$$

Finalmente, a última equação a ser resolvida é a equação de conservação de energia (Equação 2.9) a qual, após a aplicação de todas as simplificações relavantes ao sistema, reduz-se a (veja a Seção A.4 do Apêndice A para mais detalhes):

$$
\frac{\partial F_{z}}{\partial z}=\frac{9}{4} \nu \rho \frac{G M_{*}}{r^{3}} .
$$

Integrando a equação acima na direção vertical do disco, e utilizando a Equação 2.12, obtemos que a energia total liberada pela dissipação viscosa é:

$$
D=\frac{9}{4} \Sigma \nu \frac{G M_{*}}{r^{3}}
$$

a qual, após substituir a prescrição dada pela Equação 2.36, torna-se:

$$
D=\frac{3}{4 \pi} \frac{G M_{*} \dot{M}}{r^{3}}\left[1-\left(\frac{R_{*}}{r}\right)^{1 / 2}\right]
$$

A Equação 2.43 refere-se à energia dissipada pelas duas faces do disco. Se considerarmos a irradiação de apenas uma das faces, a energia dissipada passa a ser dada por: 


$$
D=\frac{3}{8 \pi} \frac{G M_{*} \dot{M}}{r^{3}}\left[1-\left(\frac{R_{*}}{r}\right)^{1 / 2}\right] .
$$

Todos os cálculos aqui mostrados encontram-se, de maneira detalhada, no Apêndice A. 


\section{Capítulo 3}

\section{O amortecimento de ondas Alfvén como fonte extra de aquecimento}

Neste capítulo, daremos uma breve descrição sobre a física das ondas Alfvén e alguns exemplos de sua aplicação em meios astrofísicos (Seção 3.1). Além disso, discutiremos brevemente os mecanismos de amortecimento de ondas Alfvén considerados nesse trabalho, a saber: o amortecimento não-linear (Seção 3.2), o amortecimento turbulento (Seção 3.3) e a absorção ressonante de ondas Alfvén de superfície (Seção 3.4). Apresentamos também um novo mecanismo, o qual acopla os efeitos do amortecimento turbulento e da absorção ressonante de ondas Alfvén de superfície (Seção 3.5).

\subsection{Ondas Alfvén}

Um fluido condutor, sob a ação de um campo magnético, origina correntes elétricas devido ao movimento do fluido. Tais correntes podem modificar o campo magnético inicial o qual, por sua vez, pode mudar o movimento do fluido. Em especial, esse processo pode dar origem à oscilações denominadas ondas Alfvén (Hasegawa e Uberoi, 1982). A frequência de uma onda Alfvén, $\omega_{A}$, propagando-se em um plasma homogêneo composto de elétrons e íons, obedece a relação de dispersão:

$$
\omega_{A}=\frac{k|\cos \theta| v_{A}}{1+\left(v_{A} / c\right)^{2}}=k v_{A}|\cos \theta|
$$

para $v_{A} \ll c$, onde $v_{A}=B / \sqrt{4 \pi \rho}$ denota a velocidade de Alfvén, e $\theta$ corresponde ao ângulo entre o campo magnético e a direção de propagação da onda. Nesse trabalho, 
consideraremos apenas as ondas que propagam-se ao longo das linhas de campo, de forma que $\theta=0$.

O primeiro indício de que ondas Alfvén poderiam ser fenômenos relevantes no contexto astrofísico se deu através do trabalho de Belcher e Davis Jr (1971), que mostrou haver uma correlação entre as flutuações de velocidade e campo magnético observadas no vento solar com flutuações de origem Alfvênicas. Desde então, a existência dessas ondas já foi suposta nos mais distintos contextos astrofísicos, como, por exemplo, na coroa solar (e.g. Escande et al., 2019; Shaikh et al., 2019), na magnetosfera de Júpiter (e.g. Manners e Masters, 2019) e em ventos estelares (e.g. Yasuda et al., 2019; David e Galtier, 2019). De maneira análoga, devido ao fato de discos associados à estrelas jovens estarem sob a atuação de campos magnéticos, ondas Alfvén também poderiam existir nesses meios (e.g. Xin-Jie, 1998; Cranmer, 2008; Jatenco-Pereira, 2015), inclusive como sendo as responsáveis por aquecer o meio e suscitar a ocorrência da IMR na zona morta (e.g. Vasconcelos et al. 2000).

De maneira geral, quando considera-se fluidos reais, onde há colisão entre partículas e condutividade finita, as ondas Alfvén sofrem um processo de amortecimento, de forma que sua relação de dispersão passa a ser dada por:

$$
\omega=\omega_{A}+i \gamma
$$

onde $\omega_{A}$ corresponde à frequência das ondas e $\gamma$ denota a taxa de amortecimento Hasegawa e Uberoi, 1982; Vasconcelos, 2000). Esse amortecimento pode transferir energia para o meio, de maneira a aquecê-lo, a uma taxa de aquecimento dada por, em $\mathrm{erg} \mathrm{cm}^{-3} \mathrm{~s}^{-1}$ :

$$
H_{A}=\frac{\Phi \gamma}{v_{A}}
$$

onde $\Phi$ corresponde ao fluxo de ondas Alfvén e $v_{A}$ é a velocidade Alfvén. Se adotarmos, conforme proposto por Vasconcelos et al. (2000) que há equipartição entre as energias magnética e cinética, obtemos que a densidade de energia das ondas $\left(\mathrm{em}_{\mathrm{erg} \mathrm{cm}}{ }^{-3}\right.$ ) passa a ser descrita por: 


$$
\epsilon_{A}=\rho<\delta v^{2}>
$$

onde $\rho$ representa a densidade volumétrica do meio e $\left\langle\delta v^{2}>\right.$ equivale à flutuação quadrática média da velocidade. Agora, se adotarmos que o fluxo de ondas, em $\mathrm{erg} \mathrm{cm}^{-2} \mathrm{~s}^{-1}$, relaciona-se à densidade de energia através de:

$$
\Phi=\epsilon_{A} v_{A}
$$

obtém-se que a taxa de aquecimento relacionado ao amortecimento de ondas Alfvén passa a ser dado por:

$$
H_{A}=\epsilon_{A} \gamma
$$

Finalmente, a única variável a ser determinada na Equação 3.3 é a flutuação quadrática da velocidade. Se supormos, conforme feito por Vasconcelos et al. (2000), que a amplitude da perturbação do campo magnético não pode ser maior que o campo magnético inicial, é possível parametrizar $<\delta v^{2}>$ em função da velocidade Alfvén, na forma:

$$
<\delta v^{2}>=\frac{<\delta B^{2}>}{4 \pi \rho}=f^{2} \frac{B^{2}}{4 \pi \rho}=f^{2} v_{A}^{2},
$$

onde $f$ equivale à um parâmetro livre menor que 1. Assim, é possível escrever o fluxo de ondas Alfvén, $\Phi$, em função do parâmetro livre $f$ como:

$$
\Phi=\rho v_{A}^{3} f^{2}
$$

de maneira que, a variação de $f$ implica, diretamente, na variação do fluxo de ondas. O impacto da variação do fluxo de ondas (i.e., do parâmetro $f$ ) no aquecimento do disco será explorado no Capítulo 5.

A partir da aplicação da Equação 3.4 na Equação 3.3 , obtemos a equação final utilizada para a taxa do aquecimento relacionado ao amortecimento das ondas: 


$$
H_{A}=\rho\left(f^{2} v_{A}^{2}\right) \gamma
$$

A Equação 3.6 será utilizada durante todo este capítulo para a obtenção das taxas de aquecimento relacionadas à cada um dos mecanismos de amortecimento considerados neste trabalho.

Integrando a Equação 3.6 em toda a extensão vertical do disco, é possível escrever a energia dissipada pelo amortecimento de ondas Alfvén, em erg $\mathrm{cm}^{-2} \mathrm{~s}^{-1}$ :

$$
D_{A}=\int_{-H}^{H} H_{A} d z
$$

\subsection{O amortecimento não-linear de ondas Alfvén}

Quando um meio condutor possui taxas de colisões entre partículas muito baixas, como é o caso nas regiões do disco de acreção mais afastadas da estrela, que não sofrem influência da ionização térmica, apenas termos de perturbações de segunda ordem passam a ser significativos (Vasconcelos, 2000), de forma que fenômenos físicos inexistentes no regime linear, passam a ser atuantes, como o amortecimento Landau não-linear (ou interações onda-partícula, e.g. Lee e Völk, 1973; Lagage e Cesarsky, 1983). Tais processos nãolineares possuem uma forte dependência com a velocidade do som no meio: para regiões onde a velocidade do som, $c_{s}$, é superior à velocidade Alfvén, $v_{A}$, postula-se que duas ondas Alfvén propagando-se em direções opostas irão interagir, originando uma onda sonora, a qual será dissipada. Em contrapartida, quando considera-se um meio onde a energia magnética é suficientemente alta $\left(c_{s} \ll v_{A}\right)$, uma onda Alfvén decai em uma onda sonora e em uma outra onda Alfvén, de menor frequência, transferindo energia para o meio na forma de uma cascata de energia (Wentzel, 1974).

O amortecimento não-linear (NL) de ondas Alfvén já foi considerado por muitos autores no estudo de ventos solares (e.g. Jatenco-Pereira e Opher, 1989a), de estrelas gigantes de tipo tardias (e.g. Jatenco-Pereira e Opher, 1989b; Falceta-Gonçalves e Jatenco-Pereira 2002; Falceta-Gonçalves et al., 2006) e em ventos protoestelares (e.g. Jatenco-Pereira e Opher, 1989c). Mais recentemente, Cranmer e Van Ballegooijen (2005) e Zhao et al. (2015) 
também utilizaram o amortecimento não-linear de ondas Alfvén em seus estudos referentes à coroa solar. Esse mesmo mecanismo também já foi aplicado como uma fonte extra de aquecimento em discos de acreção de estrelas T Tauri, como uma maneira de promover a ocorrência da IMR em uma maior região do disco (e.g. Vasconcelos et al., 2000), e como uma maneira de aquecer o plasma presente nos funis magnéticos associados à acreção magnetosférica característica dessas estrelas jovens (e.g. Vasconcelos et al., 2002).

Lagage e Cesarsky (1983), ao analisarem a componente quente do meio interestelar, consideraram que as ondas Alfvén presentes nesse meio iriam ser dissipadas apenas através da interação das partículas presentes no ambiente com as ondas de batimento oriundas da interação de duas ondas Alfvén, i.e., o mecanismo atuante seria o amortecimento Landau não-linear, atuando sob a condição $c_{s}>v_{A}$, conforme definido anteriormente. Esses mesmos autores, assim como Völk e Cesarsky (1982), também definiram dois regimes distintos para a atuação desse amortecimento: o amortecimento Landau não-linear saturado e nãosaturado. A diferença básica entre os regimes saturado e não-saturado refere-se ao fato de que, na primeira situação, as partículas do meio são aprisionadas pelos pacotes de onda, que atuam, efetivamente, como um poço de potencial, de forma que a energia extraída das ondas torna-se limitada, promovendo um amortecimento menos efetivo. No caso nãosaturado, por outro lado, as partículas deixam de estar aprisionadas, de forma que uma maior quantidade de energia é liberada através do amortecimento das ondas. Para o caso saturado, Völk e Cesarsky (1982) obtiveram que o parâmetro $\varepsilon$, definido através da razão entre a velocidade média das partículas, $v_{p}$, e a frequência íon-ciclotrônica, $\Omega_{p}$, por:

$$
\varepsilon=\frac{k v_{p}}{\Omega_{p} \sqrt{\mathcal{F}}}
$$

deve ser desprezível, $\varepsilon \ll 1$. Na equação acima, define-se $\mathcal{F}=\epsilon_{A} / \mathcal{M}$ como sendo a razão entre a densidade de energia das ondas Alfvén, definida pelas Equações 3.2 e 3.4 , e a densidade de energia magnética do meio, M. Em concordância com Vasconcelos (2000), assumimos que a hipótese $\varepsilon \ll 1$ não é satisfeita em nenhuma circunstância no presente trabalho, de forma que iremos considerar o amortecimento Landau não-saturado como sendo o mecanismo atuante no disco. Além disso, devido ao fato do disco sob consideração ser super-Alfvênico $\left(c_{s}>v_{A}\right)$ em toda sua extensão, consideramos que o amortecimento proposto por Lagage e Cesarsky (1983) pode ser utilizado para descrever, razoavelmente, 
o amortecimento não-linear nesses meios. Logo, adota-se a taxa de amortecimento relacionado à esse mecanismo como sendo definida através de (Lagage e Cesarsky, 1983):

$$
\gamma_{N L}=\frac{1}{4} \sqrt{\frac{\pi}{2}} \xi \bar{k} v_{p} \mathcal{F}
$$

onde $\bar{k}$ representa o número de onda médio e $\xi$ corresponde à um parâmetro livre que permite valores entre 5 e 10 . Se assumirmos que a velocidade média das partículas, $v_{p}$, é bem descrita pela velocidade do som no meio, obtemos que a taxa de amortecimento não-linear passa a ser dada por:

$$
\gamma_{N L}=2 \pi \sqrt{\frac{\pi}{2}} \xi c_{s} \bar{k} \frac{\epsilon_{A}}{B^{2}},
$$

onde substituiu-se a prescrição para $\mathcal{F}$ tomando a densidade de energia magnética definida como $\mathcal{M}=B^{2} / 8 \pi$.

Dessa forma, a taxa de aquecimento pode ser escrita como:

$$
H_{N L}=2 \pi \sqrt{\frac{\pi}{2}} \xi c_{s} \bar{k} \frac{\rho^{2}}{B^{2}} f^{4} v_{A}^{4}
$$

onde foi utilizada a parametrização para a densidade de energia de ondas Alfvén empregada por Vasconcelos et al. (2000, 2002). Substituindo a definição da velocidade Alfvén $\left(v_{A}=\right.$ $B / \sqrt{4 \pi \rho})$, obtemos, finalmente, que a taxa de aquecimento relacionada ao amortecimento não-linear de ondas Alfvén é dada por:

$$
H_{N L}=\frac{1}{8 \pi} \sqrt{\frac{\pi}{2}} \xi c_{s} \bar{k} f^{4} B^{2}
$$

\subsection{O amortecimento turbulento de ondas Alfvén}

Devido ao fato de grande parte dos objetos astrofísicos apresentarem um estado de turbulência e estarem, de maneira geral, submetidos à presença de campos magnéticos, diversos trabalhos debruçaram-se sobre os efeitos da turbulência na dissipação ou na propagação 
de ondas Alfvén em plasmas astrofísicos (e.g. Cranmer e Van Ballegooijen, 2005; Cranmer et al., 2007; Downs et al., 2010; Falceta-Gonçalves et al., 2010; Cranmer e Saar, 2011; Van Ballegooijen et al., 2011; Verdini et al., 2012). Mais especificamente, no caso de ondas Alfvén presentes no vento solar, o espectro de tais ondas possui diversas similaridades com o espectro de Kolmogorov para fluidos ordinários, $P_{b} \propto k^{-5 / 3}$, de maneira que Hollweg (1986) postulou, portanto, que as ondas presentes na coroa solar dissipam-se via uma cascata turbulenta, de grandes para pequenas escalas, a uma taxa de aquecimento volumétrica definida por:

$$
H_{\text {turb }}=\Gamma \frac{\rho<\delta v^{2}>^{3 / 2}}{L_{\text {corr }}}
$$

onde $L_{\text {corr }}$ corresponde ao espaçamento médio entre as linhas de campo magnético e $<\delta v^{2}>$ denota a variância de velocidades associada ao campo de onda. $\Gamma$ é um fator da ordem de 1, o qual incorpora-se à definição de $L_{c o r r}$. Essa mesma hipótese já havia sido apresentada por Hollweg (1984), através do desenvolvimento de turbulência via Instabilidade Kelvin-Helmholtz, também em um estudo sobre a contribuição do amortecimento de ondas Alfvén no aquecimento da coroa solar.

É importante salientar que a prescrição postulada por Hollweg (1986) (Equação 3.12 foi proposta baseada em propriedades empíricas, apenas, e não discute com profundidade a origem das ondas envolvidas no amortecimento ou até mesmo a evolução dos vórtices turbulentos responsáveis por amortecê-las. Apesar disso, devido à formulação simples observada na Equação 3.12 e pela ausência de formulações mais robustas para a turbulência de origem MHD em plasmas astrofísicos, tal formulação tem sido extensivamente empregada na literatura, como, por exemplo, no estudo de estrelas Wolf-Rayet (e.g. Dos Santos et al., 1993), de estrelas early-type (e.g. Gonçalves et al., 1998) e no estudo de protoestrelas (e.g. Jatenco-Pereira e Opher, 1989c; Vasconcelos et al., 2000, 2002). Esse mesmo mecanismo foi ainda empregado na investigação de ventos de estrelas gigantes late-type (e.g. Jatenco-Pereira e Opher, 1989b), quasares (e.g. Gonçalves et al., 1996) e na coroa solar (e.g. Evans et al., 2012).

Agora, perceba que, utilizando a prescrição de Vasconcelos et al. (2000) para a taxa de aquecimento volumétrica na Equação 3.12 , obtemos que a taxa de amortecimento relacionada ao mecanismo turbulento é dada por: 


$$
\gamma_{t u r b}=\frac{\Gamma<\delta v^{2}>^{1 / 2}}{L_{c o r r}}
$$

Entretanto, de acordo com Hollweg e Yang (1988), a taxa de crescimento da Instabilidade Kelvin-Helmholtz é relacionada, novamente, à variância de velocidades associada às ondas, $<\delta v^{2}>^{1 / 2}$, na forma:

$$
\gamma_{I K H} \sim \frac{2 \pi}{\Delta y} \frac{<v^{2}>^{1 / 2}}{4}
$$

onde $\Delta y$ relaciona-se à largura da interface considerada na qual a Instabilidade KelvinHelmholtz atua. Note que, se postularmos o disco como sendo dividido em finos tubos, de espessura $2 a$, de propriedades distintas, conforme apresentado na Figura 3.1, onde as linhas de campo magnético que permeiam o ambiente cruzam o disco exatamente na interface entre dois tubos vizinhos, obteremos que, para a nossa configuração de disco, o espaçamento médio entre as linhas do campo será exatamente igual à espessura de cada um desses tubos, i.e. $L_{c o r r}=2 a$. Por outro lado, devido à rotação diferencial do disco, a escala de comprimento associada ao cisalhamento de velocidades característico da IKH, também será exatamente o diâmetro de cada elemento de área $d r$ do disco, i.e. $\Delta y=2 a$. Logo, ao compararmos as prescrições dadas pelas Equações 3.13 e 3.14, obtém-se que a constante, $\Gamma$, passa a ser definida por:

$$
\Gamma=\frac{\pi}{2}
$$

sendo, efetivamente, da ordem de 1, conforme postulado por Hollweg (1986). Dessa maneira, torna-se trivial notarmos que as Equações 3.13 e 3.14 são equivalentes, uma vez assumida que a taxa de crescimento da Instabilidade Kelvin-Helmholtz, i.e., a taxa com a qual o regime turbulento é implantado no meio, corresponde exatamente à taxa com a qual a energia depositada na interface é dissipada na forma de uma cascata turbulenta. Essa mesma hipótese foi adotada por Browning e Priest (1984), Hollweg (1984) e Hollweg e Yang (1988) e torna-se relevante uma vez que concede uma origem física à turbulência supostamente atuante no meio, a qual não é dada ao utilizar-se, simplesmente, o postulado 
por Hollweg (1986) para o amortecimento das ondas.

Finalmente, devido às razões previamente expostas, adotamos que a taxa de amortecimento relacionada ao mecanismo turbulento é dada por:

$$
\gamma_{t u r b}=\gamma_{I K H}
$$

onde $\gamma_{I K H}$ corresponde à taxa de crescimento da instabilidade Kelvin-Helmholtz (IKH, obtida na Seção 3.5.3), de forma que a taxa de aquecimento volumétrica associada à esse amortecimento assume a forma:

$$
H_{\text {turb }}=\rho\left(f v_{A}\right)^{2} \gamma_{I K H}
$$

\subsection{A absorção ressonante de ondas Alfvén de superfície}

Ondas de superfície (SW, do inglês surface waves) são ondas que existem apenas em meios inomogênos, uma vez que propagam-se apenas na interface entre duas regiões de propriedades distintas. As ondas Alfvén puras, por sua vez, podem existir apenas em um plasma homogêneo, com densidade e campo magnético constantes Goossens et al. 2011). Logo, quando consideramos um plasma inomogêno, ondas Alfvén de superfície passam a existir nas descontinuidades (i.e., na interface entre dois meios com diferentes características) do plasma. Consideremos, então, um plasma cujas propriedades variam de uma maneira contínua, de forma que duas regiões adjacentes, regiões 1 e 2, por exemplo, possuam ondas Alfvén de freqûencias $\omega_{1}$ e $\omega_{2}$, respectivamente, sendo $\omega_{2}>\omega_{1}$. Na região de transição entre esses dois meios, teremos, portanto, ondas com frequências $\omega_{A}(r)$, onde $\omega_{1}<\omega_{A}(r)<\omega_{2}$. Logo, a onda Alfvén de superfície que se originará na interface entre essas duas regiões irá sofrer um processo de ressonância com as ondas Alfvén de background, o que culminará na transferência de energia das ondas para a interface Goossens et al., 1992). Esse seria o mecanismo básico por trás da absorção ressonante de ondas Alfvén de superfície. Esse mecanismo tem sido enormemente aplicado nas mais distintas áreas de astrofísica estelar como, por exemplo, no estudo do aquecimento da coroa solar (e.g. Hollweg e Yang, 1988; Evans et al., 2012), no amortecimento de oscilações em loops coronais 
(e.g. Ruderman e Roberts, 2002; Goossens et al., 2008), no estudo de ventos solares (e.g. Evans et al., 2009) e na perda de massa por ventos em estrelas late-type (e.g. JatencoPereira e Opher, 1989b; Falceta-Gonçalves e Jatenco-Pereira, 2002).

Lee e Roberts (1986) estudaram a absorção ressonante através do problema do valor inicial e obtiveram que a taxa de decaimento desse processo é dada por:

$$
\gamma=\pi \bar{k} y \frac{\Delta}{4 \omega_{K}}
$$

onde $\bar{k}$ representa o número de onda médio, $\Delta=\frac{1}{2}\left(\omega_{A i}^{2}-\omega_{A e}^{2}\right)$ onde $\omega_{A i}$ e $\omega_{A e}$ correspondem às frequências das ondas nos meios 1 e 2 , respectivamente, $y$ é a largura da camada através da qual a frequência das ondas Alfvén varia de maneira contínua e monotônica e $\omega_{K}$ denota a frequência da onda de superfície. Eles ainda afirmam que a taxa dada pela Equação 3.17 não corresponde à taxa com a qual a energia da onda de superfície vai ser dissipada; na realidade, representa a taxa com a qual a densidade de energia das perturbações coletivas de superfície são transferidas para oscilações locais na interface. Por outro lado, se efeitos dissipativos são atuantes na interface, $\gamma$ (Equação 3.17), fornece uma taxa de aquecimento efetiva.

Assumindo a extensão vertical da zona morta muito menor que a escala de altura do disco, podemos aproximar o campo magnético como sendo constante em toda a dimensão vertical da zona morta. Além disso, se considerarmos que o campo magnético que atua sobre o disco é proveniente da estrela central, é razoável afirmarmos que sua componente dominante é a componente vertical, dado que a geometria do campo magnético estelar segue um formato de dipolo, de forma que postulamos o campo magnético do disco dado por:

$$
\vec{B}=B_{0} \hat{z} \cdot 1
$$

\footnotetext{
${ }^{1} \mathrm{Na}$ realidade, conforme explicitado na Seção 4.1. assumimos que o campo é constante em $z$ mas varia com a distância radial ao objeto central, i.e. $\vec{B}=B_{0}(r) \hat{z}$. Entretanto, como no estudo da absorção ressonante consideramos apenas o efeito que duas regiões adjacentes exercem sobre a ressonância e posterior amortecimento da onda, apenas o campo que popula a interface entre as duas regiões influencia no processo, de forma que a aproximação $\vec{B}=B_{0} \hat{z}$ torna-se consistente.
} 
Essa hipótese sobre a configuração do campo que permeia o disco está de acordo com os trabalhos de Dudorov e Khaibrakhmanov (2014) e Khaibrakhmanov et al. (2017) que, ao estudarem os efeitos associados aos termos MHD não-ideais em discos de acreção de estrelas T Tauri obtiveram que, na zona morta, a componente vertical do campo magnético é a dominante. Além disso, esses mesmos autores também obtiveram que $B_{z}$ é independente da altura (i.e. $B_{z}$ constante na direção vertical). É importante comentarmos, entretanto, dos recentes estudos acerca da geometria do campo magnético em discos protoplanetários: através de simulações globais e simulações de shearing-box, cada vez mais evidências apontam para o fato de que, nesses discos, a componente dominante do campo magnético é sempre a componente azimutal, inclusive no plano médio do disco (e.g. Lesur et al. 2014; Béthune et al. 2017; Bai 2017). Esses trabalhos, por sua vez, não estudam a estrutura do campo magnético na zona morta, particularmente. Entretanto, mesmo nesses trabalhos, supõe-se que o campo magnético inicial que permeia o disco é um campo magnético vertical apenas, sendo as demais componentes do campo advindas da rotação diferencial do disco, dos efeitos MHD não-ideais presentes no meio e demais processos relevantes à dinâmica do disco. Sendo assim, o fato de postularmos que o campo magnético de equilíbrio do nosso sistema existe apenas na direção vertical, torna-se razoável, dado que essa suposição é padrão no estudo de discos associados à estrelas jovens, além de haver, conforme explicitado acima, resultados que confirmam que tal geometria é válida na zona morta.

A geometria por nós adotada é mostrada na Figura 3.1. duas ondas Alfvén propagam-se em dois tubos do disco imediatamente vizinhos. Devido à variação radial das propriedades do disco, essas ondas possuirão, portanto, frequências distintas. Note que ambas as regiões sofrem influência da mesma linha de campo, dado que as linhas de campo magnético cruzam o disco exatamente na interface entre os dois meios, de maneira que $\omega_{A e}>\omega_{A i}$, uma vez que a densidade do disco diminui com o aumento da distância radial. Essas duas ondas originam uma terceira onda que propaga-se exatamente na interface entre esses dois meios, a onda de superfície, de maneira que sua frequência, $\omega_{K}$, irá estar no contínuo de Alfvén, i.e. $\omega_{A i}<\omega_{K}<\omega_{A e}$, culminando em um processo de ressonância entre a onda de superfície e as ondas de background que, então, irá promover o decaimento da onda, transferindo energia para a interface. O processo de depósito de energia, $\epsilon$, na região de transição entre os dois meios é mostrado no detalhe da Figura 3.1. Devido à presença de viscosidade no disco, essa energia transferida será dissipada, promovendo o aquecimento 


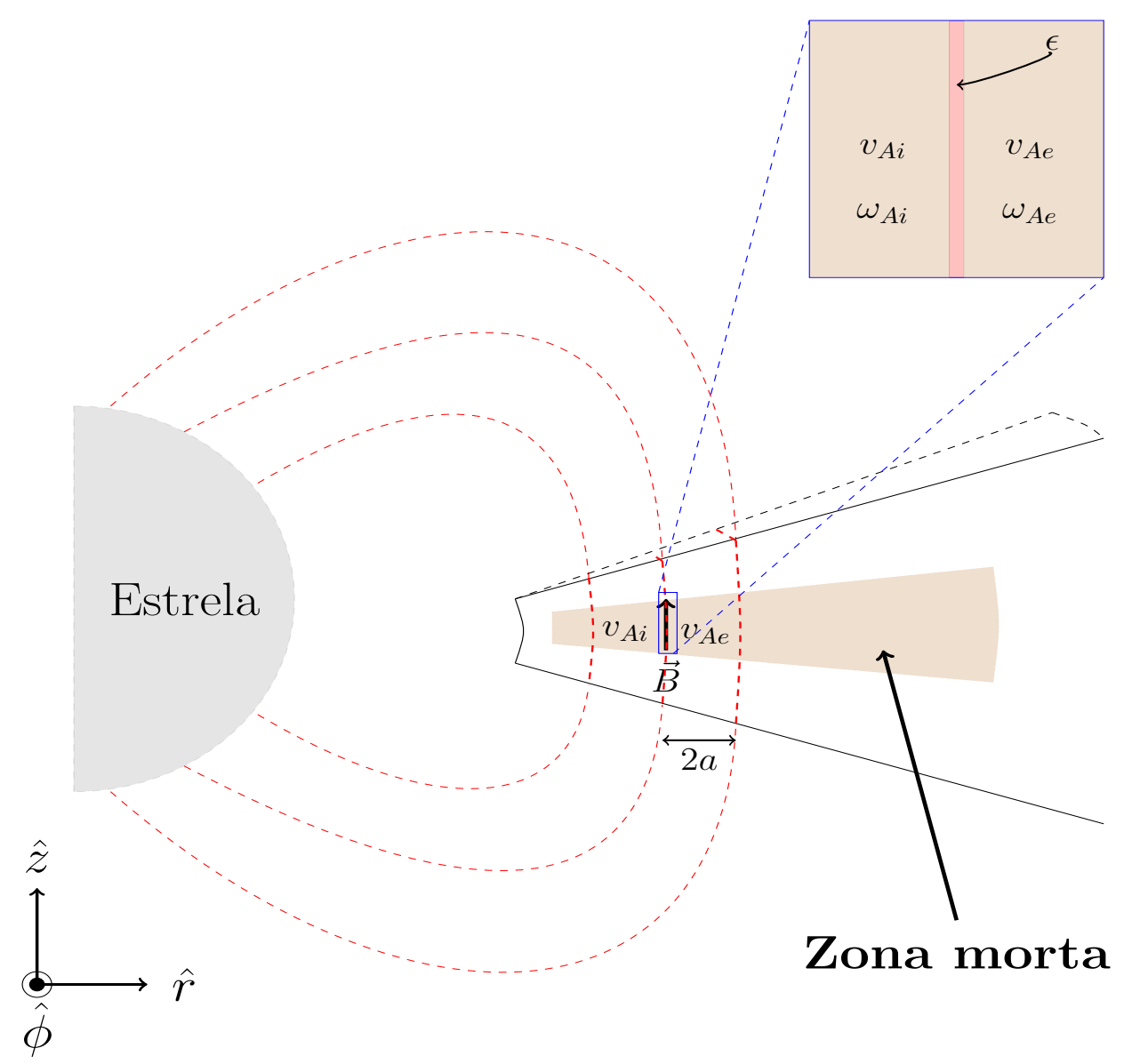

Figura 3.1: Esquema da geometria adotada para a aplicação da absorção ressonante no disco e dos processos que levam à dissipação da onda de superfície. O disco, na direção radial, é aproximado por tubos, de espessura $2 a$, de propriedades físicas distintas (devido à variação radial das propriedades do disco), de forma que dois tubos imediatamente vizinhos possuirão ondas Alfvén de frequências diferentes. Postula-se que as linhas de campo magnético, representadas pelo tracejado vermelho na figura, cruzam o disco exatamente na interface entre as duas regiões. Devido à geometria dipolar do campo e ao fato da extensão vertical da zona morta, representada em marrom claro, ser muito menor que a escala de altura do disco, pode-se aproximar o campo magnético como sendo constante na direção vertical. A onda de superfície, portanto, propaga-se exatamente na região de transição entre os dois meios, representado por rosa no detalhe da figura, de forma que sofrerá um processo de ressonância, depositando sua energia nessa região. Devido à presença de viscosidade no meio, essa energia depositada acabará sendo dissipada, promovendo o aquecimento do ambiente. 
do meio.

Para a obtenção da taxa de amortecimento relacionado à absorção ressonante, realizamos um procedimento análogo ao de Sakurai et al. (1991) e Goossens et al. (1995, 2009). O disco de acreção foi dividido em tubos, ou seja, cada fatia $d r$ do disco foi aproximada como um anel, de propriedades físicas constantes, conforme representado na Figura 3.1 . Para uma revisão sobre o método utilizado e sobre as aplicações de ondas MHD ressonantes, veja Goossens et al. (2011). A taxa de amortecimento relacionada à absorção ressonante de ondas Alfvén de superfície é dada, portanto, por (Goossens et al., 1992):

$$
\gamma_{S W}=\frac{|m| \pi \rho_{1} \rho_{2}\left(\omega_{K}^{2}-\omega_{A i}^{2}\right)\left(\omega_{K}^{2}-\omega_{A e}^{2}\right)}{2\left(\rho_{1}+\rho_{2}\right) \omega_{K} \rho\left(r_{A}\right) \Delta a}
$$

onde $\rho_{1}$ e $\rho_{2}$ denotam as densidades volumétrica dos meios 1 (mais interno) e 2 (mais externo), $2 a$ denota a espessura de cada tubo do disco, onde supõe-se as propriedades constantes, $\omega_{K}$ corresponde à frequência da onda Alfvén de superfície, definida como $\omega_{K}^{2}=$ $\left(\rho_{1} \omega_{A i}^{2}+\rho_{2} \omega_{A e}^{2}\right) /\left(\rho_{1}+\rho_{2}\right), r_{A}$ corresponde à posição da camada ressonante, ou seja, da camada onde o processo dissipativo relacionado à esse mecanismo vai ocorrer, e $\Delta=$ $\frac{d\left(\omega^{2}-\omega_{A}^{2}\right)}{d r}$, i.e., $\Delta$ denota a variação da frequência das ondas na região de transição entre os meios 1 e 2 .

Note que a Equação 3.17 e a Equação 3.19, apesar de possuírem notações diferentes, são equivalentes. De fato, a Equação 3.17 constitui-se como sendo um caso particular da Equação 3.19. Para deixar isso mais claro, façamos as seguintes definições: inicialmente, aproximamos $|m| / a \sim k_{m}$, ou seja, a razão entre $m$ e a semi-espessura do tubo equivale ao número de onda azimutal, de maneira análoga ao feito por Hollweg e Yang (1988); Arregui et al. (2007); Soler et al. (2010), e assumimos a variação nas frequências das ondas Alfvén como sendo linear, de forma que $\frac{d\left(\omega^{2}-\omega_{A}^{2}\right)}{d r} \sim\left(\omega_{A e}^{2}-\omega_{A i}^{2}\right) / 2 r_{t}$, onde $r_{t}$ corresponde ao raio da região de transição do meio 1 para o meio 2, ou seja, à largura da camada através da qual a frequência das ondas Alfvén varia de maneira contínua de $\omega_{A i}$ para $\omega_{A e}$. Note, portanto, que $r_{t}$ corresponde exatamente à variável $y$ da Equação 3.17. Além disso, substituímos, na Equação 3.19 a prescrição para $\omega_{K}$, de forma que obtemos:

$$
\gamma_{S W}=k_{m} \pi r_{t} \frac{\rho_{1}^{2} \rho_{2}^{2}}{\rho\left(r_{A}\right)\left(\rho_{1}+\rho_{2}\right)^{3}} \frac{\omega_{A e}^{2}-\omega_{A i}^{2}}{\omega_{K}} .
$$


Supondo ainda que a variação na densidade também ocorre de uma maneira linear, obtemos que a densidade $\rho\left(r_{A}\right)$ pode ser dada por:

$$
\rho\left(r_{A}\right)=\frac{\rho_{1}+\rho_{2}}{2}
$$

uma vez que a região dissipativa está localizada exatamente entre dois tubos adjacentes. Substituindo essa nova prescrição para a quantidade $\rho\left(r_{A}\right)$, obtém-se que a taxa é escrita como:

$$
\gamma_{S W}=2 \pi k_{m} r_{t} \frac{\rho_{1}^{2} \rho_{2}^{2}}{\left(\rho_{1}+\rho_{2}\right)^{4}} \frac{\omega_{A e}^{2}-\omega_{A i}^{2}}{\omega_{K}}
$$

Agora, se supormos que a densidade é constante, ou seja, $\rho_{1}=\rho_{2}$, o termo referente à densidade na Equação 3.21 desaparece, de forma que a taxa de decaimento torna-se:

$$
\gamma_{S W}=\frac{\pi}{8} k_{m} r_{t} \frac{\omega_{A e}^{2}-\omega_{A i}^{2}}{\omega_{K}},
$$

que é formalmente idêntica à Equação 3.17. Importante notar que neste trabalho, supôsse que todas variáveis variavam de maneira linear, de forma que a Equação 3.21 será utilizada daqui em diante para calcular a taxa de amortecimento e a energia dissipada por esse mecanismo.

Finalmente, para a obtenção da taxa de aquecimento relacionada à absorção ressonante, utilizamos novamente a parametrização proposta por Vasconcelos et al. (2000) para o fluxo de ondas Alfvén (Equação 3.5), de forma que a taxa de aquecimento provocado por esse processo é descrita por:

$$
H_{S W}=\rho\left(f v_{A}\right)^{2} \gamma_{S W}
$$

\subsection{A unificação dos mecanismos turbulento e ressonante}

Nas seções anteriores (vide Seções 3.2, 3.3 e 3.4), descreveu-se a fundamentação física por trás dos processos responsáveis por amortecer as ondas, além da maneira através da 
qual estes são capazes de dissipar energia. Tais mecanismos já foram estudados extensivamente como fontes extras de aquecimento (e.g. Hollweg, 1986; Vasconcelos et al., 2000; Evans et al., 2012) independentemente, entretanto, a atuação conjunta destes mecanismos, em particular em discos protoestelares, ainda é pobremente conhecida, apesar de sugestões na literatura apontarem que a propagação de ondas Alfvén em meios inomogêneos (configuração básica para a ocorrência da absorção ressonante), associada a um cisalhamento de velocidades, o qual pode gerar turbulência, é capaz de aumentar a energia dissipada de maneira significativa (e.g. Heyvaerts e Priest, 1983, Browning e Priest, 1984). De fato, alguns trabalhos investigaram o comportamento da absorção ressonante de ondas Alfvén de superfície na presença de um fluxo de background, i.e., um campo de velocidades não nulo, entretanto, tais trabalhos focam, majoritariamente, nos efeitos desses processos em loops coronais (Goossens et al., 1992, 1995; Ruderman e Roberts, 2002). Esses trabalhos debruçam-se, de maneira geral, no desenvolvimento da IKH como a matriz precursora da turbulência a qual, associada à deposição de energia em uma fina camada, proveniente da absorção ressonante, promove um cascateamento turbulento de energia, formalmente análogo ao proposto por Hollweg (1986), resultando em um fluxo líquido de energia liberada superior àquele que seria liberado caso apenas a absorção ressonante fosse atuante. Neste trabalho, nós utilizamos o mesmo princípio básico proposto por esses autores para desenvolver um novo mecanismo, responsável por acoplar o amortecimento turbulento, proposto por Hollweg (1986), com a absorção ressonante de ondas Alfvén de superfície. Para tal, foi postulado que, devido à rotação diferencial, característica de discos de acreção, a IKH seria atuante no disco, de forma que a turbulência advinda do desenvolvimento dessa instabilidade seria responsável por instaurar um regime turbulento na camada dissipativa onde há a ressonância e consequente dissipação das SW. Um estudo que leve em consideração a atuação do mecanismo turbulento, associado à absorção ressonante de SW, concomitantemente, nunca havia sido realizado no contexto de discos de acreção, particularmente no que se refere ao aquecimento do disco (e redução da zona morta resultante), sendo este trabalho pioneiro na área. Nesta seção, serão explicitados os cálculos realizados na tentativa de promover o acoplamento entre os mecanismos turbulento e ressonante, aos moldes dos processos supracitados.

A IKH configura-se como um fenômeno hidrodinâmico (HD) e magnetohidrodinâmico (MHD) cuja causa principal é a existência de um cisalhamento de velocidades na interface 
de um plasma. Para fluidos irrotacionais e de configuração planar, a IKH sempre será atuante para comprimentos de onda significativamente pequenos. Entretanto, a adição de rotação, campo magnético e processos dissipativos, e.g. viscosidade, alteram, de maneira significativa, a evolução dessa instabilidade. A presença de um campo magnético efetivo, por exemplo, pode suprimir a taxa de crescimento da instabilidade, podendo até extinguir o aparecimento da IKH por completo (Chandrasekhar, 1961). Essa propriedade pode ser vista na Figura 3.2 quando a direção do campo magnético que atua sobre o meio é perpendicular à direção do cisalhamento, os efeitos associados à esse campo são desprezados, de forma que o cenário torna-se similar à situação hidrodinâmica apenas. Por outro lado, quando as direções das linhas de campo e do cisalhamento são paralelas, a atuação do campo é extremamente significativa, tornando a IKH muito menos eficiente que no caso puramente hidrodinâmico. O mesmo pode se dizer a respeito da viscosidade, que possui um efeito estabilizador, de forma a diminuir a efetividade dessa instabilidade (e.g. Hoshoudy et al. 2019). De qualquer maneira, uma vez efetiva, a IKH induz o aparecimento de vorticidade $(\vec{\nabla} \times \vec{v} \neq 0)$ na intersecção entre os dois meios, originando vórtices instáveis que, por sua vez, podem dar origem à um regime caótico no meio, suscitando o aparecimento de turbulência.

A IKH já foi estudada em discos de acreção, como sendo advinda do cisalhamento na velocidade de rotação associado à presença de poeira (e.g. Barranco, 2009), e associada à interface entre o disco e a magnetosfera ao redor do objeto acretor (e.g. Li e Narayan, 2004; Lovelace et al. 2010). De maneira geral, esses trabalhos desconsideram a contribuição da rotação diferencial no onset da IKH. Entretanto, no presente trabalho, considera-se que o cisalhamento associado à essa rotação diferencial, apesar de pequeno em discos que seguem o modelo padrão, pode ser suficiente para incitar o aparecimento de turbulência, a qual, mesmo sendo de baixa intensidade, pode culminar em um significativo acréscimo na dissipação de energia no disco. O desenvolvimento dessa instabilidade em discos é explicitado na Subseção 3.5.3, enquanto na Subseção 3.5.4 mostramos o procedimento realizado para acoplar os efeitos dos mecanismos turbulento e ressonante.

\subsubsection{Condições iniciais e as equações-base para o disco}

Em discos de acreção, a velocidade dominante corresponde à velocidade de rotação, definida por $u_{\phi}=\Omega_{K} r$, onde $\Omega_{K}$ denota a velocidade Kepleriana e $r$ a distância radial 
(a)



(b)

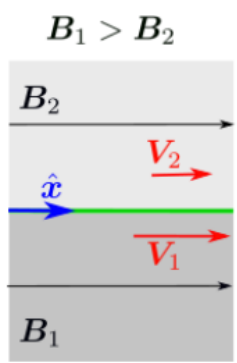

\section{Condição HD}

$\rho_{1}>\rho_{2}$

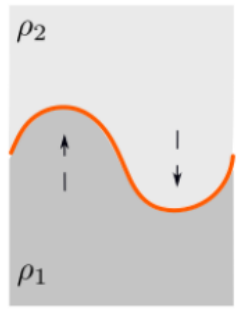

$$
V_{1}>V_{2}
$$



Vórtice IKH

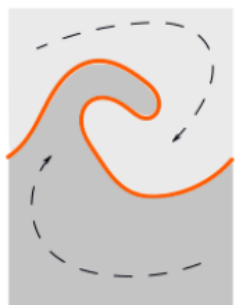

\section{Condição MHD}

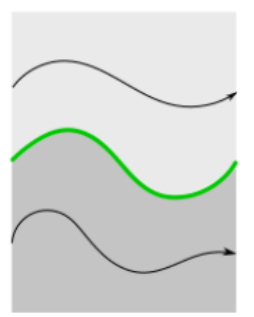



Figura 3.2: Representação esquemática do desenvolvimento da Instabilidade Kelvin-Helmholtz. No painel (a), mostra-se o desenvolvimento da IKH para o caso no qual o campo magnético é transversal à direção do cisalhamento. Neste caso, o cenário torna-se semelhante à situação hidrodinâmica, e a ação do campo magnético pode ser desprezada. Já no painel (b), mostra-se o desenvolvimento da IKH para uma configuração onde a direção do campo é paralela à direção do cisalhamento. Nas figuras mostradas acima adotou-se $\rho_{1}>\rho_{2}, v_{1}>v_{2}$ e $\mathbf{B}_{1}>\mathbf{B}_{2}$. Note que as flechas pretas indicam a formação do vórtice. Além disso, no painel (b), os vórtices relacionados à IKH são menores, em comparação aos presentes no painel (a), para explicitar o efeito estabilizador do campo magnético. Figura retirada de Murcia (2018). 
ao objeto central. Em concordância com o paradigma atual para a formação de estrelas de baixa massa, consideramos que o objeto central possui um campo magnético dipolar, responsável por truncar o disco em $r=R_{i}$, de forma que esse campo, $\vec{B}$, penetra, perpendicularmente, o disco, por toda sua extensão radial. Consideramos, portanto, o disco como sendo composto por tubos adjacentes, de espessura $2 a$, de forma que coordenadas cilíndricas serão utilizadas durante todo o procedimento. Esses tubos são correspondentes à cada fatia $d r$ do disco, e possuem propriedades distintas, as quais variam de acordo com $r$. Sendo assim, supõe-se que a diferença na velocidade de rotação entre dois elementos imediatamente subsequentes, conforme ilustrado na Figura 3.3 , pode dar origem à um cisalhamento significativo de velocidades, de forma que a IKH passa a ser atuante na interface entre os dois meios. Define-se o perfil de velocidade considerado como:

$$
u \equiv u_{\phi}= \begin{cases}u_{0} r, & r \leq a \\ 0, & r>a\end{cases}
$$

onde supôs-se o referencial inercial localizado no tubo imediatamente posterior ao tubo de interesse. Essa escolha de referencial culminaria em $u_{\phi 2}=0$ enquanto $u_{\phi 1}$ efetivo seria dado pela diferença entre as velocidades de rotação reais na Figura 3.3. Logo, temos que $u_{0} \equiv \Omega_{K}$ e $a=\left|r_{1}-r_{2}\right| / 2$ na Equação 3.23 . Além disso, em concordância com as considerações explicitadas anteriormente (veja a Seção 3.4), supomos que o campo magnético possui apenas a componente vertical, $\vec{B}=B(r) \hat{z}$, e adotamos $u_{0} a / v_{A 1} \ll 1$, i.e., consideramos o cisalhamento de velocidades muito menor que a velocidade Alfvén do meio mais interno, $v_{A i}$, como encontrado previamente na literatura (e.g. Soler et al., 2010). 


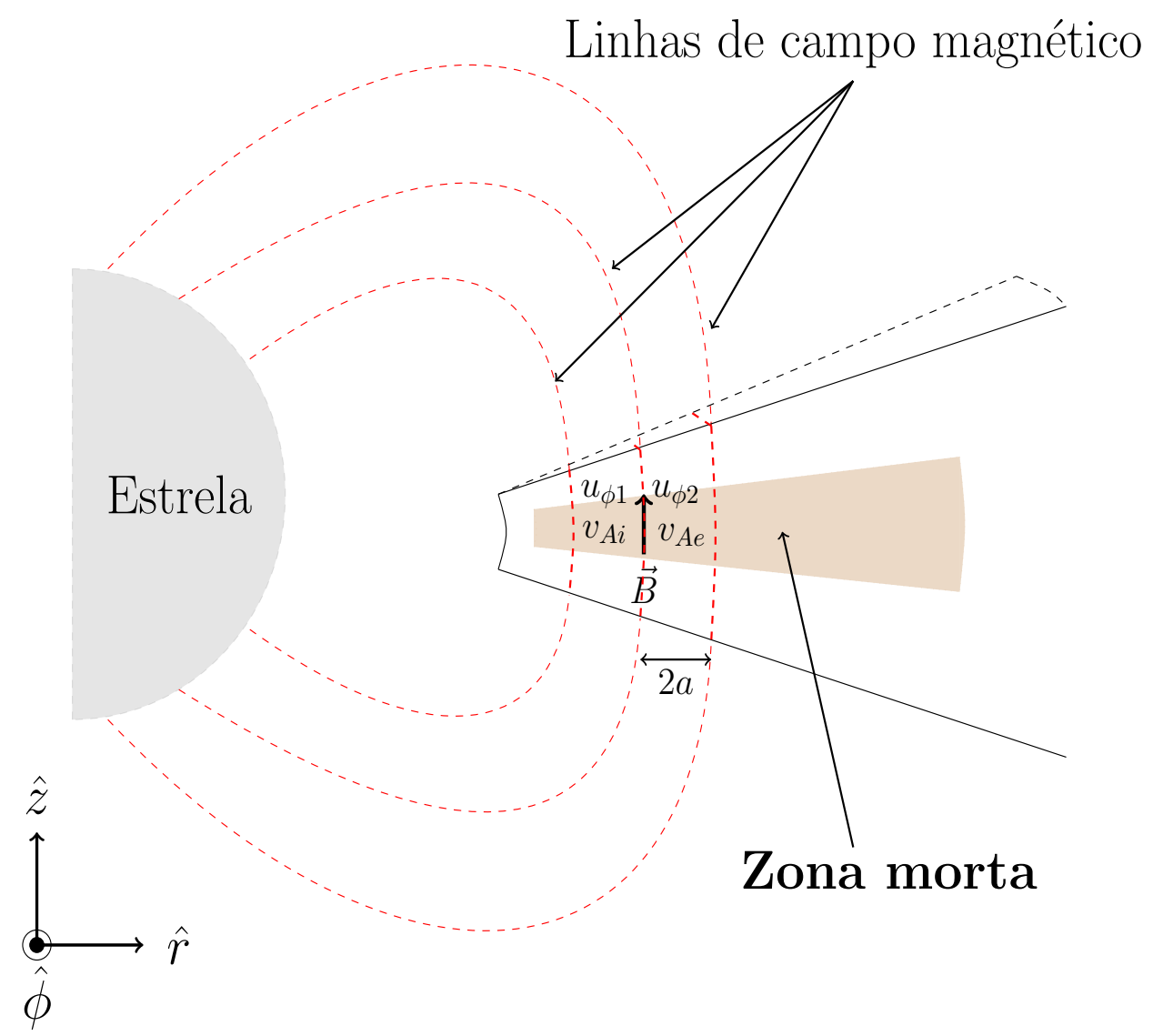

Figura 3.3: Representação esquemática da geometria adotada para o disco. O disco de acreção será dividido em tubos, de espessura $2 a$, os quais possuem propriedades diferentes de acordo com a distância radial ao objeto central. Conforme mostrado na imagem, cada elemento do disco (i.e., cada tubo) terá velocidades de rotação distintas $\left(u_{\phi 1}>u_{\phi 2}\right)$, de forma que na interface entre os dois meios ocorrerá um cisalhamento de velocidades. Note que o sistema considerado é exatamente análogo ao mostrado na Figura 3.1. com a diferença de que agora considera-se a ação da rotação diferencial do disco.

Finalmente, consideramos as três equações básicas de conservação, a saber:

\section{Equação de continuidade}

$$
\frac{\partial \rho}{\partial t}+\vec{\nabla} \cdot(\rho \vec{v})=0
$$

\section{Equação de indução}

$$
\frac{\partial \vec{B}}{\partial t}=\vec{\nabla} \times(\vec{v} \times \vec{B})
$$




\section{Equação de conservação de momento}

$$
\rho\left(\frac{\partial}{\partial t}+\vec{v} \cdot \vec{\nabla}\right) \vec{v}=-\vec{\nabla} P+\frac{1}{\mu_{e}}(\vec{\nabla} \times \vec{B}) \times \vec{B}-\frac{\mu}{K_{1}} \vec{v}
$$

Note que na Equação 3.26, a fim de diminuir a complexidade dos cálculos, parametrizamos o termo viscoso em função da permeabilidade do meio, $K_{1}$, de forma análoga ao realizado por Hoshoudy et al. (2019). Além das Equações 3.24 3.26, também foi adotada a restrição solenoidal, i.e. $\vec{\nabla} \cdot \vec{B}=0$.

Para promover o acoplamento entre os mecanismos turbulento e ressonante, é necessário, inicialmente, assegurar a existência e efetividade da Instabilidade Kelvin-Helmholtz no disco, procedimento desenvolvido nas Subseções 3.5.2 e 3.5.3 e, posteriormente, associar a atuação dessa instabilidade à interface onde a absorção ressonante de ondas Alfvén de superfíce atua (Seção 3.5.4), de maneira a obter a energia dissipada associada à atuação conjunta desses dois processos (e.g. Goossens et al., 1992, 1995).

\subsubsection{A forma da perturbação}

Suponha agora que o sistema seja perturbado, de forma que podemos assumir:

$$
\vec{B}=\overrightarrow{B_{0}}+\overrightarrow{B_{1}}, \quad \vec{v}=\overrightarrow{u_{0}}+\overrightarrow{v_{1}}, \quad \rho=\rho_{0}+\rho_{1},
$$

onde $\overrightarrow{B_{0}}, \rho_{0}$ e $\overrightarrow{u_{0}}$ denotam, respectivamente, o campo magnético, a densidade e a velocidade não-perturbados, enquanto $\overrightarrow{B_{1}}=\left(B_{1 r}, B_{1 \phi}, B_{1 z}\right), \rho_{1}$ e $\overrightarrow{v_{1}}=\left(v_{1 r}, v_{1 \phi}, 0\right)$ representam as mesmas grandezas, porém perturbadas. Ademais, tomamos a forma da perturbação como sendo dada por:

$$
q(r, \phi, z, t)=q(r) \exp (i(-\omega t+k z+m \phi))
$$

onde $k$ e $m$ denotam o número de onda vertical e número de modo azimutal, respectivamente, e $\omega$ é a frequência da perturbação. Note que $m$ aceita apenas números inteiros, enquanto $k$, definido conforme proposto por Soler et al. (2010), toma a forma:

$$
k=\frac{n \pi}{h},
$$


onde $h$ refere-se à altura do tubo e $n$ corresponde ao modo, sendo $n=1$ o modo fundamental.

Após a perturbação e subsequente linearização das Equações 3.24 3.26, com o auxílio da restrição sobre o divergente do campo magnético, obtemos as seguintes prescrições para as grandezas perturbadas:

$$
\begin{aligned}
& \Omega B_{1 r}=-k v_{1 r} B_{0} \\
& \Omega B_{1 \phi}=-k v_{1 \phi} B_{0} \\
& \Omega B_{1 z}=-i B_{0}\left(\frac{\partial v_{1 r}}{\partial r}+\frac{v_{1 r}}{r}+\frac{i m v_{1 \phi}}{r}\right) \\
& \rho_{1}=\rho_{0}\left(\frac{B_{1 z}}{B_{0}}\right) \\
& v_{1 r}=\frac{\Omega}{\Omega^{2}-k^{2} v_{A}^{2}+i\left(\nu / K_{1}\right) \Omega}\left(2 i u_{0} v_{1 \phi}-\frac{i v_{A}^{2}}{B_{0}} \frac{\partial B_{1 z}}{\partial r}\right) \\
& v_{1 \phi}=\frac{\Omega}{\Omega^{2}-k^{2} v_{A}^{2}+i\left(\nu / K_{1}\right) \Omega}\left(-2 i v_{1 r} u_{0}-\frac{i \nu}{K_{1}}\left(\frac{B_{1 z}}{B_{0}}\right) u_{\phi}+\frac{m v_{A}^{2} B_{1 z}}{r B_{0}}\right),
\end{aligned}
$$

onde definiu-se $v_{A}=B_{0} / \sqrt{\rho_{0} \mu_{e}}$ e $\Omega=\omega-m u_{0}$.

Note que a Equação $3.29 \mathrm{c}$ relaciona a perturbação na direção vertical do campo ao divergente de velocidades. Logo, substituindo as Equações 3.29e e 3.29f na Equação 3.29c, obtemos:

$$
\begin{aligned}
& \frac{\Omega i B_{1 z}}{B_{0}}=C\left[\frac{C 4 i u_{0}^{2} \Omega B_{1 z}}{B_{0}}+\frac{C 2 u_{0} \nu}{K_{1} B_{0}}\left(u_{\phi} \frac{\partial B_{1 z}}{\partial r}+2 B_{1 z} u_{0}\right)-\right. \\
& \left.-\frac{i v_{A}^{2}}{B_{0}}\left(\frac{\partial^{2} B_{1 z}}{\partial r^{2}}+\frac{1}{r} \frac{\partial B_{1 z}}{\partial r}-\frac{m^{2}}{r^{2}} B_{1 z}\right)-\frac{i \nu}{K_{1}}\left(\frac{B_{1 z}}{B_{0}}\right) u_{\phi} \frac{i m}{r}\right],
\end{aligned}
$$

onde define-se $C=\frac{\Omega}{\Omega^{2}-k^{2} v_{A}^{2}+i\left(\nu / K_{1}\right) \Omega}$.

Substituindo $C$ na Equação 3.30 e após alguma álgebra, adquire-se:

$$
\begin{array}{r}
\frac{\partial^{2} p_{T}}{\partial r^{2}}+\frac{1}{r} \frac{\partial p_{T}}{\partial r}\left(1+\frac{2 \Omega\left(\nu / K_{1}\right) i}{\Omega^{2}-v_{A}^{2} k_{2}+i\left(\nu / K_{1}\right) \Omega}\left(\frac{u_{\phi}^{2}}{v_{A}^{2}}\right)\right)+p_{T}\left(-\frac{m^{2}}{r^{2}}\right. \\
\left.+\frac{\left(\Omega^{2}-v_{A}^{2} k^{2}+i\left(\nu / K_{1}\right) \Omega\right)}{v_{A}^{2}}+\frac{4 \Omega\left(i\left(\nu / K_{1}\right)-\Omega\right)}{\Omega^{2}-v_{A}^{2} k^{2}+i\left(\nu / K_{1}\right) \Omega}\left(\frac{u_{0}^{2}}{v_{A}^{2}}\right)+i m\left(\nu / K_{1}\right) \frac{u_{0}}{v_{A}^{2}}\right)=0
\end{array}
$$

onde $p_{T}=B_{1 z} B_{0} / \mu_{e}$ é a perturbação na pressão magnética. Se definirmos as novas variáveis: 


$$
p=\frac{2 \Omega\left(\nu / K_{1}\right) i}{\Omega^{2}-v_{A}^{2} k^{2}+i\left(\nu / K_{1}\right) \Omega}\left(\frac{u_{\phi}^{2}}{v_{A}^{2}}\right), \quad n=\sqrt{p^{2}+m^{2}}
$$

temos que a solução da Equação 3.31 pode ser escrita em função das funções de Bessel de segunda ordem:

$$
p_{T}=r^{-p}\left[c_{1} I_{\sqrt{p^{2}+m^{2}}}(A r)+c_{2} K_{\sqrt{p^{2}+m^{2}}}(A r)\right]
$$

uma vez que o argumento, $A$, das funções de Bessel é um número complexo, definido como:

$$
A^{2}=\frac{\Omega^{2}-v_{A}^{2} k^{2}+i\left(\nu / K_{1}\right) \Omega}{v_{A}^{2}}+\frac{4 \Omega\left[\left(\nu / K_{1}\right) i-\Omega\right]}{\Omega^{2}-v_{A}^{2} k^{2}+i\left(\nu / K_{1}\right) \Omega}\left(\frac{u_{0}^{2}}{v_{A}^{2}}\right)+i m\left(\nu / K_{1}\right) \frac{u_{0}}{v_{A}^{2}} .
$$

Agora, se aplicarmos a restrição imposta anteriormente, que afirma que o cisalhamento de velocidade é muito menor que a velocidade de Alfvén, $u_{0} a / v_{A i} \ll 1$, obtemos $p \ll 1$, de forma que:

$$
\begin{aligned}
& p_{T}=\lim _{p \rightarrow 0}\left\{r^{-p}\left[c_{1} I \sqrt{m^{2}+p^{2}}+c_{2}(A r) K \sqrt{m^{2}+p^{2}}(A r)\right]\right\}, \\
& p_{T}=c_{1} I_{m}(A r)+c_{2} K_{m}(A r) .
\end{aligned}
$$

Aplicando as condições de contorno relevantes ao problema, a saber:

(i) na origem, todas as grandezas perturbadas devem ser finitas,

(ii) longe da interface as grandezas perturbadas devem tender a zero,

obtemos que as soluções fisicamente aceitáveis para a perturbação imposta é:

$$
p_{T}= \begin{cases}c_{1} I_{m}\left(A_{1} r\right), & r \leq a \\ c_{2} K_{m}\left(A_{2} r\right), & r>a,\end{cases}
$$

onde $A_{1}$ e $A_{2}$ recebem os valores do argumento da função de Bessel avaliado nas regiões interna e externa do tubo, respectivamente. 
Sabendo ainda que o deslocamento radial Lagrangeano relaciona-se à perturbação radial na velocidade por $\xi_{r}=i v_{1 r} / \Omega$, obtemos, com o auxílio da Equação $3.29 \mathrm{e}$

$$
\xi_{r}=\frac{\left(\Omega_{2}-\omega_{A}^{2}+i\left(\nu / K_{1}\right) \Omega\right) p_{T}^{\prime}+2 u_{0} \Omega p_{T}\left\{i\left(\nu / K_{1}\right)\left(\frac{u_{\phi}}{v_{A}^{2}}\right)-\frac{m}{r}\right\}}{\rho\left[\left(\Omega^{2}-\omega_{A}^{2}+i\left(\nu / K_{1}\right) \Omega\right)^{2}-4 u_{0}^{2} \Omega^{2}\right]},
$$

onde tomamos $\omega \equiv k v_{A}$. Finalmente, se fizermos uso da continuidade da pressão magnética e do deslocamento radial na fronteira do tubo $(r=a)$, obtém-se a relação de dispersão para a situação considerada:

$$
\begin{aligned}
& \frac{\left(\Omega^{2}-\omega_{A i}^{2}+i\left(\nu / K_{1}\right) \Omega\right) c_{1} A_{1} I_{m}^{\prime}\left(A_{1} a\right)+2 u_{0} c_{1} \Omega I_{m}\left(A_{1} a\right)\left\{i\left(\nu / K_{1}\right)\left(\frac{u_{\phi}}{v_{A i}^{2}}\right)-\frac{m}{a}\right\}}{c_{1} I_{m}\left(A_{1} a\right) \rho_{1}\left[\left(\Omega^{2}-\omega_{A i}^{2}+i\left(\nu / K_{1}\right) \Omega\right)^{2}-4 u_{0}^{2} \Omega^{2}\right]}= \\
& \frac{\left(\omega^{2}-\omega_{A e}^{2}+i\left(\nu / K_{1}\right) \omega\right) A_{2} c_{2} K_{m}^{\prime}\left(A_{2} a\right)}{c_{2} K_{m}\left(A_{2} a\right) \rho_{2}\left[\left(\omega^{2}-\omega_{A e}^{2}+i\left(\nu / K_{1}\right) \omega\right)^{2}\right]} .
\end{aligned}
$$

Note que, se desconsiderarmos a ação da viscosidade, a Equação 3.36 torna-se formalmente idêntica à Equação 16 de Soler et al. (2010).

\subsubsection{A prescrição para a Instabilidade Kelvin-Helmholtz}

A Equação 3.36 é passível de ser resolvida numericamente, entretanto, a fim de prover uma solução analítica, fizemos uso da aproximação de tubo fino (aproximação TT, do inglês thin tube approximation), $k a \ll 1$, i.e., consideramos tubos de espessura muito menor que a altura do discl2 2 É necessário ter em mente que, apesar do disco sob estudo ser geometricamente fino, i.e., $H / r_{\max } \ll 1$, tal hipótese permanece válida uma vez que a IKH é uma instabilidade de natureza local apenas. Logo, ao fazer a aproximação de tubo fino estamos afirmando que apenas a ação do anel imediatamente vizinho é levada em conta. Essa aproximação já foi extensivamente utilizada para o estudo da IKH em tubos de fluxo magnético no Sol (e.g. Soler et al., 2010; Zaqarashvili et al., 2014). Sendo a permeabilidade do meio definida como:

$$
K_{1}=\frac{Q \mu a}{S \Delta P}
$$

\footnotetext{
${ }^{2}$ A aproximação de tubo fino, na realidade, afirma que o raio do tubo, $r_{t u b o}$, é muito menor que a altura do mesmo, $h_{t u b o}$. Mas, se $r_{t u b o} \ll h_{t u b o}$, a espessura do tubo deve, necessariamente, ser muito menor que sua altura.
} 
onde $Q$ corresponde à taxa de fluxo volumétrico $(\propto v S)$, a é a semi-espessura do tubo, $\mu$ representa a viscosidade dinâmica $(\mu=\nu \rho), \Delta P$ consiste na diferença de pressão através da descontinuidade e $S$ refere-se à área da seção transversal da descontinuidade, o termo viscoso passa a ser escrito como:

$$
\nu / K_{1}=\frac{\Delta P}{c_{s} \rho a}
$$

onde definiu-se $Q=c_{s} S$, onde $c_{s}$ é a velocidade do som no meio. Logo, utilizando todas as considerações discutidas (cisalhamento de velocidades muito menor que a velocidade de Alfvén e aproximação TT), obtemos que o argumento da função de Bessel (Equação 3.32 torna-se muito pequeno, quando a aproximação de tubo fino é empregada, de forma que podemos utilizar as seguintes propriedades das funções de Bessel:

$$
\lim _{x \rightarrow 0} \frac{x I_{m}^{\prime}(x)}{I_{m}(x)}=|m| \quad \lim _{x \rightarrow 0} \frac{x K_{m}^{\prime}(x)}{K_{m}(x)}=-|m|,
$$

que simplificam de maneira significativa a Equação 3.36, que passa a ser descrita por:

$$
\begin{array}{r}
\frac{\left(\Omega^{2}-\omega_{A 1}^{2}+i\left(\nu / K_{1}\right) \Omega\right)+2 u_{0} \Omega\left\{i\left(\nu / K_{1}\right)\left(\frac{u_{\phi} a}{v_{A i}^{2}|m|}\right)-\frac{m}{|m|}\right\}}{\rho_{1}\left[\left(\Omega^{2}-\omega_{A i}^{2}+i\left(\nu / K_{1}\right) \Omega\right)^{2}-4 u_{0}^{2} \Omega^{2}\right]}= \\
-\frac{1}{\rho_{2}\left(\omega^{2}-\omega_{A e}^{2}+i\left(\nu / K_{1}\right) \omega\right)} .
\end{array}
$$

Se nos utilizarmos do fato de que o cisalhamento considerado é muito pequeno, o que nos possibilita desconsiderar as contribuições referentes aos termos proporcionais à $2 u_{0} \Omega$ e $4 u_{0}^{2} \Omega^{2}$, a Equação 3.39 pode ser expressa como uma simples equação de segundo grau:

$$
\rho_{1}\left[\Omega^{2}-\omega_{A i}^{2}+i\left(\nu / K_{1}\right) \Omega\right]=-\rho_{2}\left[\omega^{2}-\omega_{A e}^{2}+i\left(\nu / K_{1}\right) \omega\right]
$$

que possui como solução:

$$
\omega=\frac{\rho_{1}}{\rho_{1}+\rho_{2}} m u_{0}-\frac{i}{2}\left(\frac{\nu}{K_{1}}\right) \pm\left[\frac{\left(k_{1}^{2} \rho_{1} v_{A i}^{2}+k_{2}^{2} \rho_{2} v_{A e}^{2}\right)}{\rho_{1}+\rho_{2}}-\frac{\rho_{1} \rho_{2}}{\left(\rho_{1}+\rho_{2}\right)^{2}} m^{2} u_{0}^{2}-\frac{\nu^{2}}{4 K_{1}^{2}}\right]^{1 / 2} .
$$


Agora, sabendo que para a Instabilidade Kelvin-Helmholtz ocorrer a frequência deve ser um número complexo, com as partes real e imaginária positivas, na forma $\omega=\omega_{0}+i \gamma_{K H}$, onde $\omega_{0}$ representa a frequência da perturbação e $\gamma_{K H}$ corresponde à taxa de crescimento da instabilidade, obtemos que a condição para a ocorrência da IKH é descrita por:

$$
\left(\frac{u_{0} a}{v_{A i}}\right)^{2}>\frac{\left(k_{1}^{2}+k_{2}^{2}\right) a^{2}}{m^{2}} 2\left(1+\frac{\rho_{1}}{\rho_{2}}\right)-\frac{\nu^{2} a^{2}}{K_{1}^{2}} \frac{\left(\rho_{1}+\rho_{2}\right)^{2}}{4 v_{A 1}^{2} m^{2} \rho_{1} \rho_{2}}
$$

onde $k_{1}$ e $k_{2}$ são os números de onda verticais dos meios 1 e 2 , respectivamente. Uma forma mais conveniente de escrever a condição descrita na Equação 3.42 é em função do número azimutal $m$, o qual descreve a intensidade da perturbação na direção azimutal. Isolando $m$ da Equação 3.42 , obtemos:

$$
m^{2}>\frac{v_{A i}^{2}}{u_{0}^{2}}\left(k_{1}^{2}+k_{2}^{2}\right) 2\left(1+\frac{\rho_{1}}{\rho_{2}}\right)-\frac{\nu^{2}}{K_{1}^{2}} \frac{\left(\rho_{1}^{2}+\rho_{2}^{2}\right)}{4 u_{0}^{2} \rho_{1} \rho_{2}},
$$

ou seja, existe um valor crítico para $m$ abaixo do qual a IKH não é efetiva. Em outras palavras, a perturbação na direção azimutal apenas incita o desenvolvimento da IKH se for mais intensa que um valor de perturbação limite. O estudo do impacto da variação da intensidade da perturbação na direção azimutal (ou seja, o impacto da variação de $m$ ) também é realizado no Capítulo 5.

A frequência das ondas e a taxa de crescimento da instabilidade, por outro lado, são, respectivamente, dadas por:

$$
\begin{aligned}
& \omega_{0}=\frac{\rho_{1}}{\rho_{1}+\rho_{2}} m u_{0} \\
& i \gamma_{I K H}=-\frac{i}{2}\left(\frac{\nu}{K_{1}}\right) \pm\left[\frac{\left(k_{1}^{2} \rho_{1} v_{A i}^{2}+k_{2}^{2} \rho_{2} v_{A e}^{2}\right)}{\rho_{1}+\rho_{2}}-\frac{\rho_{1} \rho_{2}}{\left(\rho_{1}+\rho_{2}\right)^{2}} m^{2} u_{0}^{2}-\frac{\nu^{2}}{4 K_{1}^{2}}\right]^{1 / 2}
\end{aligned}
$$

Note que, conforme esperado, a ação da viscosidade, $\left(\nu / K_{1}\right)$, não impossibilita a ocorrência da IKH mas torna-a menos efetiva, i.e. diminui sua taxa de crescimento (Equação 3.44b). 


\subsubsection{A Instabilidade Kelvin-Helmholtz como um mecanismo de acoplamento entre o amortecimento turbulento e a absorção ressonante de ondas Alfvén de superfície}

Durante todo o procedimento adotado para o desenvolvimento da IKH, supôs-se a existência de uma descontinuidade real, ou seja, supôs-se que as propriedades variavam de maneira instantânea do meio 1 para o meio 2. Entretanto, se substituirmos esta descontinuidade por uma fina região de transição, i.e., assumirmos que a variação das propriedades dar-se-ão de maneira contínua ao longo da região de transição, a ressonância passa a ser um efeito atuante no sistema. O efeito da ressonância, portanto, seria responsável por invalidar a continuidade para algumas das grandezas perturbadas (e.g. Goossens et al. 1992, 2011). Perceba que a ressonância considerada é estritamente similar àquela responsável pela absorção ressonante de ondas Alfvén de superfície. O acoplamento entre os mecanismos turbulento e ressonante, portanto, dar-se-ia da seguinte maneira: a IKH seria responsável por incitar a turbulência no meio. Deste modo, o build-up de energia na zona de transição, proveniente da transferência de energia das perturbações coletivas de superfície para as oscilações locais dentro da zona de transição (devido ao efeito de ressonância), transmutação característica do mecanismo ressonante de ondas de superfície (Lee e Roberts, 1986), associado à turbulência do meio, promoveria um cascateamento de energia, de grandes para pequenas escalas, mecanismo básico do amortecimento turbulento (Hollweg, 1986), culminando em uma dissipação de energia diferente daquela dissipada pelos mecanismos atuando independentemente. Uma representação esquemática do mecanismo supracitado é mostrado na Figura 3.4 .

Para a determinação do 'pulo' ao longo da descontinuidade (ou da região de transição), analisamos o termo de compressão, escrito em função do deslocamento Lagrangeano, o qual define-se por (vide Equação 3.29c):

$$
\vec{\nabla} \cdot \xi=\frac{-p_{T} \Omega^{2}}{v_{A}^{2} \rho \Omega^{2}},
$$

onde, novamente, $p_{T}$ denota a perturbação na pressão magnética. Utilizando as Equações $3.29 \mathrm{f}$ e $3.29 \mathrm{e}$ e tomando $\xi_{\phi}=i v_{1 \phi} / \Omega$, obtemos que o deslocamento azimutal é: 

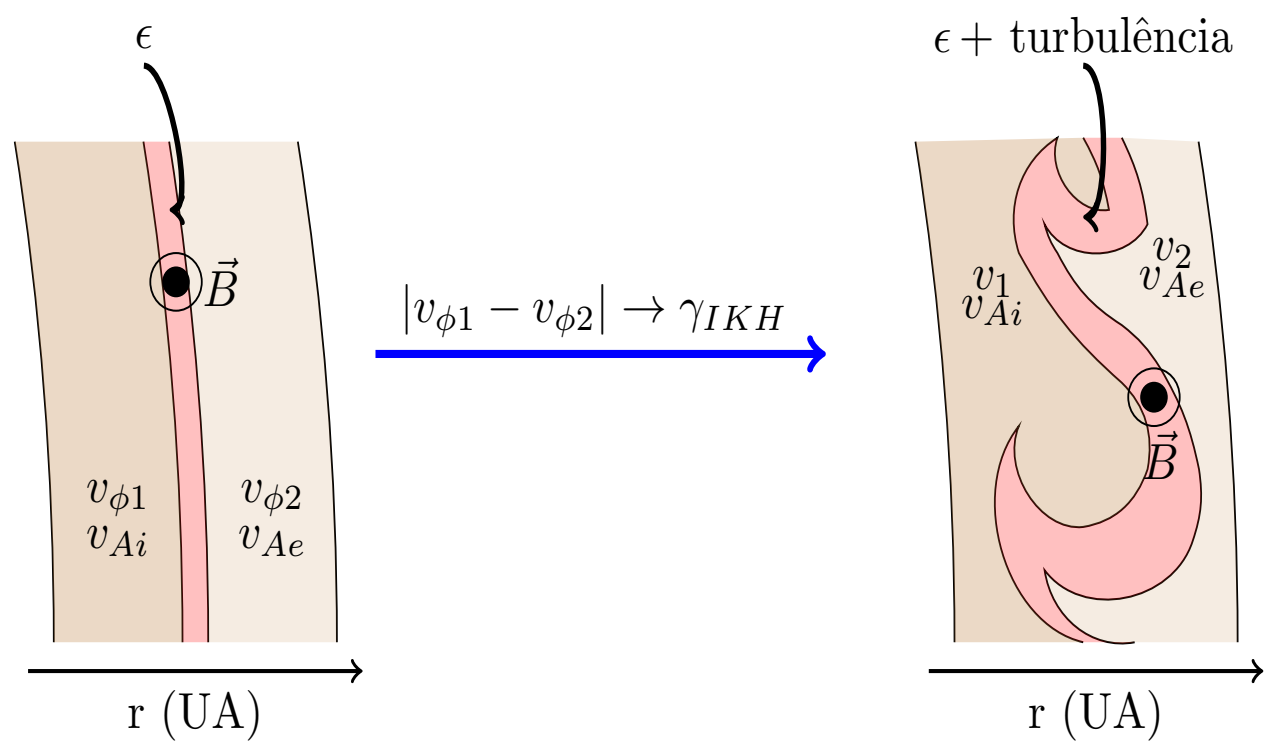

Figura 3.4: Representação esquemática do mecanismo proposto para unificar os amortecimentos turbulento e ressonante. Devido à variação das propriedades magnéticas do meio 1 para o meio 2 , na zona de transição, um efeito de ressonância passará a existir, de forma que energia, de origem magnética (ou seja, associada às ondas Alfvén), irá se acumular nesta fina camada de transição (representada em rosa na figura). Por outro lado, a rotação diferencial, característica de discos, culminará na presença de um cisalhamento de velocidades que, por sua vez, possibilita o surgimento da IKH. Tal instabilidade então promoveria a turbulência na interface entre os dois meios, a qual irá romper as ondas concentradas na interface, de maneira a promover um cascateamento de energia, o qual liberará a energia, a priori contida na região de transição, de maneira turbulenta, culminando em um aquecimento do disco.

$$
\xi_{\phi}=\frac{i p_{T}(m / r)}{\rho\left[\Omega^{2}-\omega_{A}^{2}+i\left(\nu / K_{1}\right) \Omega\right]},
$$

o qual, ao ser substituído na Equação 3.45, resulta na equação diferencial responsável por ditar o comportamento do deslocamento radial na região de transição:

$$
D \frac{\partial}{\partial r}\left(r \xi_{r}\right)=p_{T} r\left[-\Omega^{2}+\Omega^{2} v_{A}^{2}\left(\frac{m^{2}}{r^{2}}+k^{2}\right)\right]
$$

onde novamente aplicamos as hipóteses iniciais (i.e., $u_{0} a / v_{A i} \ll 1$ e $u_{0} \ll 1$ ) e $D=$ $\rho v_{A}^{2} \Omega^{2}\left[\Omega^{2}-\omega_{A}^{2}+i\left(\nu / K_{1}\right) \Omega\right]$.

Se avaliarmos a Equação 3.47 ao redor do ponto de ressonância $\left(r=r_{A}\right)$ e, fizermos 
uso do fato de que $\Omega^{2}\left(r_{A}\right)=\omega^{2}\left(r_{A}\right)=\omega_{K}^{2}$, onde $\omega_{K}$ corresponde à frequência das ondas de superfície, a Equação 3.47 torna-se:

$$
\left[s \Delta+i\left(\nu / K_{1}\right) \Omega\right] \frac{\partial \xi_{r}}{\partial r}=\frac{p_{T}}{\rho} \frac{m^{2}}{r^{2}}
$$

onde $s=r-r_{A}$ e $\Delta=d\left(\Omega^{2}-\omega_{A}^{2}\right) / d s$. Note que para obter a Equação 3.48 foi realizada uma análise em série de Taylor, ao redor de $r=r_{A}$, na Equação 3.47.

Como o efeito da viscosidade é considerado no presente trabalho, efeitos dissipativos podem ocorrer de maneira efetiva no sistema (e.g. Lee e Roberts, 1986; Sakurai et al., 1991). De fato, a dissipação torna-se importante quando os dois termos à esquerda da igualdade na Equação 3.48 tornam-se comparáveis, i.e.:

$$
s \Delta \sim\left(\nu / K_{1}\right) \Omega
$$

Dessa maneira, podemos estimar a largura da zona dissipativa através da quantidade $\delta_{A}$, a qual é definida por:

$$
\delta_{A}=\frac{\nu \Omega}{K_{1} \Delta}
$$

Finalmente, basta integrar a Equação 3.48, ao redor do ponto de ressonância, para obter o 'pulo' do deslocamento radial devido à dissipação. Tomando $\delta_{A} \ll s_{A} \ll a$ (e.g. Ruderman e Roberts, 2002), temos que:

$$
\left[\xi_{r}\right]=\frac{p_{T}}{\rho} \frac{m^{2}}{r^{2}} \int_{-s_{A}}^{s_{A}} \frac{d s}{\left[s \Delta+i\left(\nu / K_{1}\right) \Omega\right]}
$$

a qual, após a introdução da nova variável $x=s \Delta+i \nu / K_{1}$, apresenta como solução:

$$
\begin{array}{r}
{\left[\xi_{r}\right]=\frac{p_{T} m^{2}}{\rho \Delta r^{2}}\left[i\left\{2 t g^{-1}\left(\frac{\delta_{A}}{s_{A}}\right)-\pi\right\}\right]} \\
{\left[\xi_{r}\right]=\frac{-i \pi p_{T} m^{2}}{\rho \Delta r^{2}} .}
\end{array}
$$


Importante frisar que a restrição $\delta_{A} \ll s_{A}$, denominada de aproximação de fronteira fina (aproximação TB, do inglês thin boundary approximation) assume que a região de transição e a região dissipativa coincidem, o que simplifica, de maneira significativa, os cálculos (e.g. Goossens et al. 2009).

Logo, obtemos que a relação de dispersão passa a ser obtida por:

$$
\xi_{r 2}-\xi_{r 1}=\left[\xi_{r}\right]
$$

de forma que a relação de dispersão torna-se:

$$
\begin{aligned}
& \rho_{1}\left(\Omega^{2}-\omega_{A i}^{2}+i\left(\nu / K_{1}\right) \Omega\right)+\rho_{2}\left(\omega^{2}-\omega_{A e}^{2}+i\left(\nu / K_{1}\right) \omega\right)= \\
& \frac{i|m| \pi}{r \rho \Delta} \rho_{1} \rho_{2}\left(\Omega^{2}-\omega_{A i}^{2}+i\left(\nu / K_{1}\right) \Omega\right)\left(\omega^{2}-\omega_{A e}^{2}+i\left(\nu / K_{1}\right) \omega\right),
\end{aligned}
$$

quando a IKH e a absorção ressonante são consideradas atuando conjuntamente, sob as aproximações TT e TB. Note que a Equação 3.51 torna-se análoga à Equação 74 de Goossens et al. (1992) quando o termo $\nu / K_{1}=0$.

Agora, é importante salientar que, dado que a IKH é suposta atuante no sistema, a frequência $\omega$ deve ser complexa, de forma que:

$$
\begin{aligned}
& \omega=\omega_{r}+i \omega_{i}, \\
& \Omega=\left(\omega_{r}+i \omega_{i}\right)-m u_{0}, \\
& \omega^{2}=\omega_{r}^{2}-\omega_{i}^{2}+2 i \omega_{r} \omega_{i}, \\
& \Omega^{2}=\omega_{r}^{2}-\omega_{i}^{2}+2 i \omega_{r} \omega_{i}+m^{2} u_{0}^{2}-2 \omega_{r} m u_{0}-2 i \omega_{i} m u_{0},
\end{aligned}
$$

onde $\omega_{r}$ e $\omega_{i}$ correspondem à parte real e imaginária da frequência, respectivamente, definidas pelas Equações 3.44a e 3.44b. Essa natureza complexa da frequência da onda faz com que a relação de dispersão representada na Equação 3.51 também apresente componentes real e imaginária. Logo, reescrevemos a Equação 3.51 da seguinte maneira:

$$
\rho_{1}\left(F_{r}+i F_{i}\right)+\rho_{2}\left(G_{r}+i G_{i}\right)-\mathcal{C}\left[i\left(F_{r} G_{r}-F_{i} G_{i}\right)-\left(F_{r} G_{i}+F_{i} G_{r}\right)\right]=0
$$

onde define-se: 


$$
\begin{aligned}
& \mathcal{C}=\frac{|m| \pi \rho_{1} \rho_{2}}{\rho\left(r_{A}\right) \Delta r_{A}}, \\
& F_{r}=\left(\omega_{r}-m u_{0}\right)^{2}-\omega_{i}\left(\omega_{i}+\nu / K_{1}\right)-\omega_{A i}^{2} \\
& F_{i}=\left(2 \omega_{i}+\frac{\nu}{K_{1}}\right)\left(\omega_{r}-m u_{0}\right) \\
& G_{r}=\left(\omega_{r}^{2}-\omega_{A e}^{2}\right)-\omega_{i}\left(\omega_{i}+\nu / K_{1}\right) \\
& G_{i}=\left(2 \omega_{i}+\nu / K_{1}\right) \omega_{r} .
\end{aligned}
$$

Logo, as partes real e imaginária da relação de dispersão são dadas, respectivamente, por:

$$
\begin{aligned}
& D_{r}=\rho_{1} F_{r}+\rho_{2} G_{r}+\mathcal{C}\left(F_{r} G_{i}+F_{i} G_{r}\right) \\
& D_{i}=\rho_{1} F_{i}+\rho_{2} G_{i}+\mathcal{C}\left(F_{i} G_{i}-F_{r} G_{r}\right) .
\end{aligned}
$$

Mas, segundo Krall e Trivelpiece (1973), a taxa de deposição de energia (e subsequente absorção) pode ser obtida através de :

$$
\gamma=\frac{-D_{i}}{\left(\partial D_{r} / \partial \omega_{r}\right)}
$$

onde $\omega_{r}$ é a parte real da frequência, avaliada para uma verdadeira descontinuidade. Sendo as derivadas das componentes de $D_{r}$ definidas como:

$$
\begin{aligned}
& \frac{\partial F_{r}}{\partial \omega_{r}}=2\left(\omega_{r}-m u_{0}\right), \\
& \frac{\partial G_{r}}{\partial \omega_{r}}=2 \omega_{r}, \\
& \frac{\partial\left(F_{r} G_{i}\right)}{\partial \omega_{r}}=2\left(\omega_{r}-m u_{0}\right) G_{i}+F_{r}\left(2 \omega_{i}+\nu / K_{1}\right), \\
& \frac{\partial\left(F_{i} G_{r}\right)}{\partial \omega_{r}}=\left(2 \omega_{i}+\nu / K_{1}\right) G_{r}+2 \omega_{r} F_{i},
\end{aligned}
$$

obtemos que a derivada do termo real da relação de dispersão é dado por:

$$
\begin{array}{r}
\frac{\partial D_{r}}{\partial \omega_{r}}=2\left\{\omega_{r}\left(\rho_{1}+\rho_{2}\right)-\rho_{1} m u_{0}+\mathcal{C}[\right. \\
\left(\omega_{i}+\nu /\left(2 K_{1}\right)\right)\left(F_{r}+G_{r}\right)+ \\
\left.\left.+\omega_{r}\left(G_{i}+F_{i}\right)-m u_{0} G_{i}\right]\right\} .
\end{array}
$$


Finalmente, substituindo a Equação 3.55 na equação para a taxa (Equação 3.54), obtemos a taxa de amortecimento para o mecanismo que acopla a absorção ressonante e o amortecimento turbulento:

$$
\gamma_{\text {acop }}=\frac{-\left[2\left\{\left(\omega_{i}+\nu /\left(2 K_{1}\right)\right)\left(\omega_{r}\left(\rho_{1}+\rho_{2}\right)-\rho_{1} m u_{0}\right)\right\}+\mathcal{C}\left(F_{i} G_{i}-F_{r} G_{r}\right)\right]}{2\left\{\omega_{r}\left(\rho_{1}+\rho_{2}\right)-\rho_{1} m u_{0}+\mathcal{C}\left[\left(\omega_{i}+\nu /\left(2 K_{1}\right)\right)\left(F_{r}+G_{r}\right)+\omega_{r}\left(G_{i}+F_{i}\right)-m u_{0} G_{i}\right]\right\}} .
$$

Note que, se assumirmos que não há um fluxo de background (ou seja, apenas o efeito da absorção ressonante de ondas Alfvén de superfície for levado em conta), $u_{0}=0$, a Equação 3.41 torna-se:

$$
\omega=-\frac{i}{2}\left(\frac{\nu}{K_{1}}\right) \pm \sqrt{\omega_{K}^{2}-\frac{\nu^{2}}{4 K_{1}^{2}}}
$$

onde teríamos $\omega_{K}^{2}>\frac{\nu^{2}}{K_{1}^{2}}$, de forma que as componentes real e imaginária de $\omega$ seriam, respectivamente, $\omega_{r}=\sqrt{\omega_{K}^{2}-\nu^{2} /\left(4 K_{1}^{2}\right)}$ e $\omega_{i}=-\nu / 2 K_{1}$. Ou seja, as componentes da relação de dispersão seriam dadas por:

$$
\begin{aligned}
& F_{r}=\omega_{K}^{2}-\omega_{A i}^{2}, \\
& F_{i}=0, \\
& G_{r}=\omega_{K}^{2}-\omega_{A e}^{2}, \\
& G_{i}=0,
\end{aligned}
$$

de forma que $\gamma$ torna-se simplesmente:

$$
\gamma=\frac{|m| \pi \rho_{1} \rho_{2}\left(\omega_{K}^{2}-\omega_{A i}^{2}\right)\left(\omega_{K}^{2}-\omega_{A e}^{2}\right)}{2 \omega_{r}\left(\rho_{1}+\rho_{2}\right) \rho\left(r_{A}\right) \Delta r_{A}}
$$

que corresponde precisamente à taxa de absorção para o mecanismo ressonante (e.g. Lee e Roberts, 1986, Goossens et al., 1992). O fato da Equação 3.57 ser independente do termo relacionado à viscosidade já era esperado dado que quando efeitos dissipativos são considerados, a viscosidade neste caso, a largura da região onde o build-up de energia se 
dará ajusta-se de tal maneira que a taxa de aquecimento resultante (relacionado à taxa $\gamma$ ) será independente dos termos dissipativos (Ionson, 1978).

A taxa de aquecimento associada ao mecanismo acoplado é escrita, portanto, como:

$$
H_{\text {acop }}=\rho\left(f v_{A}\right)^{2} \gamma_{\text {acop }}
$$


Capítulo 4

\section{O código numérico}

Nesse capítulo, explicitaremos o método numérico utilizado na simulação de um disco de acreção protoestelar, ao redor de uma estrela T Tauri, a fim de definir a localização da zona morta. Na Seção 4.1. mostramos o procedimento utilizado na simulação de um disco que segue o modelo padrão $\alpha$, geometricamente fino, opticamente espesso e no regime estacionário. Explicitaremos, ainda, as hipóteses utilizadas para obter o comportamento das propriedades do disco no plano médio e, posteriormente, a estrutura vertical do disco, através de um modelo 1D+1D. Na Seção 4.2, demonstramos a técnica utilizada para incluir nos cálculos os efeitos dos mecanismos de amortecimento de ondas Alfvén, enquanto na Seção 4.3 , apresentamos os cálculos referentes à obtenção da fração eletrônica das partículas constituintes do disco. Finalmente, na Seção 4.4, exibimos os procedimentos adotados para, a partir do valor da fração eletrônica, obtermos a extensão da zona morta no disco, i.e. a região onde a ionização é insuficiente para permitir a ocorrência da IMR.

\subsection{Código-base: simulação de um disco geometricamente fino, opticamente espesso no regime estacionário}

A partir do procedimento detalhado na Seção 2.3, obtém-se um conjunto de equações responsáveis por descrever, no regime estacionário, um disco geometricamente fino e opticamente espesso. Essas equações ditam a variação radial das propriedades físicas do disco, quando a dissipação viscosa é considerada o único mecanismo atuante no aquecimento desse objeto (Shakura e Sunyaev, 1973). Logo, é possível obter os perfis de densidade volumétrica $(\rho)$, escala de altura $(H)$, densidade superficial $(\Sigma)$, profundidade óptica $(\tau)$, velocidade do som $\left(c_{s}\right)$, velocidade Alfvén $\left(v_{A}\right)$, viscosidade $(\nu)$ e pressão $(P)$ através das 
seguintes prescrições:

$$
\begin{gathered}
\rho=\Sigma /(2 H), \\
H=c_{s} / \Omega_{K}, \\
\Sigma=\frac{\dot{M}}{3 \pi}\left[1-\left(R_{i} / r\right)^{1 / 2}\right], \\
\tau=(\Sigma / 2) \kappa, \\
c_{s}^{2}=P / \rho, \\
\nu=\alpha c_{s} H, \\
P=\frac{\rho k_{B} T_{c}}{\mu m_{p}}, \\
B=(8 \pi \alpha P)^{1 / 2},
\end{gathered}
$$

onde definimos $\Omega_{K}=\sqrt{\frac{G M_{*}}{r^{3}}}$ como sendo a velocidade Kepleriana, $\dot{M}$ corresponde à taxa de acreção do disco, em $M_{\odot} /$ ano, $R_{i}$ denota o raio de truncamento (i.e., raio interno) do disco e $\alpha$ refere-se ao parâmetro de viscosidade anômala, conforme proposto por Shakura e Sunyaev (1973). Além disso, temos que $\kappa$ corresponde à opacidade do meio, $\mu$ é o peso molecular médio, $k_{B}$ e $m_{p}$ assumem os valores da constante de Boltzmann e da massa do próton, respectivamente, e $T_{c}$ refere-se à temperatura central do disco.

Sendo a opacidade dependente da densidade, $\rho$, e temperatura, $T$, do meio, esta pode ser escrita como:

$$
\kappa=\kappa_{0} \rho^{a} T^{b}
$$


onde os parâmetros $\kappa_{0}, a$ e $b$ são característicos de cada regime de opacidade. Esses regimes são definidos de acordo com os principais responsáveis pela opacidade em cada região considerada. No presente trabalho, adotou-se a lei de opacidades de Bell e Lin (1994), de forma que pode-se identificar três regiões distintas no disco, conforme proposto por Gammie (1996):

- Região 1: consiste das porções do disco mais próximas ao objeto central, nas quais a opacidade pode ser bem descrita pela seguinte relação:

$$
\kappa=0.1 \sqrt{T_{c}} \mathrm{~g} \mathrm{~cm}^{-2}
$$

A Equação 4.10 pode ser utilizada para descrever aquelas regiões onde a principal fonte de opacidade é a presença de grãos de ferro e silicato, desde que a temperatura central, calculada a partir da Equação 4.13, esteja entre $2290 \rho^{2 / 49} \mathrm{~K}$ e $203 \mathrm{~K}$.

- Região 2: definida como sendo a fração do disco onde a opacidade é dominada pela sublimação do gelo, de forma que o regime de temperaturas contemplado é $167 K<T_{c} \leq 203 K$. A opacidade segue, portanto, a segunte lei de potência:

$$
\kappa=2.0 \times 10^{16} T_{c}^{-7} \mathrm{~g} \mathrm{~cm}^{-2}
$$

Nota-se que a opacidade é inversamente proporcional à temperatura. Essa propriedade será responsável por manter a temperatura central aproximadamente constante nesta região (vide Figura 5.1.

- Região 3: definida para temperaturas inferiores à $167 \mathrm{~K}$. Corresponde às regiões do disco onde a opacidade é dominada pela presença de grãos de gelo, sendo descrita por:

$$
\kappa=2.0 \times 10^{-4} T_{c}^{2} \mathrm{~g} \mathrm{~cm}^{-3} .
$$


Como foi suposto o disco opticamente espesso em toda sua extensão, é razoável assumir que a energia é transportada radiativamente, de forma que a temperatura central passa a ser definida por (Frank et al., 2002; Hartmann, 2009):

$$
T_{c}^{4}=\frac{3}{4} \tau T_{e f f}^{4}
$$

onde a profundidade óptica, $\tau$, foi previamente definida (Equação 4.4), e a temperatura efetiva, $T_{e f f}$, é definida, simplesmente, por:

$$
\sigma T_{e f f}^{4}=\frac{3 \Omega_{K}^{2}}{8 \pi}\left[1-\left(\frac{R_{i}}{r}\right)^{1 / 2}\right] \equiv D
$$

onde $D$ refere-se à energia dissipada quando apenas a dissipação viscosa atua no disco. Logo, ao resolvermos o sistema dado pelas Equações 4.144.13, obtemos uma descrição da variação radial das propriedades físicas do disco. O código numérico desenvolvido, responsável por calcular o disco sob a atuação apenas da dissipação viscosa, i.e., na ausência dos mecanismos de amortecimento estudados no presente trabalho, possui 5 parâmetros livres, a serem determinados pelo usuário, a saber: a massa do objeto central, $M_{*}$, a taxa de acreção do sistema, $\dot{M}$, o peso molecular médio do gás que compõe o disco, $\mu$, o parâmetro $\alpha$ e o raio interno do disco, $R_{i}$. Dado estes parâmetros, os cálculos iniciam-se para uma distância radial de $0.1 \mathrm{UA}$, de forma que o código desenvolve-se, de maneira autoconsistente, até que o disco deixa de ser opticamente espesso. Assim, ao final, o output será uma matriz que descreve a estrutura do disco nas direções radial e vertical. Na Subseção 4.1.1. explicitaremos, brevemente, os métodos utilizados para resolver a estrutura radial do disco, enquanto na Subseção 4.1.2, mostramos como podemos extrapolar os resultados obtidos para um modelo unidimensional, de forma a obter uma simulação 2D que descreva a evolução do disco nas direções radial e vertical.

\subsubsection{Obtenção das propriedades no plano médio do disco}

Das Equações 4.1,4.14, nota-se que as únicas propriedades dependentes apenas das condições iniciais são a velocidade Kepleriana e a temperatura efetiva do disco, as quais dependem apenas das propriedades iniciais do sistema, como massa e raio do objeto central, 
taxa de acreção do disco (suposta constante durante toda a simulação) e distância radial ao objeto central. Logo, ambas as propriedades são as primeiras a serem definidas pelo código. Por outro lado, pelas Equações 4.1, 4.8, nota-se que todas as demais propriedades do disco (e.g. densidades volumétrica e superficial, pressão, viscosidade, etc) dependem, direta ou indiretamente, da temperatura central. Portanto, uma vez que a temperatura central esteja definida, a obtenção de todos os outros parâmetros relevantes ao disco são obtidas de imediato, a partir apenas da aplicação direta das fórmulas que os definem.

A temperatura central, no entanto, devido à sua dependência com a opacidade (vide Equação 4.13), não pode ser obtida de maneira tão direta. Note que a opacidade também depende da temperatura central. Para a obtenção da temperatura central, portanto, fez-se uso do método de Newton, dado que esta temperatura é uma função implícita dela mesma.

O método de Newton (ou método de Newton-Raphson) nada mais é que um algoritmo reponsável por estimar o zero de funções. Em linhas gerais, esse método utiliza a tangente da função de interesse, e aproxima o ponto onde a função tangente cruza o zero como sendo a estimativa da raiz da função. Sendo a tangente de uma função qualquer, $f(x)$, calculada em um ponto $x=x_{0}$, dada por:

$$
y=f\left(x_{0}\right)+f^{\prime}\left(x_{0}\right)\left(x-x_{0}\right)
$$

e afirmando que em um dado ponto $x_{1}$, a tangente irá cruzar o eixo $x$, obtemos:

$$
0=f\left(x_{0}\right)+f^{\prime}\left(x_{0}\right)\left(x_{1}-x_{0}\right)
$$

de forma que podemos definir o ponto $x_{1}$ tendo conhecimento apenas do comportamento da função em $x=x_{0}$ :

$$
x_{1}=x_{0}-\frac{f\left(x_{0}\right)}{f^{\prime}\left(x_{0}\right)} .
$$

A Equação 4.17 corresponde à primeira estimativa para a raiz da função $f(x)$. Logo, obtemos que a relação de recorrência para o método de Newton é dada por: 


$$
x_{n+1}=x_{n}-\frac{f\left(x_{n}\right)}{f^{\prime}\left(x_{n}\right)} .
$$

Para a implementação do método de Newton na obtenção da temperatura central, uma pequena manipulação deve ser feita na Equação 4.13 para deixá-la no formato mais adequado para o uso desse método. Sendo a profundidade óptica, $\tau$, descrita pela Equação 4.4. e sabendo que a opacidade depende apenas de $T_{c}$ (Equações 4.10 4.12), reescrevemos a Equação 4.13 da seguinte maneira:

$$
T_{c}^{4}=\frac{3}{8} \Sigma \kappa_{0} T_{c}^{b} T_{e f f}^{4}
$$

onde substituiu-se a prescrição para $\tau$ (Equação 4.4) na fórmula para $T_{c}$ (Equação 4.13). Mas, das Equações 4.2, 4.3, 4.5 e 4.6, obtém-se que a densidade superficial, $\Sigma$, pode ser obtida da seguinte maneira:

$$
\Sigma=\frac{\dot{M}}{3 \pi} \frac{\Omega_{K} \mu m_{p}}{k_{B} T_{c}}\left[1-\left(\frac{R_{i}}{r}\right)^{1 / 2}\right]
$$

de forma que $T_{c}$ passa a ser escrito como um polinômio, de forma:

$$
T_{c}^{4}-\frac{\kappa_{0} \Omega_{K} \mu m_{p} \dot{M}}{8 \pi \alpha k_{B}} T_{e f f}^{4}\left[1-\left(\frac{R_{i}}{r}\right)^{1 / 2}\right] T_{c}^{b-1}=0 .
$$

Perceba que agora a temperatura central depende apenas das propriedades conhecidas do sistema e dos parâmetros relacionados à lei de opacidades $\left(\kappa_{0}\right.$ e $\left.b\right)$, diferentemente do que era visto na Equação 4.13. Dessa forma, $T_{c}$ passa a ser facilmente definida, uma vez fixada qual região, da lei de opacidades, está sendo considerada, através do método de Newton, após a substituição da Equação 4.20 e de sua derivada na relação de recorrência explicitada na Equação 4.18. O procedimento adotado, portanto, é o seguinte: supõe-se, inicialmente, que a prescrição para a região 1, dada pela Equação 4.10, é válida. Caso a temperatura seja menor que o limite inferior definido para essa região, i.e. $T_{c}<203 \mathrm{~K}$, supõe-se que a opacidade é definida de acordo com a região 2 (Equação 4.11); no caso da 
temperatura estar fora do intervalo característico dessa região, automaticamente assumese os parâmetros relacionados à opacidade dados pela região 3, determinando-se, assim, a temperatura central a uma dada distância radial, $r$. É importante frisar que o método de Newton pode ser instável em algumas ocasiões, como na presença de extremos (máximos ou mínimos) locais, de forma que uma boa escolha do 'chute' inicial, $x_{0}$, é necessária. Logo, após alguns testes, definiu-se, para a aplicação do método de Newton, os seguintes valores iniciais para $T_{c}$ :

- Região 1: $T_{c}^{0}=4000 K$,

- Região 2: $T_{c}^{0}=170 \mathrm{~K}$,

- Região 3: $T_{c}^{0}=150 \mathrm{~K}$.

A condição de parada para o método de Newton acontece quando a precisão, ou seja, a diferença entre duas estimativas consecutivas, for menor que $10^{-10}$. Uma vez obtida a temperatura central, calcula-se o valor da densidade superficial, através da Equação 4.19 e da profundidade óptica (Equação 4.4). Finalmente, de posse dos valores dessas três propriedades (temperatura central, densidade superficial e profundidade óptica), é possível obter todas as demais variáveis, a saber: velocidade do som $\left(c_{s}\right)$, escala de altura do disco $(H)$, densidade volumétrica $(\rho)$, viscosidade $(\nu)$, pressão do gás $(P)$ e a intensidade do campo magnético $(B)$. O procedimento supracitado é realizado até $r=100 U A$ ou até o disco tornar-se opticamente fino (i.e., $\tau<1$ ). Esse processo é explicitado no fluxograma apresentado na Figura 4.1 pelas caixas laranjas: o programa inicia e, para cada distância radial ( $r \leq 100 \mathrm{UA}$ ), é obtida a velocidade Kepleriana e a temperatura efetiva do disco. De posse dessas duas quantidades, utiliza-se o método de Newton para a definição da temperatura central. Isso é feito até que se atinja a precisão, $\epsilon$, imposta, dada por $\epsilon=$ $10^{-10}$. Finalmente, obtém-se, então, as demais propriedades do disco.

\subsubsection{O modelo de disco de acreção $2 D(1 D+1 D)$}

De forma geral, a construção de um modelo bidimensional é algo bastante complexo e custoso do ponto de vista computacional. Entretanto, algumas aproximações podem ser realizadas que simplificam o problema razovelmente. Sendo as mudanças na estrutura radial do disco dadas pela escala de tempo viscosa e sabendo que esta é muito maior 
que as escalas de tempo para os demais processos físicos que ocorrem no disco (como, por exemplo, as escalas de tempo dinâmica e para o equilíbrio hidrostático vertical $\left.\right|^{1}$, é possível desacoplar as direções vertical e radial do disco, de forma que um modelo 2D passa a ser descrito por um modelo 1D+1D. Apesar das diferenças entre um modelo 1D+1D e um modelo 2D existirem, espera-se, quando estamos no regime estacionário, que é o considerado no presente trabalho, que o modelo $1 \mathrm{D}+1 \mathrm{D}$ seja representativo do modelo $2 \mathrm{D}$ (Pringle, 1981; Ilgner et al., 2004).

Uma vez que a estrutura no plano médio do disco é obtida (vide Subseção 4.1.1), a estrutura em sua direção vertical passa a ser resolvida. Uma importante hipótese adotada nesse trabalho é que a temperatura do disco independe da altura, i.e., estamos supondo um disco isotérmico na direção vertical. Essa hipótese torna-se razoável uma vez que o disco simulado é opticamente espesso. Sendo assim, espera-se que não haja gradientes relevantes da temperatura na direção vertical. Partindo desta isotermalidade em z, resolvese, inicialmente, a equação de equilíbrio hidrostático (Equação 4.21) a fim de obter o comportamento da densidade volumétrica na direção vertical:

$$
\frac{\partial \rho_{z}}{\partial z}=-\frac{\rho_{z}}{c_{s}^{2}} g_{z}, \quad g_{z} \equiv \Omega^{2} z
$$

A Equação 4.21 é uma simples equação diferencial ordinária de primeira ordem, a qual possui como solução:

$$
\rho_{z}=c \exp \left[-z^{2} / 2\left(H^{2}\right)\right]
$$

onde fez-se uso da relação entre a velocidade do som e a escala de altura do disco, dada pela Equação 4.2. Se aplicarmos a condição de contorno para $\rho_{z}$, a saber, $\rho_{z}$ deve tender ao valor da densidade volumétrica no plano médio, $\rho$, quando $z=0$, obtemos que a constante de integração, $c$, torna-se $c=\rho$, de forma que a densidade volumétrica segue a seguinte

\footnotetext{
${ }^{1}$ No modelo de disco considerado, as escalas de tempo dinâmica, $t_{\phi}$, e para o equilíbrio hidrostático vertical, $t_{z}$, são equivalentes, i.e., $t_{z} \sim t_{\phi}$ (Frank et al. 2002$)$. Para uma distância radial de 1 UA, por exemplo, a escala de tempo dinâmica é cerca de cinco ordens de grandeza menor que a escala de tempo viscosa $\left(t_{v i s} \sim r^{2} / \nu\right)$. No Capítulo 5 é apresentado o comportamento radial dessas duas escalas de tempo características do disco.
} 
relação na direção vertical:

$$
\rho(r, z)=\rho(r) \exp \left[-z^{2} / 2\left(H^{2}\right)\right]
$$

Uma vez que o perfil da densidade volumétrica em z é obtido, descreve-se o comportamento da densidade superficial, também na direção vertical, através da Equação 4.23 .

$$
\Sigma(z)=\int_{z}^{\infty} \rho(z) d z
$$

Sendo a densidade volumétrica definida pela Equação 4.22 , obtém-se que a densidade superficial é obtida através da integração do termo exponencial, ou seja:

$$
\Sigma(r, z)=\rho(r) \int_{z}^{\infty} \exp \left[-z^{2} / 2\left(H^{2}\right)\right] d z .
$$

Para o cálculo da integral da Equação 4.23, fez-se uso de uma subrotina que calcula integrais em intervalos infinitos ou semi-infinitos através do método de quadratura de Gauss-Kronrod. Tal subrotina faz parte da biblioteca para integração numérica QUADPACK do Fortran 77, e recebe como input, entre outras informações, a subrotina que contém a função a ser integrada (nesse caso, a função exponencial), além do argumento dessa função, ou seja, a altura, $z$, e a escala de altura, $H$. De maneira resumida, o método de Gauss-Kronrod é uma adaptação da quadratura de Gauss-Legendre. A quadratura de Gauss é um algoritmo que aproxima a integral por uma somatória dos valores da função (abscissas), avaliada em um conjunto de pontos escolhidos de maneira a maximizar a acurácia do método, multiplicados por um peso adequado. A principal diferença entre os métodos de Gauss e de Gauss-Kronrod reside no fato de que, diferentemente do método de Gauss, a quadratura de Gauss-Kronrod permite a reutilização das abscissas calculadas na iteração anterior, ao passo de que na quadratura usual, todas as abscissas necessitariam ser recalculadas a cada iteração (Press et al., 1992).

Tendo obtido os valores das densidades superficial e volumétrica na altura, $z$, é trivial obter todas as demais propriedades do disco na direção vertical. Note que a velocidade do som, a escala de altura, a viscosidade, a pressão e o campo magnético não variam verticalmente, dado que é adotada a hipótese de isotermalidade em z. Apresentamos um 
esquema referente ao procedimento utilizado para resolver a estrutura vertical do disco na Figura 4.1. As caixas rosas representam as etapas adotadas nesse processo: utilizando o equilíbrio hidrostático, obtém-se a densidade volumétrica, superficial e a profundidade óptica (relacionada à densidade superficial, conforme Equação 4.4) para cada altura, z. Caso $\tau_{z}>1$, ou seja, se a aproximação de disco opticamente espesso for válida, obtém-se o comportamento de todas as demais propriedades na direção vertical. Esse procedimento é realizado até que o disco torna-se opticamente fino.

\subsection{Inclusão dos mecanismos de amortecimento de ondas Alfvén}

Uma vez que a estrutura do disco está resolvida (vide Seção 4.1), aplica-se os mecanismos de amortecimento das ondas Alfvén estudados (amortecimento não-linear, turbulento, ressonante e acoplado). Para tal, utiliza-se as prescrições referentes à cada amortecimento (Seções 3.2, 3.3, 3.4 e 3.5), as quais são implementadas no código na forma de subrotinas. Essas subrotinas são responsáveis por calcular a taxa de aquecimento volumétrica, $H_{A}$, para cada um dos mecanismos considerados. Subsequentemente, obtém-se a energia dissipada pelo amortecimento das ondas Alfvén, $D_{A}$, a partir da seguinte equação:

$$
D_{A}=\int_{-H}^{H} H d z
$$

onde $H$ representa a escala de altura do disco, em centímetros. Obtém-se, portanto, a nova temperatura efetiva do disco, a qual é dada por:

$$
\sigma T_{e f f}^{4}=D+D_{A}
$$

onde $D$ é definido pela Equação 4.14. A partir do valor da nova temperatura efetiva, resolve-se novamente a estrutura do disco, utilizando o mesmo procedimento descrito na Seção 4.1. Devido à nova fonte de calor (o amortecimento de ondas Alfvén), todos os novos valores para a estrututura do disco serão, a priori, diferentes dos valores anteriores, de forma que esse procedimento é repetido até que as estruturas atual e imediatamente anterior sejam iguais, para uma dada precisão, $\epsilon_{A}$. 


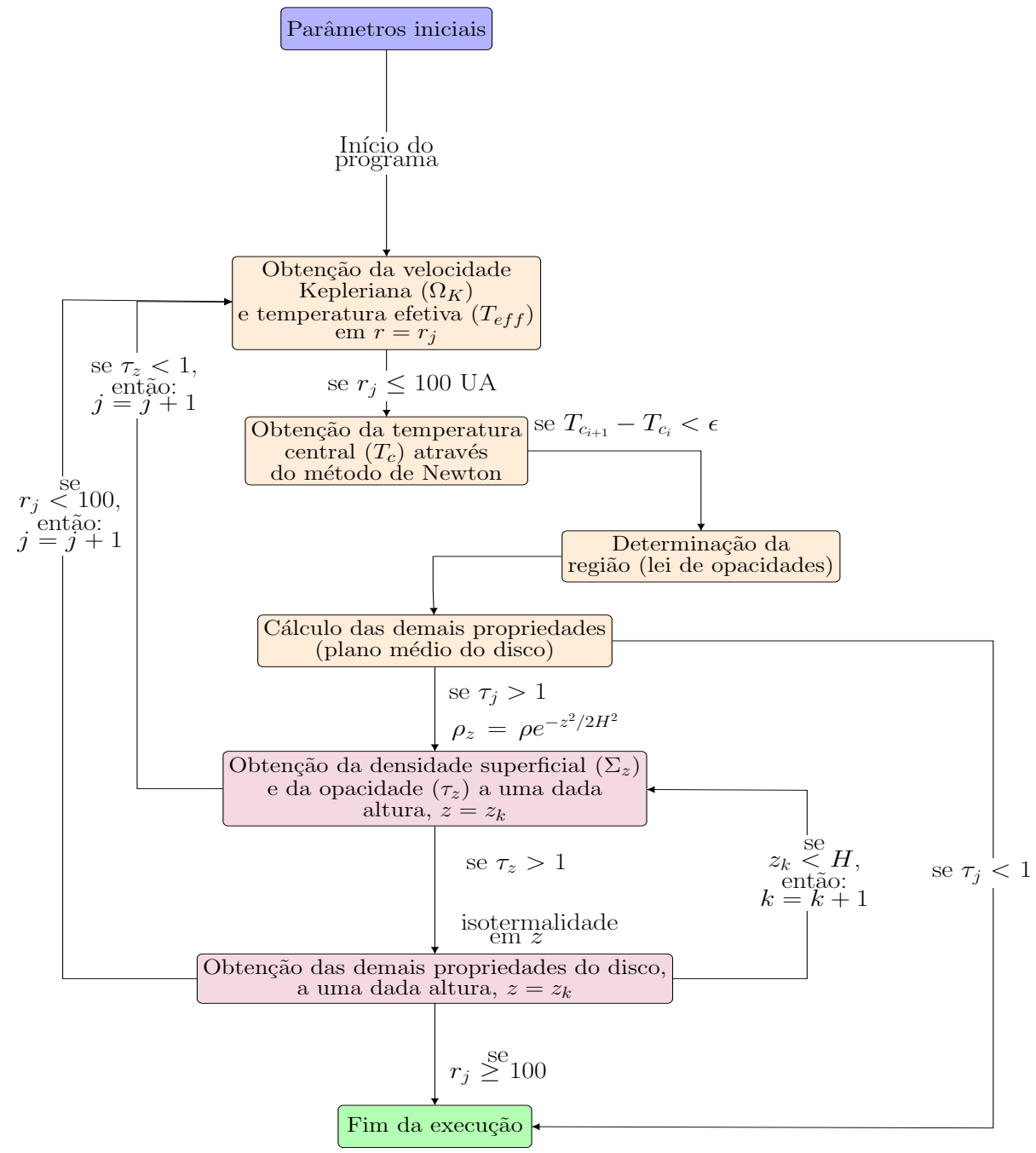

Figura 4.1: Fluxograma do método utilizado para obter a estrutura do disco na ausência dos mecanismos de aquecimento considerados, ou seja, quando apenas a dissipação viscosa é atuante. Nas caixas laranjas, apresenta-se o procedimento para a obtenção da estrutura radial, enquanto as caixas rosas referem-se ao processo utilizado para a obtenção da estrutura vertical do disco. Os cálculos iniciam-se para $r=0.1$ UA e procedem até $r=100$ UA ou até o disco tornar-se opticamente fino. Inicialmente, obtém-se a temperatura efetiva e a velocidade Kepleriana do disco para uma dada distância radial. Posteriormente, através do método de Newton, a temperatura central é obtida, através da qual todas as outras propriedades são derivadas. Subsequentemente à resolução da estrutura radial do disco, utilizando o equilíbrio hidrostático, calcula-se o comportamento, na direção vertical, da densidade volumétrica, superficial e da profundidade óptica. Caso a hipótese de disco opticamente espesso mostrar-se ainda válida, obtém-se as demais propriedades do disco em $z$. 


\subsection{Código responsável por obter a fração eletrônica no disco de acreção e simular a extensão da zona morta}

Uma das maneiras de definir a extensão da zona morta é a partir do número de Reynolds magnético $\left(R_{e M}\right)$. Simulações MHD (Fleming et al., 2000) mostram que para números de Reynolds magnético menores que um valor crítico, $R_{e M}^{c r i t}$, a turbulência não pode ser mantida e o disco retorna à um estado quasi-laminar. Esse valor limite ainda não é muito bem determinado e depende da configuração do campo magnético no disco. Gammie (1996) fixou $R_{e M}^{c r i t}=1$, entretanto, simulações mais recentes apontam que o valor mais apropriado seria igual à $R_{e M}^{c r i t}=100$ para um campo magnético constante na direção vertical e $R_{e M}^{c r i t}=10^{4}$ na ausência de um fluxo líquido do campo (e.g. Fromang et al., 2002, Ilgner e Nelson, 2006). O número de Reynolds magnético pode ser definido da seguinte forma:

$$
R_{e M}=\frac{c_{s} H}{\eta}
$$

onde $c_{s}$ é a velocidade do som no meio, $H$ corresponde à escala de altura do fluido e $\eta$ é a resistividade magnética, dada por (Hayashi, 1981):

$$
\eta=6.5 \times 10^{3} x^{-1} \mathrm{~cm} \mathrm{~s}^{-1}
$$

onde $x$ é a fração eletrônica.

No presente trabalho, consideramos 3 fontes de ionização para o disco: a ionização térmica, a ionização por raios-X e a ionização por raios cósmicos. Além disso, foram levados em conta os processos de recombinação que podem atuar no disco, de forma a contrabalancear os efeitos da ionização. Procedimentos similares a esse, para a determinação da zona morta, foram realizados por Fromang et al. (2002), Ilgner e Nelson (2006) e Martin et al. (2012).

\subsubsection{Ionização térmica}

A ionização térmica ocorre quando átomos estão imersos em um meio onde a temperatura é suficientemente alta, de forma que a colisão térmica passa a ser um processo efetivo 
de ionização desses átomos. Na parte mais interna e mais densa do disco, onde a temperatura ultrapassa $1000 \mathrm{~K}$, os íons alcalinos $\mathrm{Na}^{+}$e $\mathrm{K}^{+}$serão abundantes, de forma a serem a fonte dominante de ionização térmica nessas regiões. Nesse caso, a equação de Saha pode ser aproximada por (Balbus e Hawley, 2000):

$$
x_{e}=6.47 \times 10^{-13}\left(\frac{a}{10^{-7}}\right)^{1 / 2}\left(\frac{T}{10^{3}}\right)^{3 / 4}\left(\frac{2.4 \times 10^{15}}{n}\right)^{1 / 2} \frac{\exp (-25188 / T)}{1.15 \times 10^{-11}}
$$

onde $a$ é a abundância de $\mathrm{K}$ em relação ao Hidrogênio e $n$ é a densidade numérica de partículas, dada em $\mathrm{cm}^{-3}$. No presente trabalho, adotou-se $a=10^{-7}$, em concordância com Fromang et al. (2002).

\subsubsection{Ionização por raios- $X$}

Objetos jovens são fortes emissores de radiação X, com luminosidades típicas, em raios$\mathrm{X}$, entre $10^{29}-10^{32} \mathrm{erg} \mathrm{s}^{-1}$ (e.g. Telleschi et al., 2007; Santos-Silva et al., 2018) e fótons com energias entre 1 e $5 \mathrm{keV}$. Glassgold et al. (1997) propuseram que essa poderia ser a principal fonte de ionização não-térmica em discos protoestelares e modelaram a fonte de raio-X como sendo um anel coronal isotérmico $\left(T=T_{X}\right)$, localizado acima e abaixo do plano médio. Dessa forma, a emissão total em X seria dada por $L_{X}$, com cada hemisfério contribuindo com $L_{X} / 2$. A taxa de ionização por raios-X seria dada, portanto, por (e.g. Fromang et al., 2002 e referências contidas contidas nesse artigo):

$$
\zeta_{X}=\frac{\left(L_{X} / 2\right)}{4 \pi r^{2} k T_{X}} \sigma\left(k T_{X}\right) \frac{k T_{X}}{\Delta \epsilon} J(\tau)
$$

onde $\Delta \epsilon$ equivale à energia necessária para um fotoelétron primário fazer uma ionização secundária, e $\sigma\left(k T_{X}\right)$ é a seção de choque da fotoionização, definida por (Igea e Glassgold, 1999):

$$
\sigma\left(k T_{X}\right)=8.5 \times 10^{-23}\left(k T_{X} / k e V\right)^{-n} \mathrm{~cm}^{2},
$$

sendo a potência, $n$, definida por $n=2.81$. Por fim, a variável adimensional $J$ é definida como: 


$$
J(\tau)=A \tau^{-a} \exp \left(-B \tau^{b}\right)
$$

onde $\tau$ é a profundidade óptica a uma dada energia $k T_{X}$ (Igea e Glassgold, 1999):

$$
\tau=0.85\left(\frac{N}{10^{22}}\right)\left(k T_{X}\right)^{-n}
$$

onde $N$ denota a densidade numérica de coluna do disco $\left(N=\Sigma / \mu m_{H}\right)$. Na Equação 4.31, as variáveis $A, B, a$, e $b$ correspondem aos parâmetros livres. No presente trabalho, considerou-se $A=0.686, a=0.606, B=1.778, b=0.262$ e $\Delta \epsilon=37 \mathrm{eV}$, assim como foi feito por Fromang et al. (2002).

\subsubsection{Ionização por raios cósmicos}

Finalmente, a última fonte de ionização considerada no presente trabalho são os raios cósmicos. Esses raios, a priori, atingem toda a extensão do disco, entretanto, devido à densidade de coluna desse objeto, os raios cósmicos acabam por ser atenuados durante sua passagem pelo disco (e.g. Gammie, 1996), de forma que a taxa de ionização desse efeito passa a ser dada por (Fleming e Stone, 2003):

$$
\zeta_{C R}=\zeta_{0} \exp (-\Sigma(z) / 100)
$$

onde $\zeta_{0}=10^{-17} \mathrm{~s}^{-1}$ corresponde à taxa de ionização por raios cósmicos no meio interestelar (Spitzer Jr e Tomasko, 1968).

\subsubsection{Recombinação}

Nas regiões onde a ionização térmica (Seção 4.3.1) não é efetiva, os processos de recombinação, balanceados pela ionização por raios cósmicos e por raios-X, passam a ser a principal fonte de ionização do disco. Como no presente trabalho a ação da poeira é desprezada, o processo dominante de recombinação será a recombinação dissociativa molecular. Se considerarmos um equilíbrio estacionário, temos que a fração eletrônica é determinada por (Oppenheimer e Dalgarno, 1974): 


$$
x_{e}^{3}-10^{-3} T^{1 / 2} x_{M} x_{e}^{2}-\frac{\zeta}{\beta n_{n}} x_{e}-100 T^{1 / 2} \frac{\zeta}{\beta n_{n}} x_{M}=0,
$$

onde $n_{n}$ representa a densidade numérica de partículas neutras, em $\mathrm{cm}^{-3}, x_{M}$ denota a abundância de metal, $\beta$ é o coeficiente da taxa de recombinação dissociativa para íons moleculares e $\zeta$ corresponde à taxa de ionização total. Se assumirmos que a abundância de metais é desprezível, obtemos que a fração eletrônica passa a ser dada simplesmente por:

$$
x=\sqrt{\frac{\zeta}{\beta n_{n}}},
$$

onde $\beta=3 \times 10^{-6} T^{-1 / 2} \mathrm{~cm}^{3} \mathrm{~s}^{-1}$, e $\zeta$ recebe a soma das taxas de ionização por raios cósmicos e raios-X, $\zeta=\zeta_{C R}+\zeta_{X}$.

\subsection{Procedimento adotado}

O código responsável por obter a extensão da zona morta utiliza de todas as considerações explicitadas acima e procede da seguinte maneira: inicialmente, realiza-se a hipótese de que $n_{n} \sim n$, de forma que a densidade numérica de partículas é obtida por:

$$
n=\frac{\rho}{\mu m_{H}} .
$$

De maneira análoga, supõe-se que a densidade numérica na coluna é obtida através de:

$$
N=\frac{\Sigma}{\mu m_{H}}
$$

Subsequentemente, obtém-se a fração eletrônica através das Equações 4.28 e 4.35 , dependendo da temperatura do ponto considerado, ou seja, se $T>1000 K$, a Equação 4.28 é utilizada e nos casos onde essa condição não é satisfeita, a Equação 4.35 é empregada. De posse da fração eletrônica, obtém-se a resistividade magnética, definida através da Equação 4.27, a qual é utilizada para o cálculo do número de Reynolds magnético (vide Equação 4.26). 
De posse dos valores do número de Reynolds magnético para cada um dos pontos do disco, compara-se esse valor com o limite mínimo estabelecido para o aparecimento de turbulência, de origem magnética, no meio. No presente trabalho, adotou-se um valor crítico de $R_{e M}^{c r i t}=100$, dado que uma das hipóteses de trabalho é que o campo magnético existe apenas na direção vertical. A partir da comparação entre os valores obtidos e o valor limítrofe, criou-se uma matriz que guarda os valores de distância radial e altura, $z$, dos pontos correspondentes à zona morta, i.e., com $R_{e M}<R_{e M}^{c r i t}$. Na sequência, utilizando os valores mínimo e máximo para a altura da zona morta, à uma dada distância radial, obtém-se a densidade de coluna da zona morta, em $\mathrm{cm}^{-2}$, através da seguinte equação:

$$
\Sigma_{D Z}(r)=\rho(r) \int_{z_{\min }}^{z_{\max }} \exp \left(-z^{2} / 2 H^{2}\right)
$$

onde $\Sigma_{D Z}$ denota a densidade de coluna da zona morta, em $\mathrm{g} \mathrm{cm}^{-2}, \rho(r)$ representa a densidade volumétrica, calculada no plano médio, $z_{\min }$ e $z_{\max }$ assumem os valores das alturas mínima e máxima da zona morta, à uma distância $r$, e $H$, conforme definido anteriormente, é a escala de altura do disco. Para obter, então, a densidade numérica de coluna da zona morta, utiliza-se novamente que a densidade numérica pode ser obtida por:

$$
N_{D Z}=\frac{\Sigma_{D Z}}{\mu m_{H}}
$$

Finalmente, a partir dos valores para a densidade de coluna total do disco $(N=$ $\Sigma / \mu m_{H}$, onde $\Sigma$ representa a densidade superficial total do disco) e da zona morta, estimase a densidade numérica da zona ativa, $N_{A}$, da seguinte relação:

$$
N_{A}=N-N_{D Z}
$$




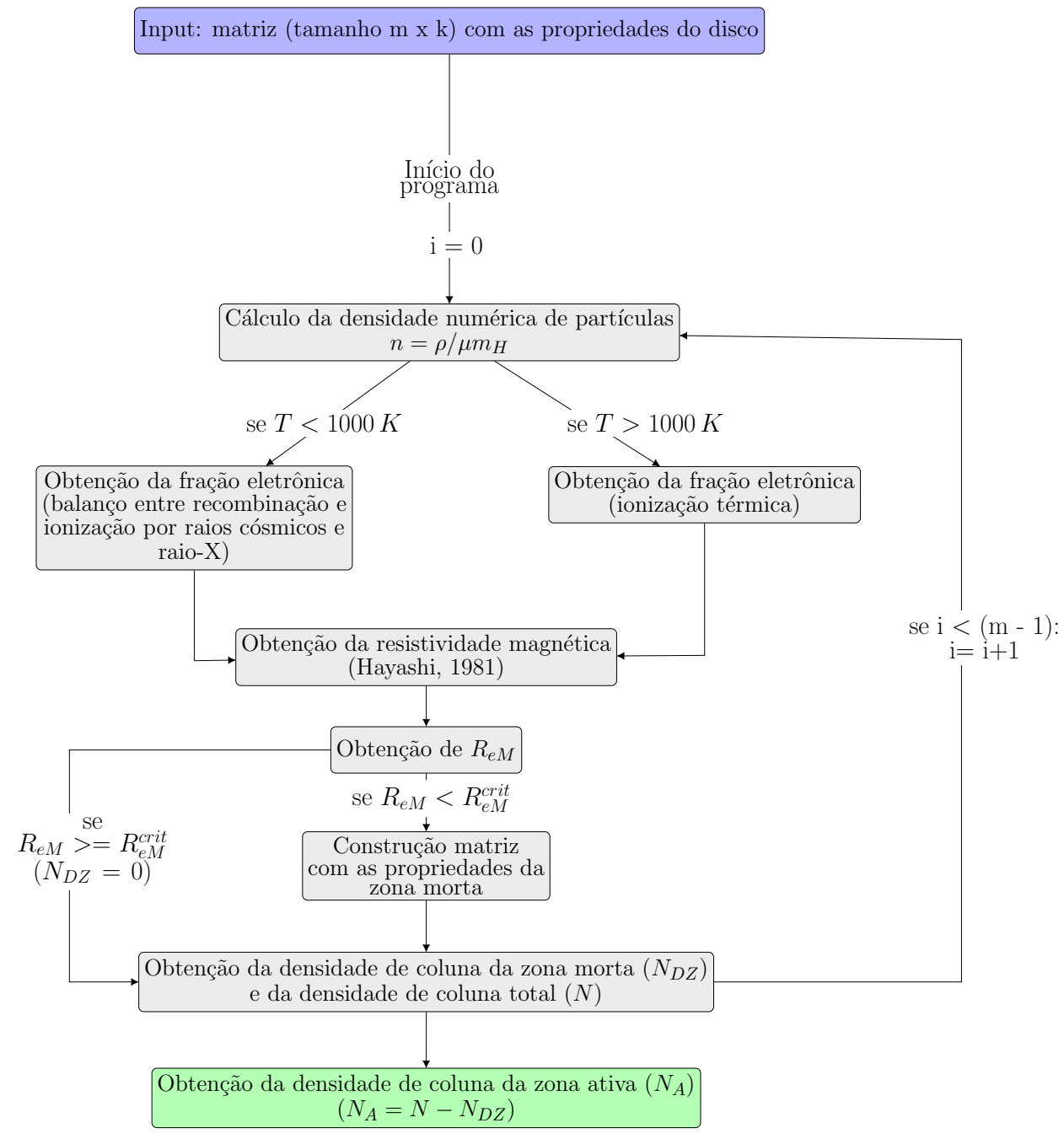

Figura 4.2: Fluxograma do procedimento utilizado para obter a fração de ionização no disco e estimar a extensão da zona morta. Inicialmente, o programa lê um arquivo externo que contém as propriedades do disco, nas direções radial e vertical. Em seguida, são obtidas as densidades numérica de partículas no disco, para um dado par $(r, z)$, através da Equação 4.36. Na sequência, calcula-se a fração eletrônica, a partir da Equação 4.28 para regiões onde a temperatura é superior a $1000 \mathrm{~K}$, ou através da Equação 4.35 para os pontos com temperatura inferior à esse limite. Obtém-se, então, a resistividade magnética (Equação 4.27) e o número de Reynolds magnético correspondente (Equação 4.26. Caso $R_{e M}<R_{e M}^{c r i t}$, as propriedades desse ponto $(r, z)$ são guardadas em uma matriz que recebe as informações a respeito da zona morta. Finalmente, é possível obter a densidade de coluna da zona morta, através da Equação 4.39 a densidade de coluna total do disco (Equação 4.37) e a densidade de coluna da zona ativa através da subtração dessas duas quantidades, $N_{A}=N-N_{D Z}$. 
Capítulo 5

\section{Simulações e Resultados}

No presente capítulo, apresentamos os resultados obtidos utilizando o código numérico descrito no Capítulo 4. Inicialmente (Seção 5.1), apresentamos as simulações referentes a um disco geometricamente fino, opticamente espesso e que obedece o modelo padrão de Shakura e Sunyaev (1973), i.e., apresentaremos as propriedades do disco de acreção quando apenas a dissipação viscosa atua no seu aquecimento. Posteriormente, na Seção 5.2 , será explicitado os resultados após a atuação de cada um dos mecanismos de amortecimento de ondas Alfvén considerados, a fim de analisarmos a efetividade desses mecanismos extras de aquecimento. Todos os resultados obtidos foram calculados supondo um disco ao redor de um objeto central de massa $M_{*}=0.7 M_{\odot}$, com taxa de acreção $\dot{M}=10^{-7} M_{\odot}$ ano $^{-1}$, raio interno dado por $R_{i}=5 R_{\odot}$, peso molecular médio de $\mu=2.33$ e parâmetro $\alpha$ igual à $\alpha=0.01$. Esses mesmos parâmetros foram utilizados por Jatenco-Pereira (2013) em seu estudo sobre a influência do amortecimento cíclotron da poeira no aquecimento do plano médio de discos de acreção associados à estrelas T Tauri.

\subsection{Simulações referentes ao disco-base}

Inicialmente, simulou-se um disco-base, que segue o modelo padrão de Shakura e Sunyaev (1973) e o modelo de camadas proposto por Gammie (1996). Esse disco é, inicialmente, aquecido apenas pela dissipação viscosa e sua opacidade pode ser bem descrita pela lei de opacidades de Bell e Lin (1994). Devido à nossa hipótese inicial afirmar que o disco é opticamente espesso, nossas simulações transcorrem enquanto tal aproximação é válida, i.e., o disco sob simulação é truncado a partir de um dado ponto espacial $(r, z)$ onde $\tau \leq 1$. O procedimento adotado para a obtenção dos resultados mostrados abaixo é descrito na 
Seção 4.1 .

Nas Figuras 5.1 e 5.2, apresentamos os perfis para as temperaturas central e efetiva e para a densidade superficial do disco. Enquanto a temperatura efetiva (linha cheia na Figura 5.1) possui uma dependência bem definida com a distância ao objeto central, $T \propto r^{-3 / 4}$ (e.g. Hartmann, 2009), nota-se que a temperatura central (linha traço-ponto na Figura 5.1) e a densidade superficial exibem variações abruptas no seu comportamento. Esses mesmos comportamentos podem ser vistos no trabalho de Jatenco-Pereira $(2013)$ e são explicados devido às transições no regime de opacidade de acordo com a distância ao objeto central: como a opacidade e a temperatura central são grandezas correlacionadas e, para cada regime de opacidade essas grandezas relacionam-se diferentemente (veja Equações 4.10 4.12), a inclinação das curvas para a temperatura central e densidade superficial, mudam de acordo com a região do disco considerada. Dessa forma, analisando os perfis dessas duas grandezas podemos determinar a extensão de cada uma das regiões definidas pela lei de opacidades de Bell e Lin (1994): de 0.1-3UA a opacidade é dominada pela presença de grãos de ferro e silicato (região 1); de $3 \sim 5 \mathrm{UA}$, a sublimação do gelo é a principal fonte de opacidade (região 2) e além de 5 UA, os grãos de gelo são a fonte dominante de opacidade no disco (região 3). Chamamos também a atenção para o fato de que os comportamentos mostrados nas Figuras 5.1 e 5.2 são equivalentes aos perfis M-2 (modelo sem a inclusão de poeira, considerando apenas os modelos de Shakura e Sunyaev (1973) e Gammie (1996)) das Figuras 1 e 2 de Jatenco-Pereira (2013), o que demonstra a funcionalidade do procedimento por nós adotado.

Nas Figuras 5.3 e 5.4 apresentamos a estrutura em duas dimensões do disco, calculada através do método 1D+1D explicitado na Seção 4.1.2. Nessas figuras é mostrada apenas a região mais interna do disco $(r \lesssim 4 \mathrm{UA})$, a região de interesse do presente trabalho, uma vez que é nessa porção do disco que a zona morta está localizada (vide Figura 5.5). Na Figura 5.3. os contornos referem-se a valores de densidade volumétrica de $10^{-9}$ e $10^{-10} \mathrm{~g} \mathrm{~cm}^{-3}$, respectivamente. Já na Figura 5.4, a linha denota o valor de densidade superficial de $100 \mathrm{~g} \mathrm{~cm}^{-2}$, valor limite definido por Gammie 1996) para a penetração de raios cósmicos no disco (i.e. regiões com densidade superficial maiores que esse valor não permitiriam que os raios cósmicos penetrassem nas áreas mais internas do disco). Note que, enquanto a densidade volumétrica exibe uma diminuição contínua com o aumento das distâncias radial e vertical, o perfil da densidade superficial é mais concentrado no plano médio do disco, 


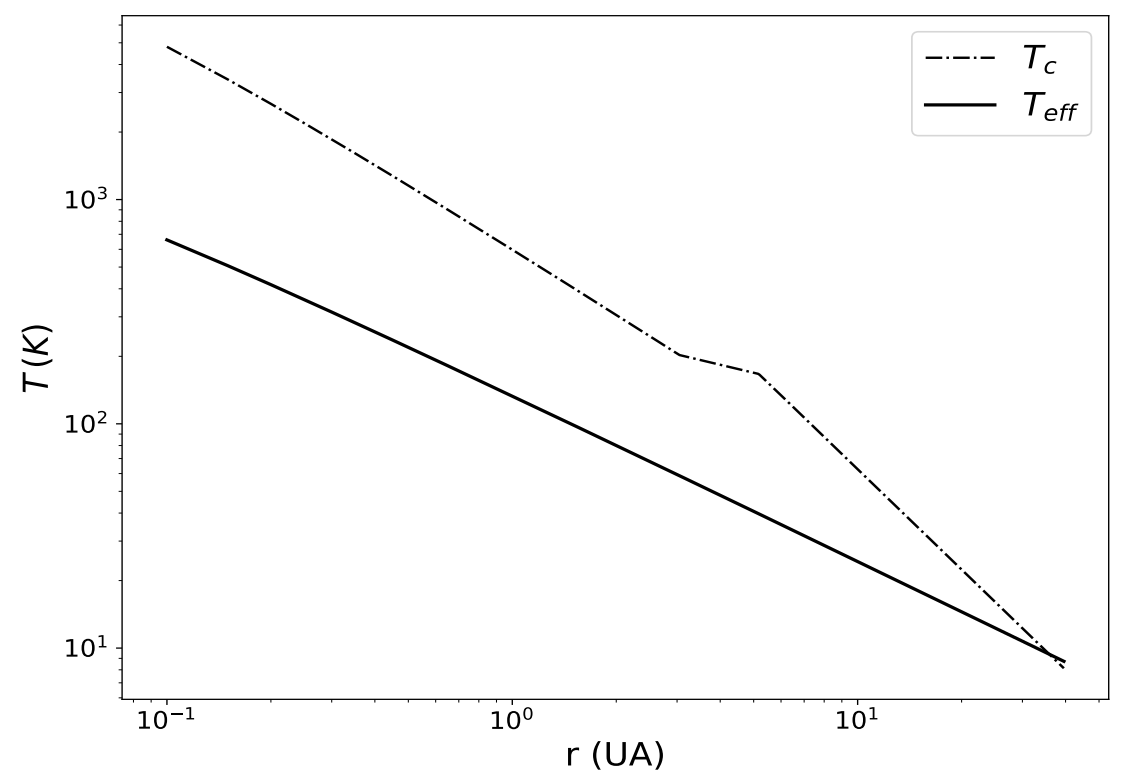

Figura 5.1: Perfil radial das temperaturas central (traço-ponto) e efetiva (linha cheia) para um disco de acreção ao redor de uma estrela T Tauri de massa $M_{*}=0.7 M_{\odot}$, quando apenas a dissipação viscosa é atuante. Note que, enquanto a temperatura efetiva exibe uma variação suave, a temperatura central possui algumas variações abruptas em seu comportamento. Essas variações na temperatura central correspondem às regiões onde ocorre a mudança no regime de opacidade.

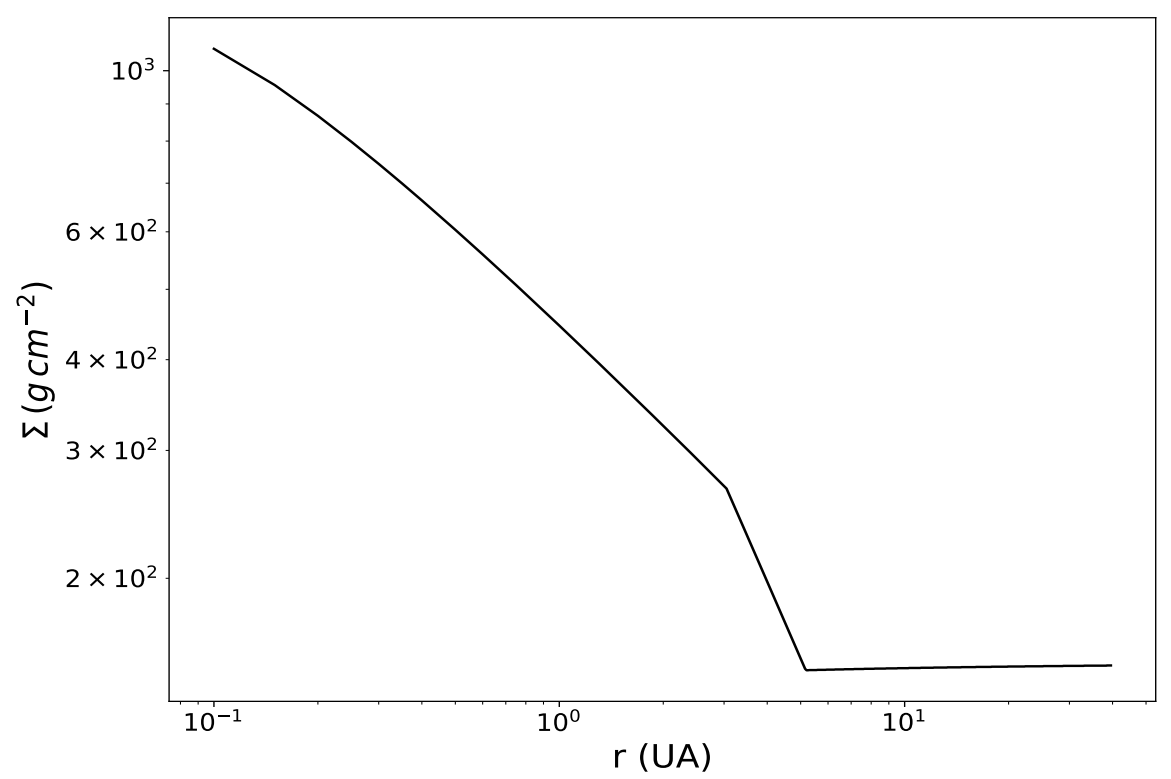

Figura 5.2: Perfil radial da densidade superficial para um disco de acreção ao redor de uma estrela T Tauri de massa $M_{*}=0.7 M_{\odot}$, quando apenas a dissipação viscosa é atuante. As diferenças abruptas no comportamento da densidade superficial ocorrem nas distâncias radiais correspondentes às mudanças no regime de opacidade. 


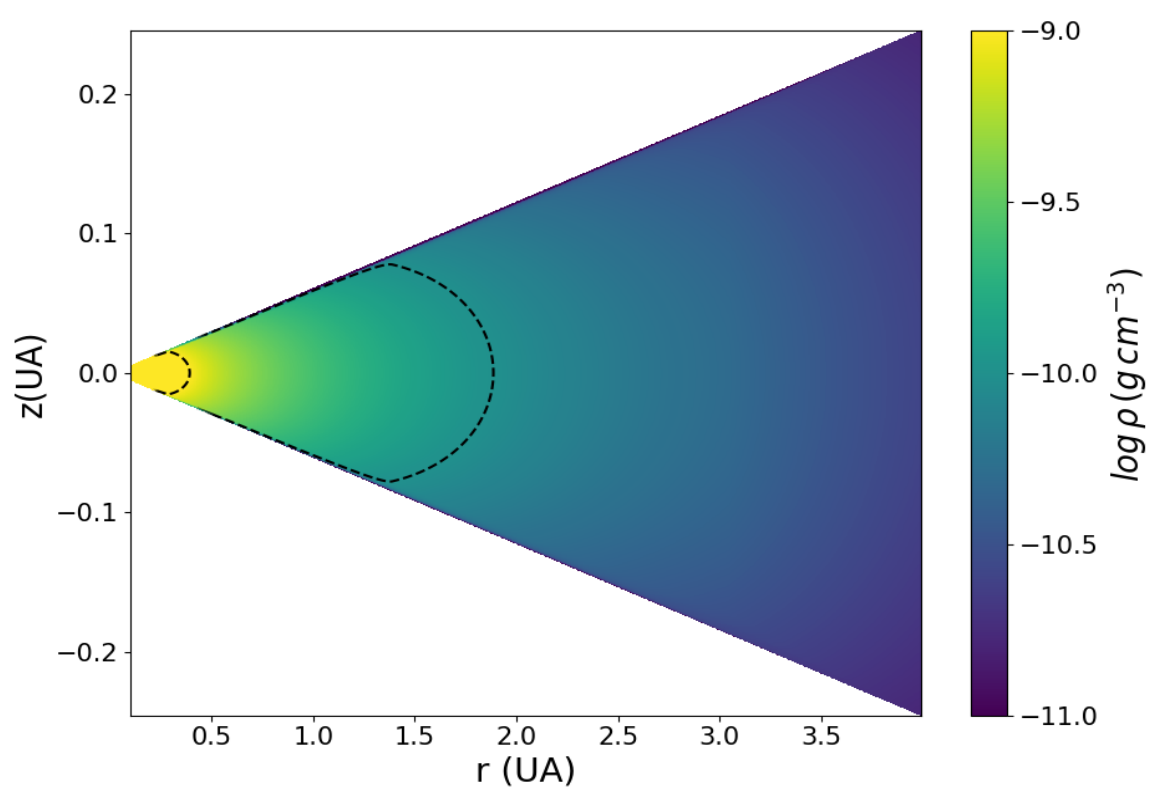

Figura 5.3: Perfil da variação da densidade volumétrica do modelo de disco de acreção ao redor uma estrela T Tauri de massa $M_{*}=0.7 M_{\odot}$, nas direções radial e vertical, quando apenas a dissipação viscosa é atuante. As linhas de contorno correspondem à valores de densidade de $10^{-9}$ e $10^{-10} \mathrm{~g} \mathrm{~cm}^{-3}$, respectivamente.

possuindo altos valores mesmo para regiões mais afastadas radialmente do disco, conforme pode ser visto na região mais à direita da Figura 5.4. Esse comportamento da densidade superficial está intrinsicamente relacionado à localização e extensão da zona morta.

Finalmente, na Figura 5.5 apresentamos a extensão da zona morta para um disco que segue o modelo padrão de Shakura e Sunyaev (1973) e o modelo de camadas de Gammie (1996), ou seja, nesse caso, o único processo interno ao disco, capaz de aquecê-lo, é a dissipação viscosa. Conforme dito anteriormente (veja Seção 4.3), para a determinação da localização da zona morta, supôs-se que o disco sofre ionização térmica por íons alcalinos nas partes mais internas, além de estar submetido à ionização por raios-X e raios cósmicos, assim como processos de recombinação capazes de contrabalancear a ionização. Nessa figura, a linha cheia corresponde à densidade de coluna total do disco $\left(\mathrm{em}^{\mathrm{cm}} \mathrm{m}^{-2}\right)$, enquanto a linha tracejada denota a densidade de coluna das zonas ativas, i.e., das zonas onde a fração de ionização é suficientemente alta para a ocorrência da IMR. A extensão da zona morta é, portanto, definida pela região entre as duas linhas. Dessa forma, ao analisar a Figura 5.5 , nota-se que, na ausência de mecanismos extras de aquecimento, a zona morta extende-se de 0.4-4 UA. Gammie (1996), por sua vez, obteve que a zona morta ocuparia a região entre 0.1-6 UA. Essa diferença pode ser explicada pelo fato de que Gammie (1996) considerou 


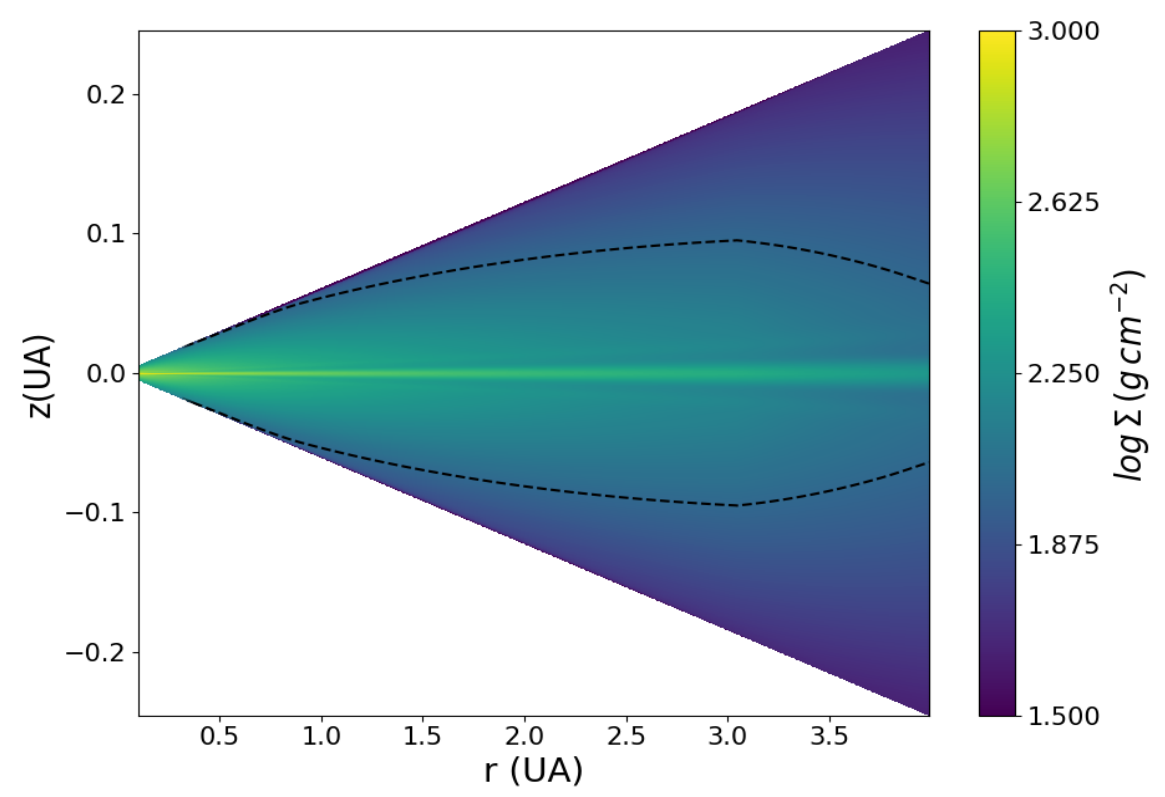

Figura 5.4: Perfil da variação da densidade superficial do modelo de disco de acreção ao redor de uma estrela T Tauri de massa $M_{*}=0.7 M_{\odot}$, nas direções radial e vertical, quando apenas a dissipação viscosa é atuante. A linha de contorno corresponde à densidade superficial igual à $100 \mathrm{~g} \mathrm{~cm}^{-2}$.

apenas os efeitos da ionização térmica e por raios cósmicos, enquanto nesse trabalho, consideramos, além dos dois mecanismos supracitados, a influência da ionização por raios$\mathrm{X}$ provenientes do objeto central. A inclusão dos efeitos associados aos raios-X promove um impacto significativo na estrutura do disco, dado que a ionização devido à esse processo apresenta uma efetividade considerável no disco (e.g. Schulz, 2005; Armitage, 2011). Por outro lado, a borda interna da zona morta obtida através do nosso modelo $(r \sim 0.4 \mathrm{UA})$ é compatível com os resultados obtidos por Fromang et al. (2002) e Ilgner e Nelson (2006). Entretanto, enquanto no nosso disco essa região quiescente deixa de existir após 4 UA, esses autores obtiveram que a zona morta extende-se até a borda externa do disco. Mais uma vez, essa discrepância ocorre devido aos mecanismos de ionização considerados: enquanto Fromang et al. (2002) e Ilgner e Nelson (2006) consideraram apenas a ionização térmica e por raios-X, nós consideramos também a presença de raios cósmicos, os quais promovem um grande impacto na fração de ionização das regiões radialmente mais externas. De fato, Martin et al. (2012) ao considerar, de maneira análoga ao Gammie (1996), a influência apenas da ionização por raios cósmicos e colisional, obteve que a zona morta reduz-se às porções mais internas do disco $(r<10 \mathrm{UA})$. 




Figura 5.5: Perfil da densidade de coluna $\left(\mathrm{em}^{-2}\right)$ para um disco de acreção, que segue o modelo $\alpha$ padrão e o modelo de camadas, ao redor de uma estrela $\mathrm{T}$ Tauri de massa $M_{*}=0.7 M_{\odot}$, quando apenas a dissipação viscosa é atuante. A linha cheia corresponde à densidade de coluna total do disco, enquanto a linha tracejada corresponde à densidade de coluna da zona ativa do disco (i.e., onde a IMR é efetiva). A zona morta estaria, portanto, localizada na região entre as duas linhas. Nota-se que, em nosso modelo de disco, a zona morta extende-se de 0.4 UA até, aproximadamente, 4 UA.

\subsection{Simulações após a atuação dos mecanismos de amortecimento}

Apresentamos abaixo os resultados obtidos após a atuação dos mecanismos extras de aquecimento considerados no presente trabalho. Adotou-se, para todas as simulações mostradas, $h=10^{-2} H$ e $n=1$, onde $h$ e $n$ referem-se aos parâmetros utilizados para a definição do número de onda vertical, $k=n \pi / h$, e supôs-se a espessura do tubo como sendo dado por $a=10^{-6}$ UA. A escolha de $a$ deu-se devido à necessidade de garantir a validade da aproximação TT (veja, por exemplo, a Seção 3.5.3). Note que, para os parâmetros explicitados acima, a IKH passa a ser atuante para números azimutais maiores que 90, $m>90$ (veja Equação 3.43), onde $m$ denota a intensidade da perturbação. Variaram-se os parâmetros $m$ e $f$, o qual representa o fluxo de ondas Alfvén presente no meio (vide Equação 3.5), a fim de analisar a influência destes parâmetros no aquecimento do disco. É importante frisar que, como estamos supondo esses mecanismos de amortecimento de ondas Alfvén atuantes na zona morta, região onde acredita-se que a atividade magnética seja reduzida, iremos considerar nesse trabalho apenas fluxos de ondas Alfvén pequenos (i.e. $f<1$ ), uma vez que o objetivo é garantir a redução da zona morta com o mínimo 
possível de energia.

\subsubsection{Simulações com parâmetro de fluxo de ondas $f=0.01$}

Na Figura 5.6 mostramos o perfil da temperatura central após a atuação dos mecanismos ressonante (linha traço-ponto laranja), não-linear (traço-ponto-ponto vermelha), acoplado (linha pontilhada azul) e turbulento (linha tracejada verde), além da temperatura central associada ao modelo padrão de disco (linha espessa tracejada preta), i.e. quando apenas a dissipação viscosa é atuante, para comparação. Nesta simulação, adotou-se o parâmetro de energia como $f=0.01$ e o número azimutal dado por $m=40000$. Note que como $m$ representa a intensidade da perturbação azimutal, ao adotarmos um valor de $m$ tão grande, estamos afirmando que a perturbação ao sistema é extremamente intensa. Apesar de uma perturbação dessa magnitude não ser esperada (a perturbação equivalente à $m=40000$ é mais de 400 vezes mais forte que a necessária para o desenvolvimento da IKH), apenas perturbações dessa ordem são efetivas para um fluxo de ondas pequeno como o considerado neste caso $(f=0.01)$. Para esses parâmetros, apenas os amortecimentos acoplado e turbulento culminam em um aumento significativo da temperatura central.

O comportamento das temperaturas mostrado na Figura 5.6 reflete-se na extensão da zona morta: nas Figuras 5.7 e 5.8, é mostrado o tamanho da zona morta após a atuação dos mecanismos que geram os perfis de temperatura exibidos na Figura 5.6. Conforme esperado, os mecanismos ressonante (painel (a) da Figura 5.7) e não-linear (painel (b) da Figura 5.7) não promovem nenhuma alteração na dimensão da zona morta, enquanto os amortecimentos acoplado (painel (a) da Figura 5.8) e turbulento (painel (b) da Figura 5.8) culminam em uma pequena diminuição, principalmente na espessura, da zona morta. Ademais, conforme previamente visto na Figura 5.6, o amortecimento turbulento é o mecanismo, para os parâmetros considerados, que mais auxilia na redução dessa região, promovendo uma diminuição de, aproximadamente, $18 \%$ na extensão da zona morta.

\subsubsection{Simulações com parâmetro de fluxo de ondas $f=0.02$}

Nas Figuras 5.9, 5.10 e 5.11 apresentamos os resultados para $f=0.02$ e $m=40000$. Pela Figura 5.9, nota-se que, à semelhança do observado na Subseção 5.2.1, a absorção ressonante de ondas Alfvén de superfície (linha traço-ponto laranja) e o amortecimento não-linear de ondas Alfvén (linha traço-ponto-ponto vermelha), não produzem nenhum 


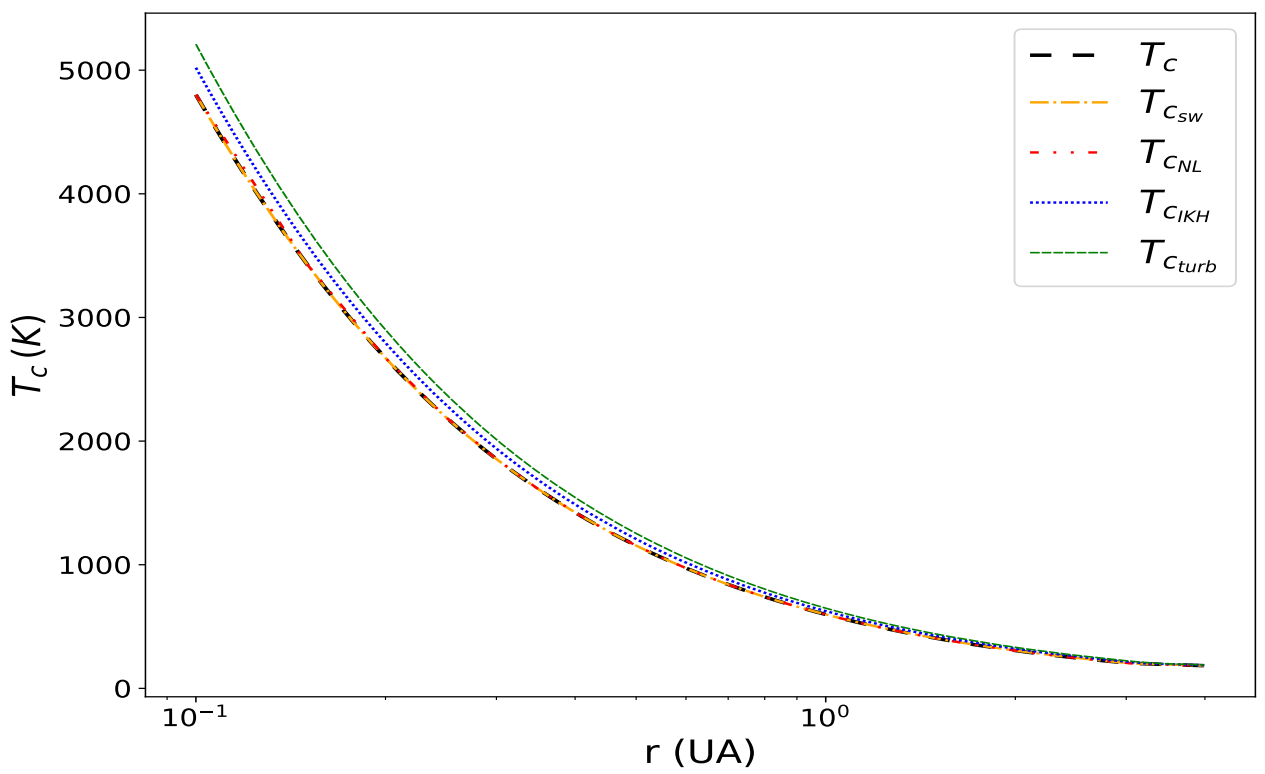

Figura 5.6: Perfil radial da temperatura central do disco considerado. A linha espessa tracejada preta representa a variação da temperatura quando apenas a dissipação viscosa é atuante, enquanto as demais linhas representam o perfil da temperatura central após a atuação de cada um dos mecanismos estudados. A linha traço-ponto laranja corresponde à temperatura associada à absorção ressonante de ondas Alfvén de superfície; a curva traço-ponto-ponto vermelha refere-se ao amortecimento não-linear; a linha azul pontilhada denota as temperaturas associadas ao mecanismo acoplado e a curva tracejada verde é associada ao amortecimento turbulento de ondas Alfvén. Nesse caso, adotou-se $f=0.01$ e $m=40000$. Nota-se que, para os parâmetros considerados, os mecanismos acoplado e turbulento são os únicos que promovem um aumento na temperatura central do disco, sendo o amortecimento turbulento o mais efetivo. 


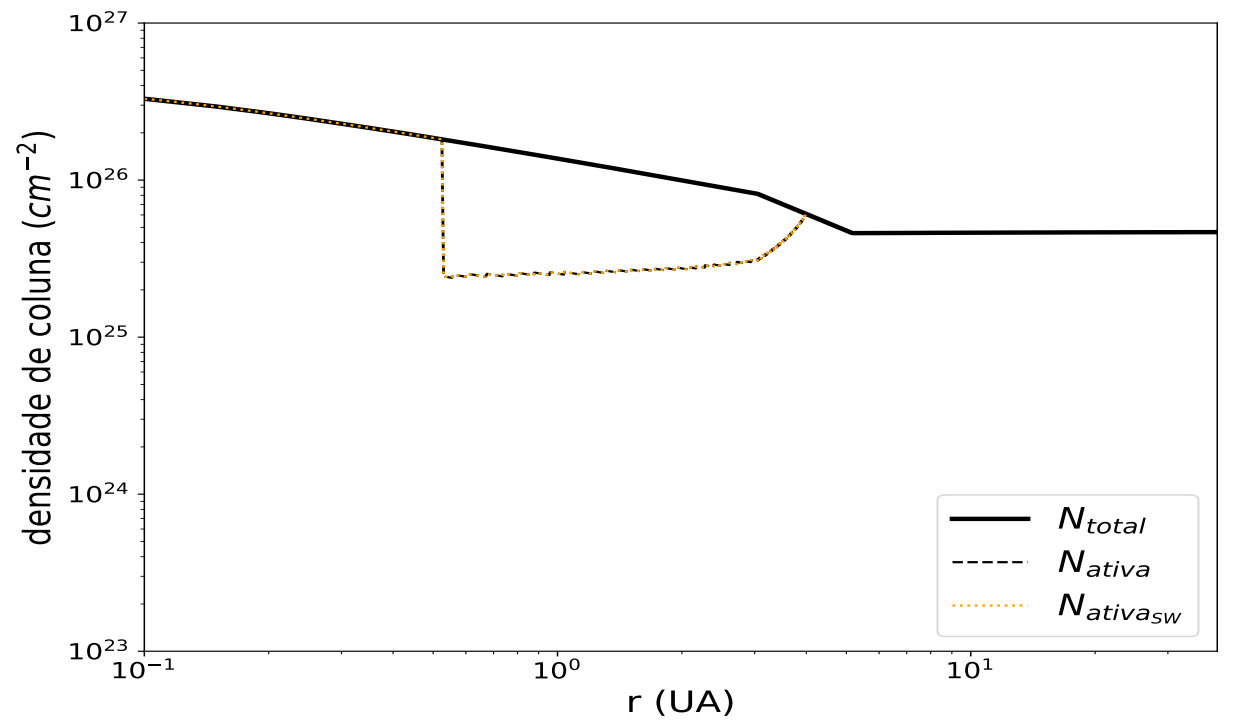

(a)

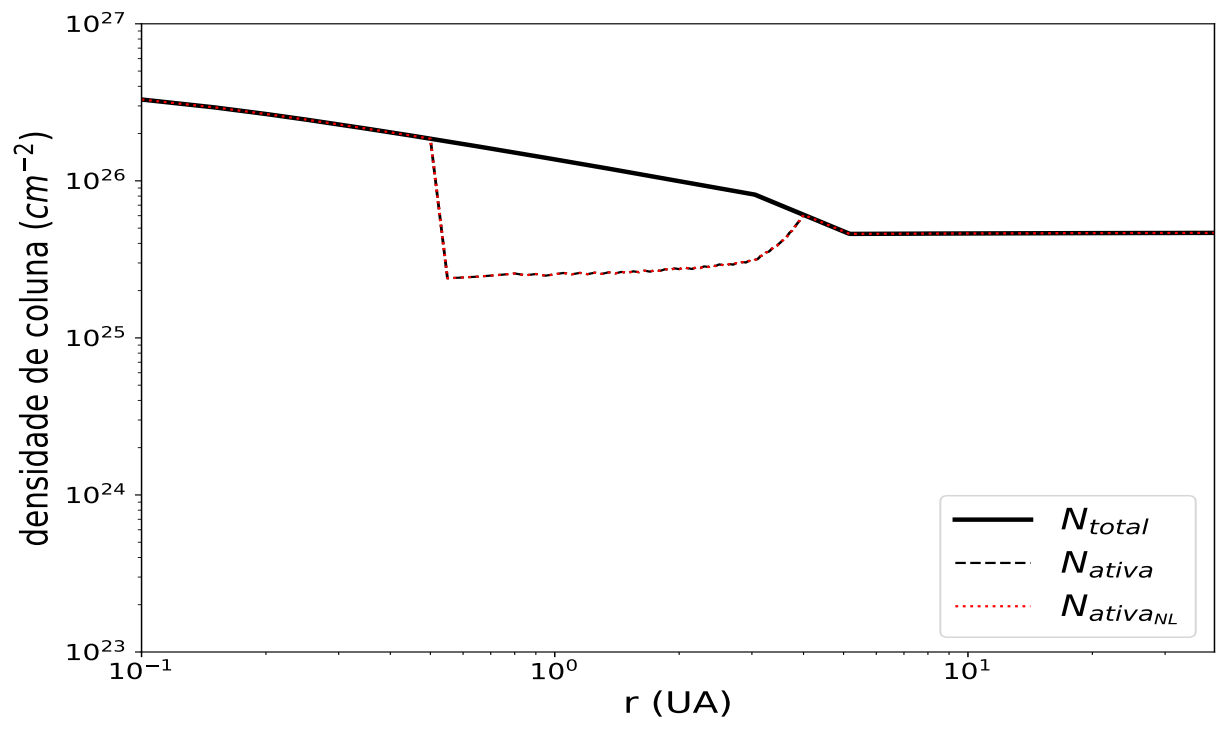

(b)

Figura 5.7: Extensão da zona morta após a atuação da absorção ressonante de ondas Alfvén de superfície (painel (a)) e do amortecimento não-linear de ondas Alfvén (painel (b)). A linha preta cheia representa a densidade de coluna $\left(\mathrm{em}^{-2}\right.$ ) total do disco, enquanto a linha tracejada representa a densidade de coluna da zona ativa do disco, i.e., das regiões onde a IMR é efetiva, quando apenas a dissipação viscosa é atuante. As linhas pontilhadas laranja e vermelha representam, respectivamente, a densidade de coluna da zona ativa após a atuação da absorção ressonante e do amortecimento não-linear. A zona morta consiste na região entre a linha cheia e as demais linhas. Nesta simulação, adotou-se o parâmetro de fluxo de ondas, $f$, como $f=0.01$, e o número azimutal como $m=40000$. Percebe-se que para $f=0.01$, ambos os mecanismos não resultam em uma diminuição significativa da zona morta. 




(a)



(b)

Figura 5.8: Extensão da zona morta após a atuação da mecanismo acoplado (painel (a)) e do amortecimento turbulento de ondas Alfvén (painel (b)). A linha preta cheia representa a densidade de coluna (em $\mathrm{cm}^{-2}$ ) total do disco, enquanto a linha tracejada representa a densidade de coluna da zona ativa do disco, i.e., das regiões onde a IMR é efetiva, quando apenas a dissipação viscosa é atuante. As linhas pontilhadas azul e verde representam, respectivamente, a densidade de coluna da zona ativa após a atuação do mecanismo acoplado e do amortecimento turbulento. A zona morta consiste na região entre a linha cheia e as demais linhas. Nesta simulação, adotou-se o parâmetro de fluxo de ondas, $f$, como $f=0.01$, e o número azimutal, $m=40000$. Apesar de ambos os mecanismos promoverem uma diminuição da zona morta, nota-se que o amortecimento turbulento é o mais eficiente em reduzir o tamanho dessa região. 


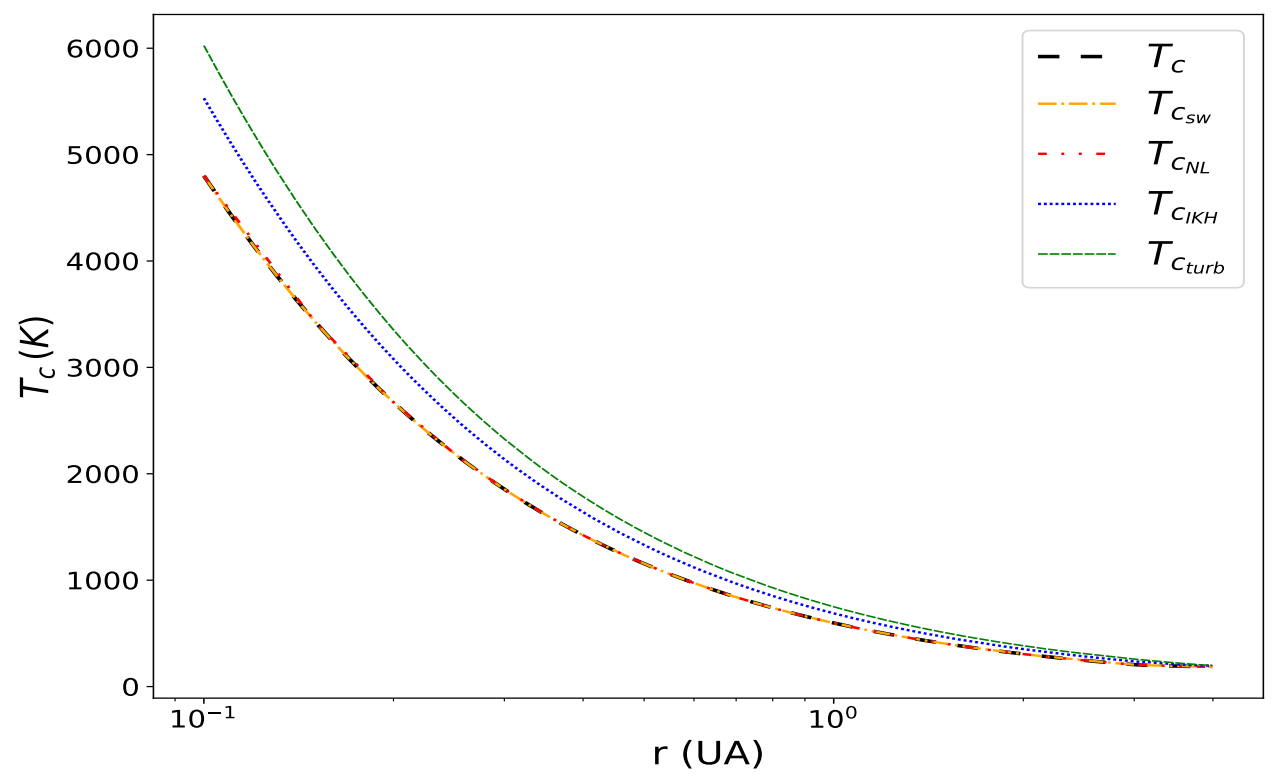

Figura 5.9: O mesmo que a Figura 5.6. mas para $f=0.02$. Novamente, apenas os amortecimentos acoplado e turbulento promovem um aumento na temperatura central do disco. O amortecimento turbulento permanece sendo o mais efetivo.

aumento significativo na temperatura do disco, de forma que a extensão da zona morta permanece inalterada após a atuação desses mecanismos (vide Figura 5.10). De maneira análoga, os amortecimentos acoplado (linha pontilhada azul) e turbulento (linha tracejada verde) continuam sendo os mais relevantes em aquecer o disco e, consequentemente, aumentar a região onde a IMR é atuante. A redução da zona morta promovida pelo amortecimento acoplado (ressonante + turbulento) e turbulento foi de $33 \%$ e $53 \%$, respectivamente.

Além disso, na Figura 5.12, mostramos o impacto dos amortecimentos turbulento e acoplado na redução da zona morta quando assumimos $m=4000$, supondo ainda um fluxo de ondas Alfvén definido por $f=0.02$. Percebe-se que a redução do número azimutal afeta, significativamente, a eficiência de tais mecanismos, de forma que a alteração na extensão da zona morta torna-se praticamente desprezível no caso do amortecimento acoplado (painel (a) da Figura 5.12, redução de $\sim 4 \%$ ) e extremamente pequena para o amortecimento turbulento (painel (b) da Figura 5.12, redução de $\sim 8 \%$ ). Mesmo assim, esse último continua sendo o mecanismo mais importante no aquecimento do disco. 


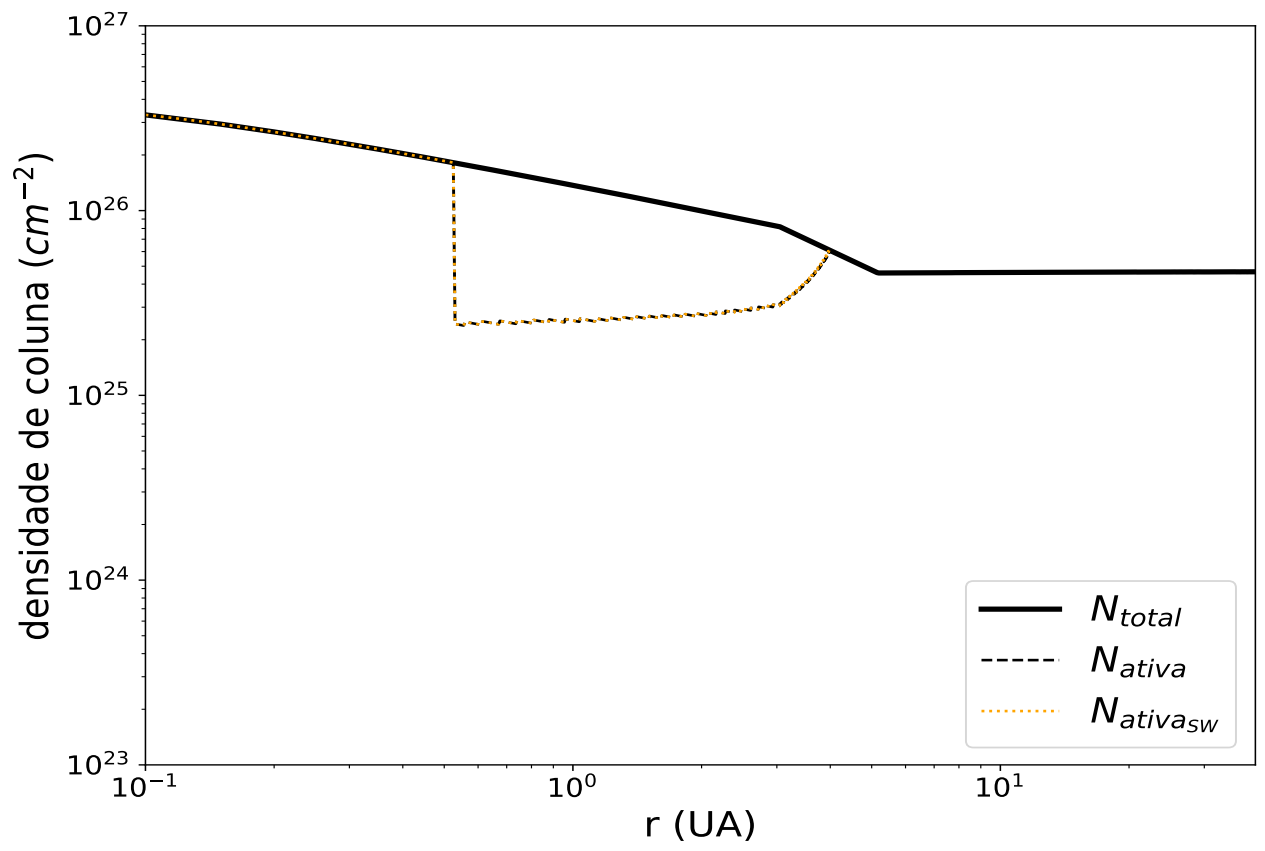

(a)

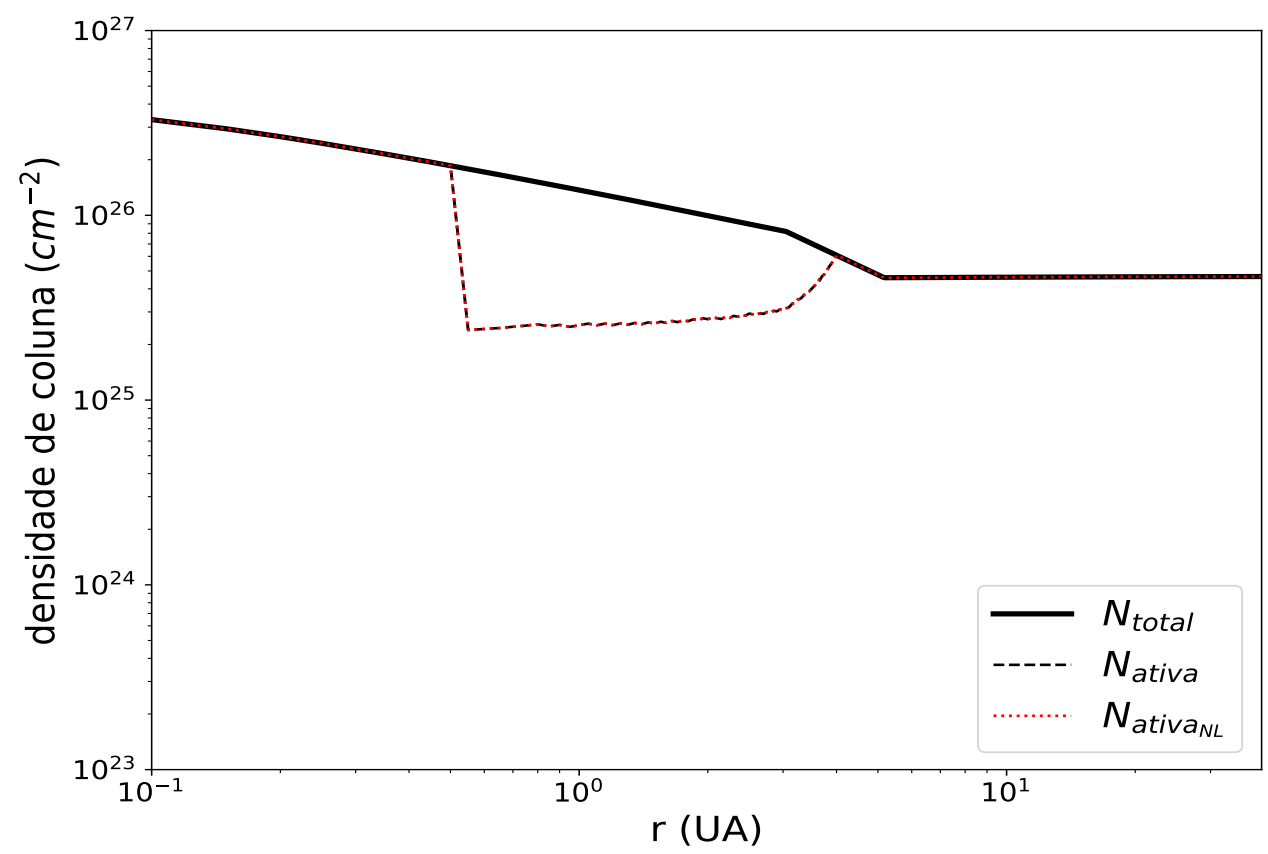

(b)

Figura 5.10: O mesmo que a Figura 5.7, mas para um parâmetro de fluxo de ondas de $f=0.02 \mathrm{e}$ $m=40000$. A atuação dos mecanismos ressonante e não-linear, para o parâmetro $f$ considerado, ainda não é suficiente para promover uma redução da extensão da zona morta. 


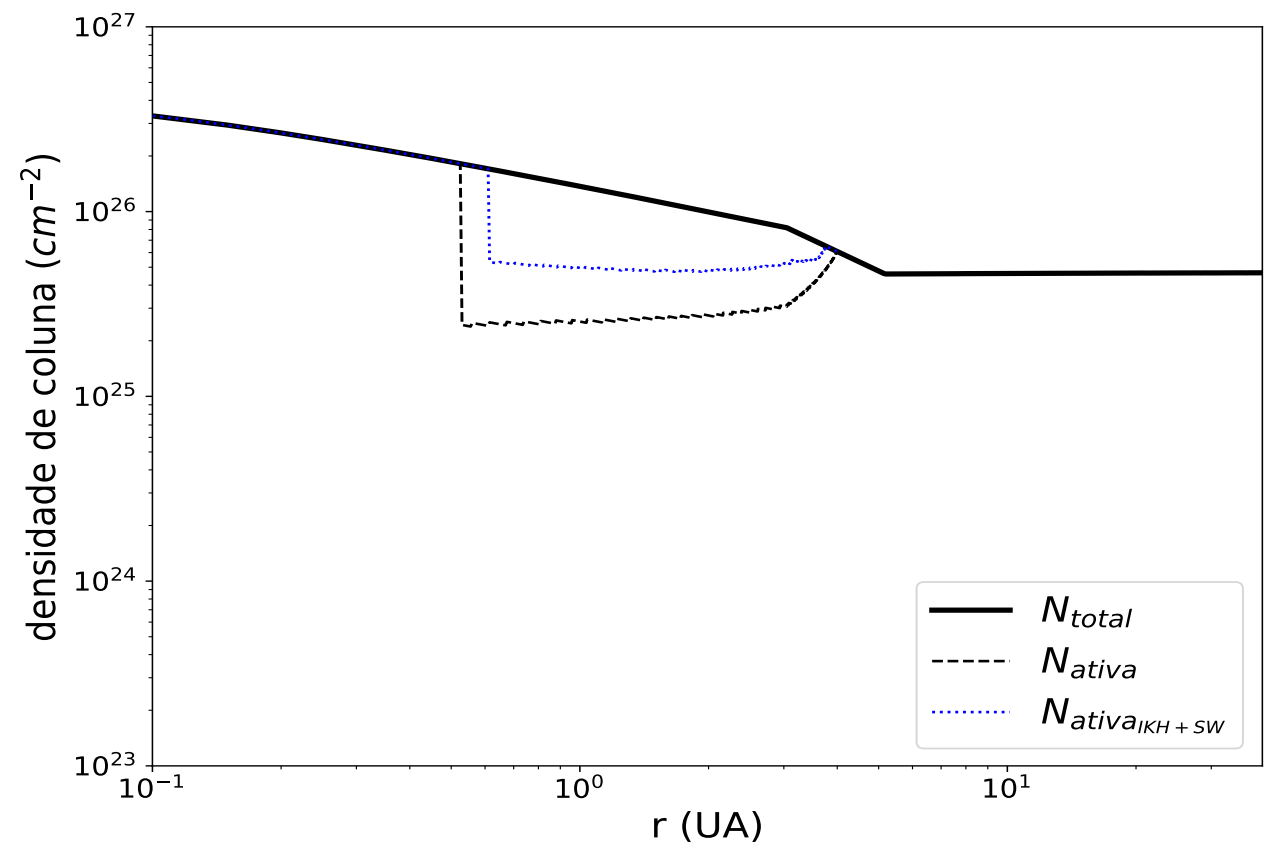

(a)



(b)

Figura 5.11: O mesmo que a Figura 5.8 mas para $f=0.02$ e $m=40000$. Novamente, ambos os mecanismos geram uma redução expressiva, tanto radial quanto verticalmente, da zona morta, ao mesmo tempo em que o amortecimento turbulento configura-se como o mecanismo mais efetivo. 




(a)

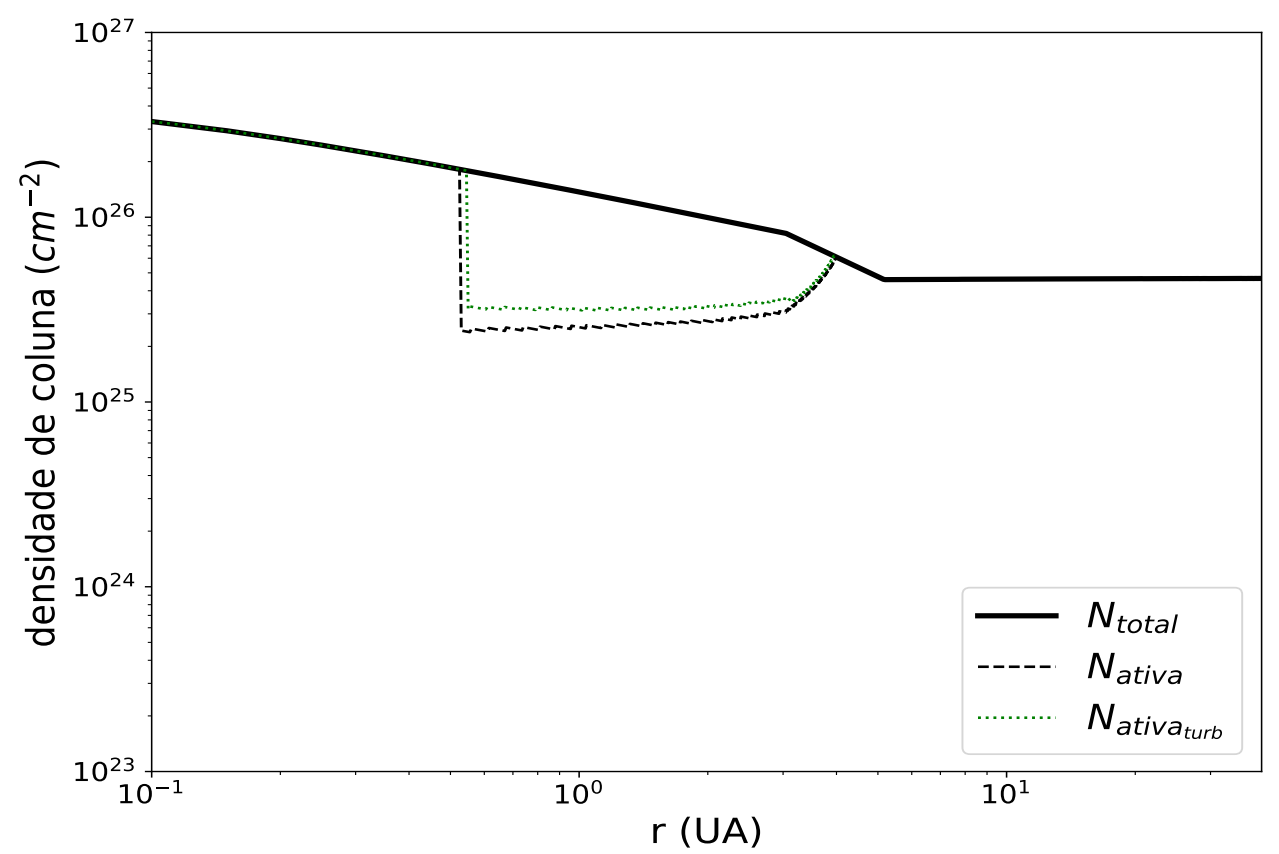

(b)

Figura 5.12: O mesmo que a Figura 5.8 mas para $f=0.02$ e $m=4000$. Para os parâmetros considerados, os amortecimentos acoplado e turbulento promovem uma pequena redução na extensão da zona morta. 


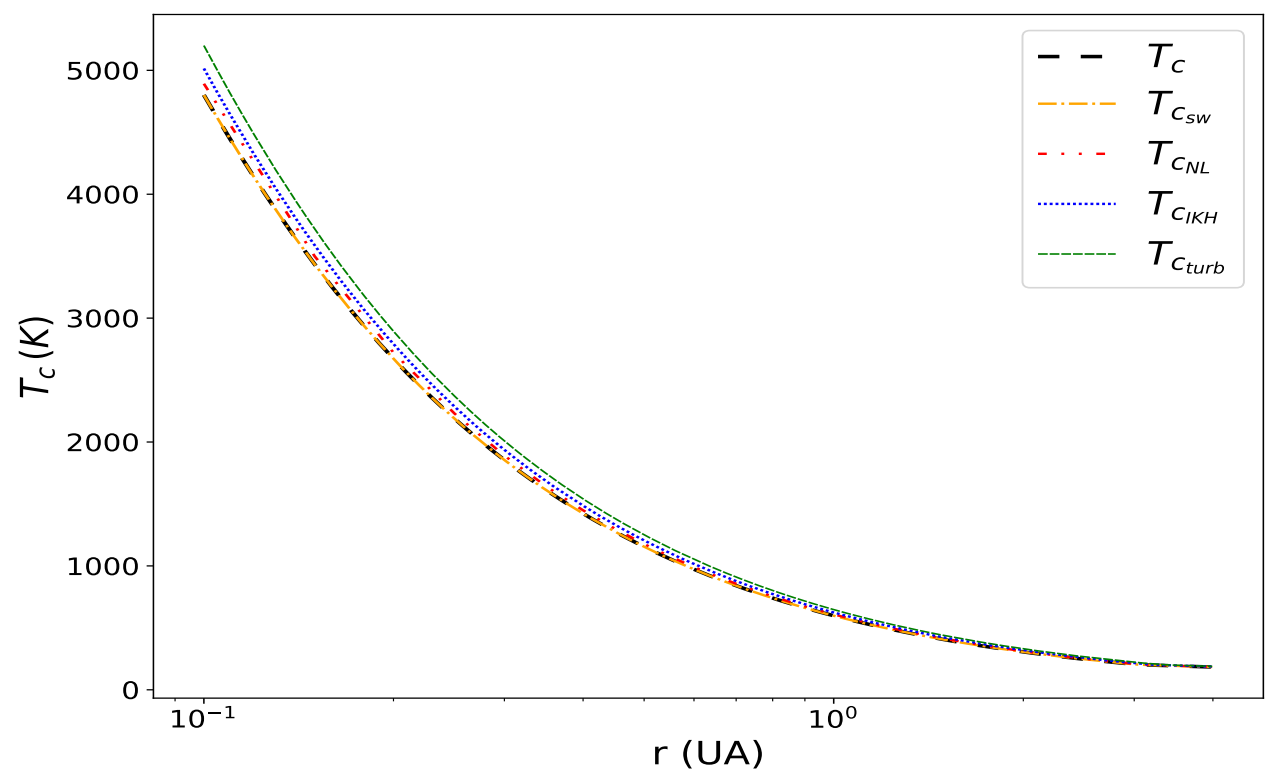

Figura 5.13: O mesmo que a Figura 5.6. mas para $f=0.1$ e $m=400$. A absorção ressonante de ondas Alfvén de superfície permanece não afetando a estrutura do disco. Entretanto, para os parâmetros agora considerados, o amortecimento não-linear promove um pequeno aquecimento. Mesmo assim, os amortecimentos acoplado e turbulento continuam sendo os responsáveis por gerar as maiores temperaturas no plano médio do disco.

\subsubsection{Simulações com parâmetro de fluxo de ondas $f=0.1$}

Na Figura 5.13, mostramos o perfil da temperatura central para os mecanismos considerados, supondo $f=0.1$ e $m=400$. Note que, diferentemente do observado nas Subseções 5.2.1 e 5.2.2, o amortecimento não-linear agora provoca um aumento na temperatura do disco. Tal aquecimento, entretanto, é menor que o provocado pelos amortecimentos acoplado e turbulento. Novamente, a absorção ressonante não promove nenhuma mudança significativa na temperatura do disco.

Nas Figuras 5.14 e 5.15 é possível ver o efeito do aquecimento do disco, mostrado na Figura 5.13, na dimensão da região onde a IMR é inefetiva. Como esperado, a absorção ressonante não afeta o tamanho da zona morta. O amortecimento não-linear, por sua vez, apesar de gerar um aquecimento no disco, não afeta, de maneira significativa, essa região quiescente do disco (vide painel (b) da Figura 5.14, redução de $\sim 4 \%$ ). Um comportamento semelhante é observado para o mecanismo acoplado (painel (a) da Figura 5.15): apesar de promover uma redução na profundidade da zona morta (i.e., essa região torna-se mais estreita verticalmente), essa diminuição é bem modesta, resultando em uma diminuição 
total da extensão dessa região de 10\%. O amortecimento turbulento (painel (b) da Figura 5.15), mais uma vez, é o responsável por promover uma diminuição mais significativa dessa região $(\sim 18 \%)$.

\subsubsection{Simulações com parâmetro de fluxo de ondas $f=0.2$}

Na Figura 5.16, mostramos novamente o perfil da temperatura central, associado à atuação de cada um dos mecanismos, para $f=0.2$ e $m=400$. O comportamento observado nas demais simulações, mostradas anteriormente, deixa de ser válido para esses parâmetros: diferentemente do que foi observado para as situações onde o fluxo de ondas Alfvén era menor (vide Seções 5.2.1 5.2.3), agora o amortecimento não-linear é responsável por gerar temperaturas mais altas que o amortecimento acoplado. De fato, o aquecimento promovido pelo mecanismo NL é quase tão efetivo, na presente situação, que o amortecimento turbulento, que configura-se como o mecanismo mais eficiente, em aquecer o disco, dentre os considerados. Novamente, a absorção ressonante de ondas Alfvén de superfície não promove nenhuma alteração significativa na temperatura (e, consequentemente, estrutura) do disco.

Os efeitos do aumento da temperatura do disco, mostrados na Figura 5.16, na dimensão da zona morta são explicitados nas Figuras 5.17 e 5.18. conforme esperado, a absorção ressonante (painel (a) da Figura 5.17) não afeta a extensão da zona morta, enquanto o amortecimento NL (painel (b) da Figura 5.17) promove uma redução, tanto radial quanto vertical, no tamanho dessa região $(\sim 44 \%)$. Novamente, os mecanismos acoplado e turbulento (painel (a) e (b) da Figura 5.18, respectivamente) produzem uma redução significativa na extensão da zona morta de $32 \%$ e $52 \%$, respectivamente.

Novamente, a fim de analisar o impacto do número azimutal na eficiência desses mecanismos, simulou-se a nova estrutura do disco quando $f=0.2$ e $m=100$. Os resultados obtidos são mostrados na Figura 5.19. Assim como observado na Subseção 5.2.2, a redução de $m$ impacta fortemente na efetividade dos mecanismos considerados. Nesse caso, os mecanismos acoplado e turbulento, os quais reduzem a zona morta em $30 \%$ ou mais quando $m=400$, implicam em uma diminuição quase desprezível para $m=100$, de forma que, para esses parâmetros, o amortecimento NL torna-se o mais relevante, uma vez que, dentre os mecanismos considerados, é o único que independe do número azimutal, $m$.

Na Tabela 5.1, encontra-se um resumo de todos os resultados mostrados acima, além 




(a)

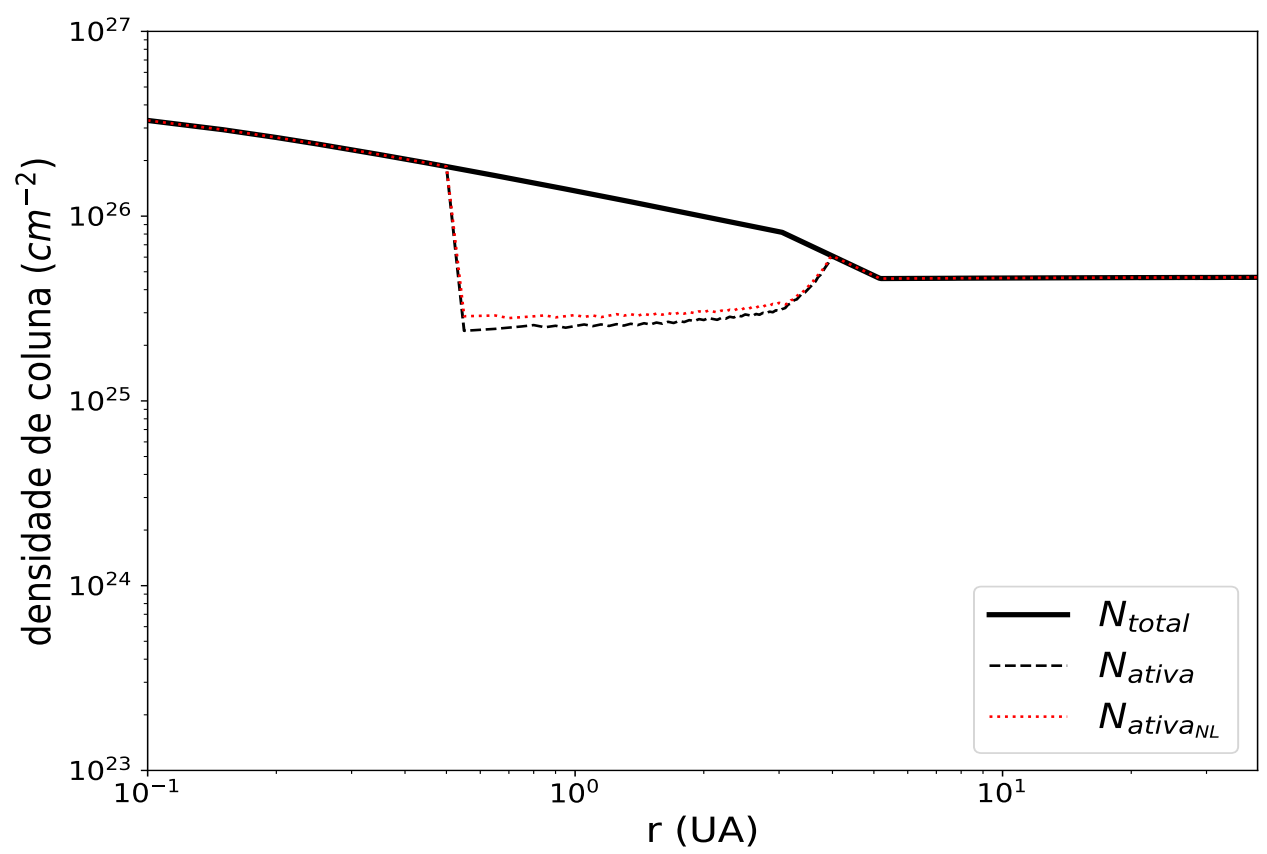

(b)

Figura 5.14: O mesmo que a Figura 5.7 mas para um parâmetro de fluxo de ondas de $f=0.1$ e $m=400$. 


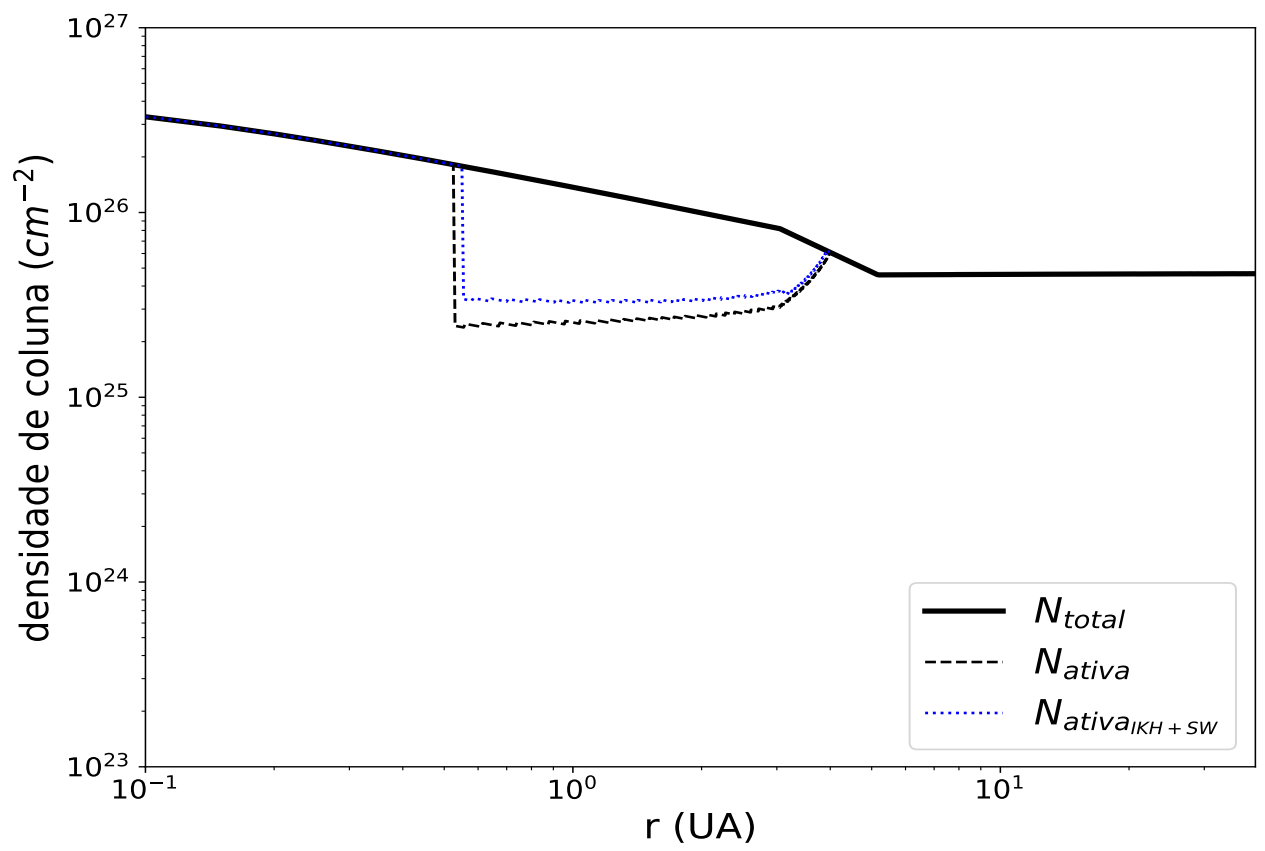

(a)

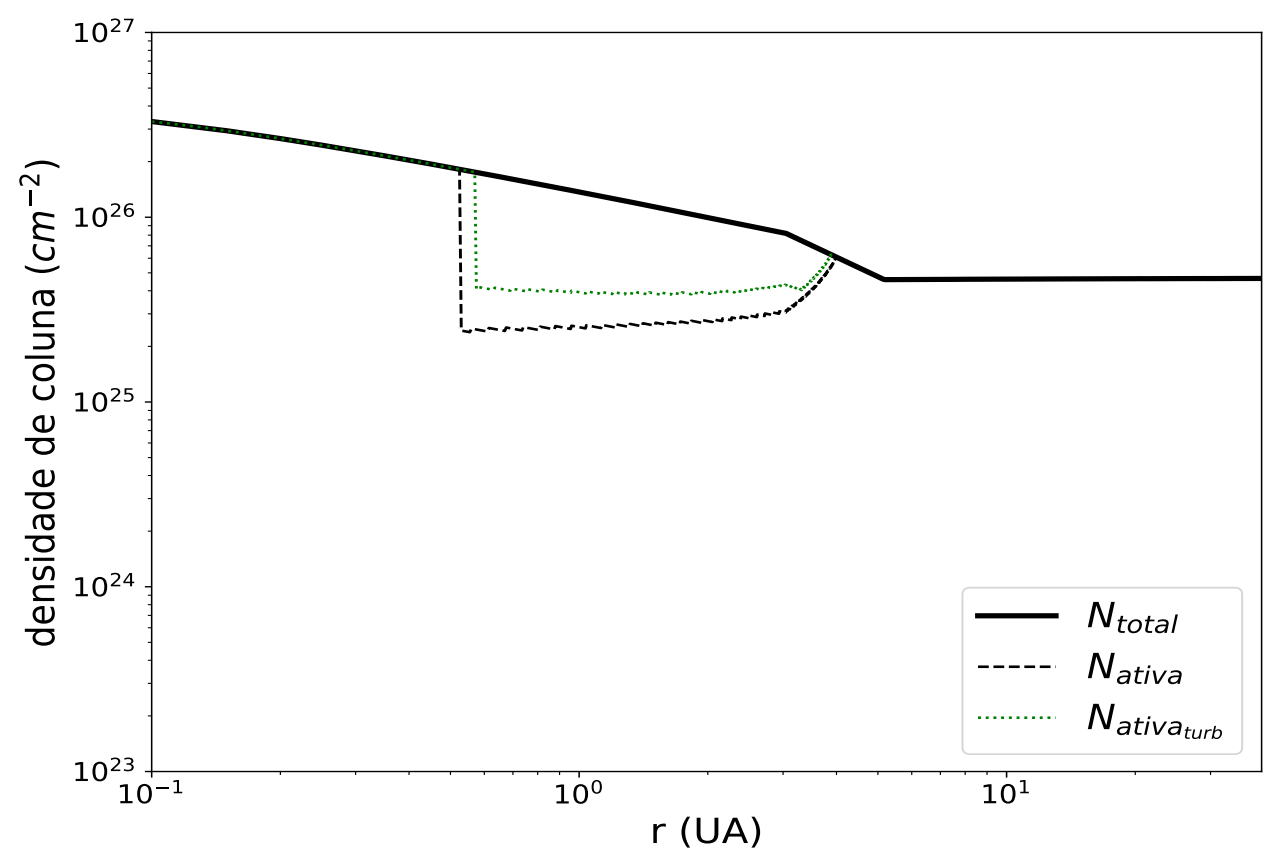

(b)

Figura 5.15: O mesmo que a Figura 5.8, mas para $f=0.1$ e $m=400$. Para os parâmetros considerados, os amortecimentos acoplado e turbulento promovem uma pequena redução na extensão da zona morta. 




Figura 5.16: O mesmo que a Figura 5.6. mas para $f=0.2$ e $m=400$. Todos os mecanismos, à exceção da absorção ressonante de ondas Alfvén de superfície promovem um aumento significativo na temperatura do disco. Note que, apesar do amortecimento turbulento ainda se mostrar o mais efetivo em aquecer o disco, para os parâmetros agora considerados, o amortecimento não-linear torna-se mais importante que o amortecimento acoplado.

da redução percentual na extensão da zona morta após a atuação dos mecanismos de amortecimento de ondas Alfvén. Para a obtenção da redução no tamanho dessa região quiescente, foi realizada uma estimativa da massa contida na zona morta, antes e depois da atuação dos mecanismos de aquecimento, através da seguinte relação (Hartmann, 2009):

$$
M_{D Z}=\int_{r_{e x t}}^{r_{i n}} 2 \pi \Sigma_{D Z} r d r,
$$

onde $\Sigma_{D Z}$ é definida pela Equação 4.38 e $r_{i n}$ e $r_{e x t}$ referem-se às bordas radiais interna e externa, respectivamente, da zona morta.

Analisando os resultados contidos na Tabela 5.1, para diferentes fluxos de energia de onda e números azimutais, nota-se que o amortecimento não-linear torna-se um mecanismo relevante para o aquecimento do disco apenas quando considera-se grandes fluxos de energia, ou seja, para $f>0.1$. Isso se dá devido à forte dependência desse mecanismo com o fluxo de ondas Alfvén: sua taxa de aquecimento é proporcional à $f^{4}$ (veja a Equação 3.11 na Subseção 3.2. . De fato, a própria taxa de amortecimento desse mecanismo depende da densidade de energia das ondas Alfvén, $\epsilon_{A}$ (vide Equação 3.9), que, por sua 


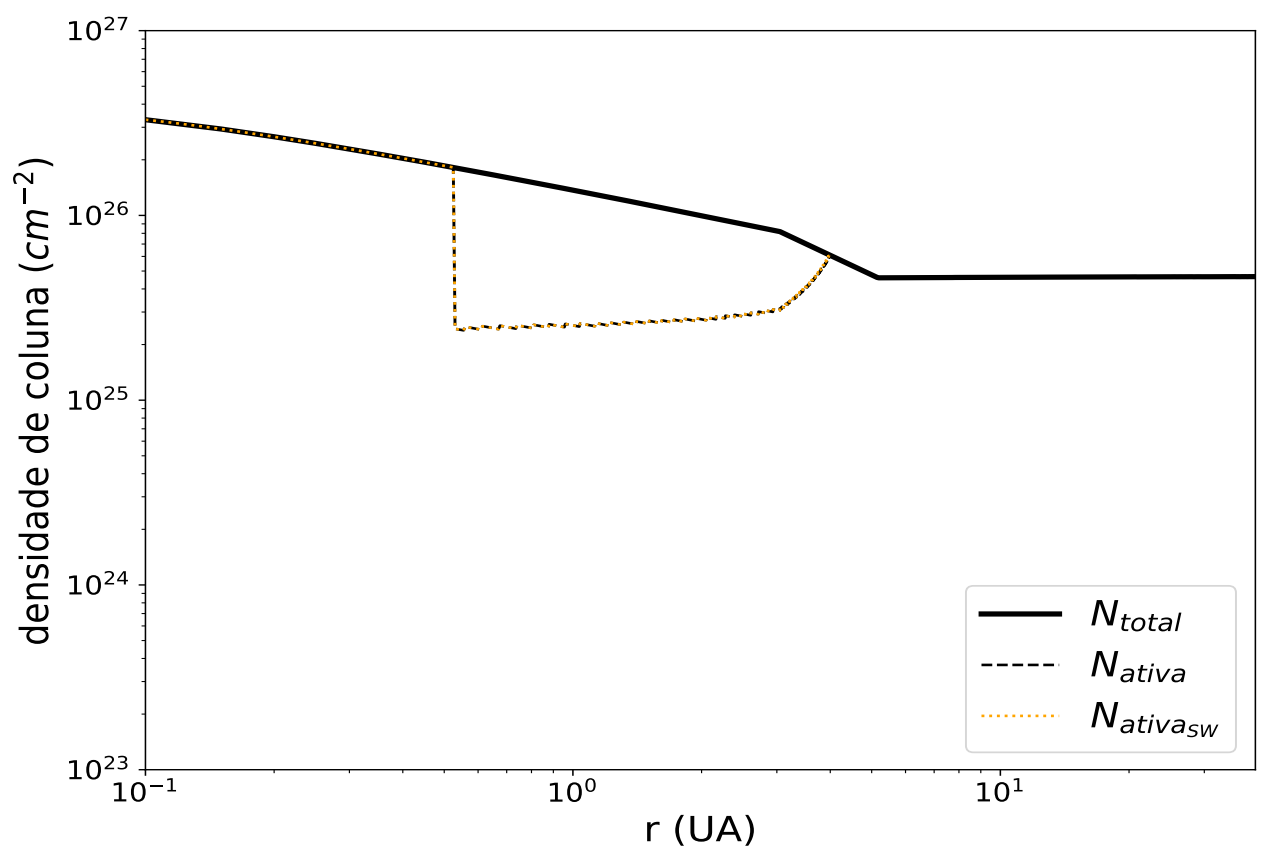

(a)

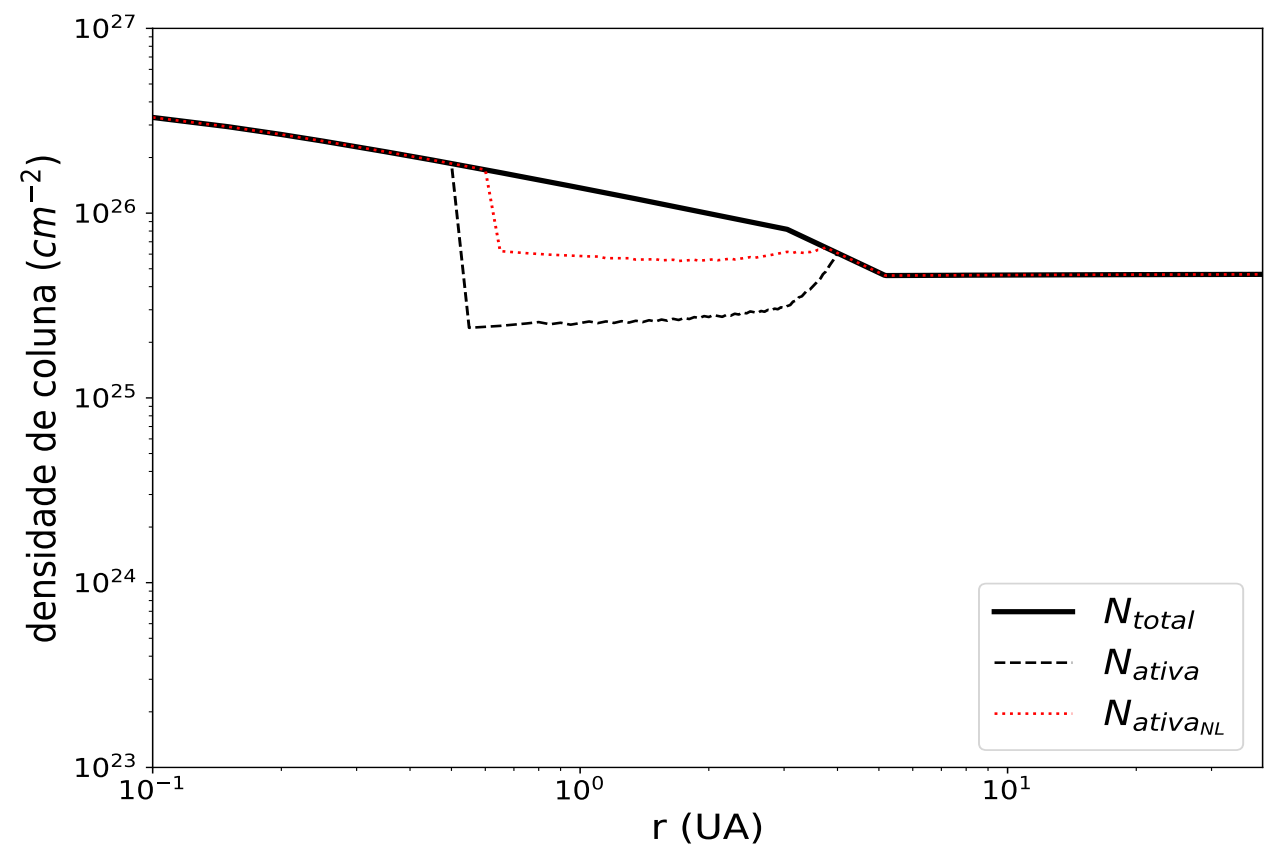

(b)

Figura 5.17: O mesmo que a Figura 5.7 mas para um parâmetro de fluxo de ondas de $f=0.2$ e $m=400$. 


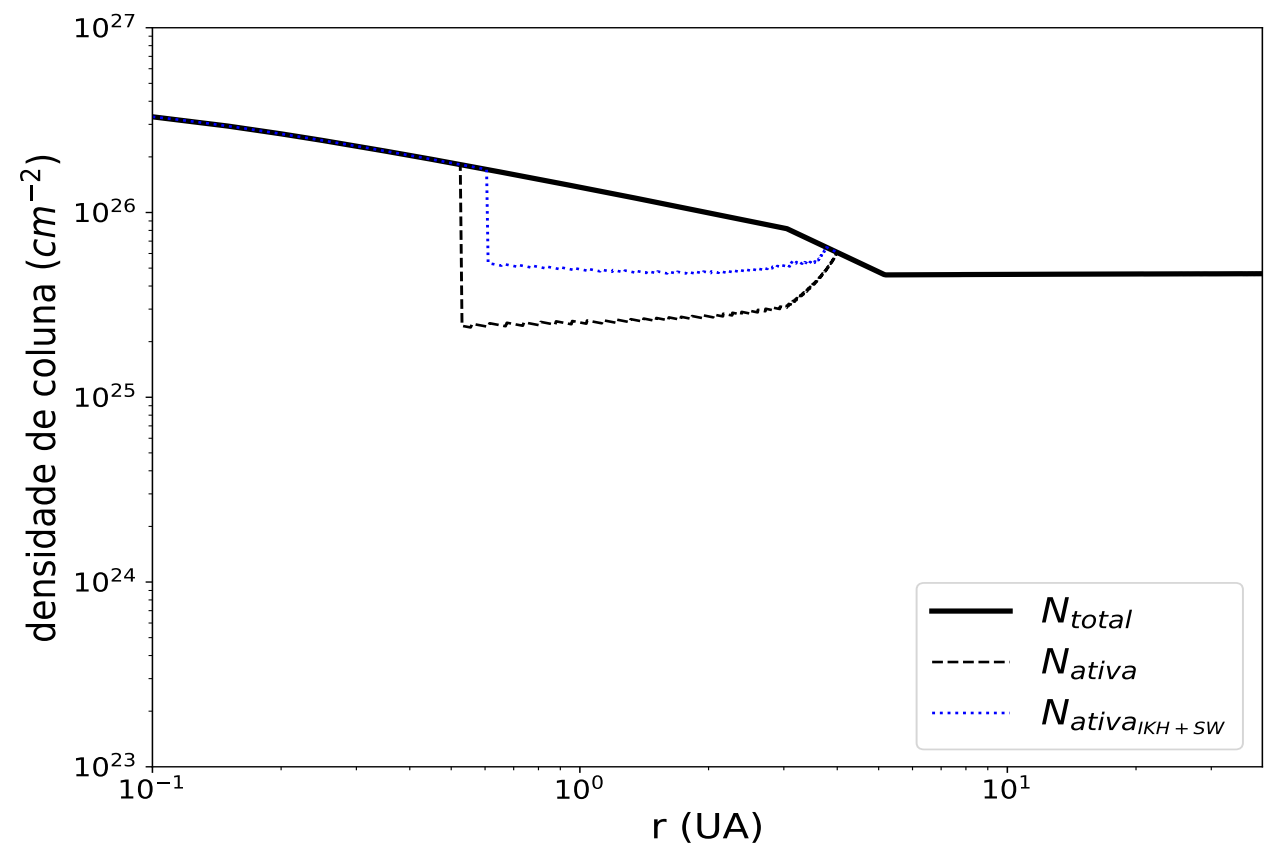

(a)

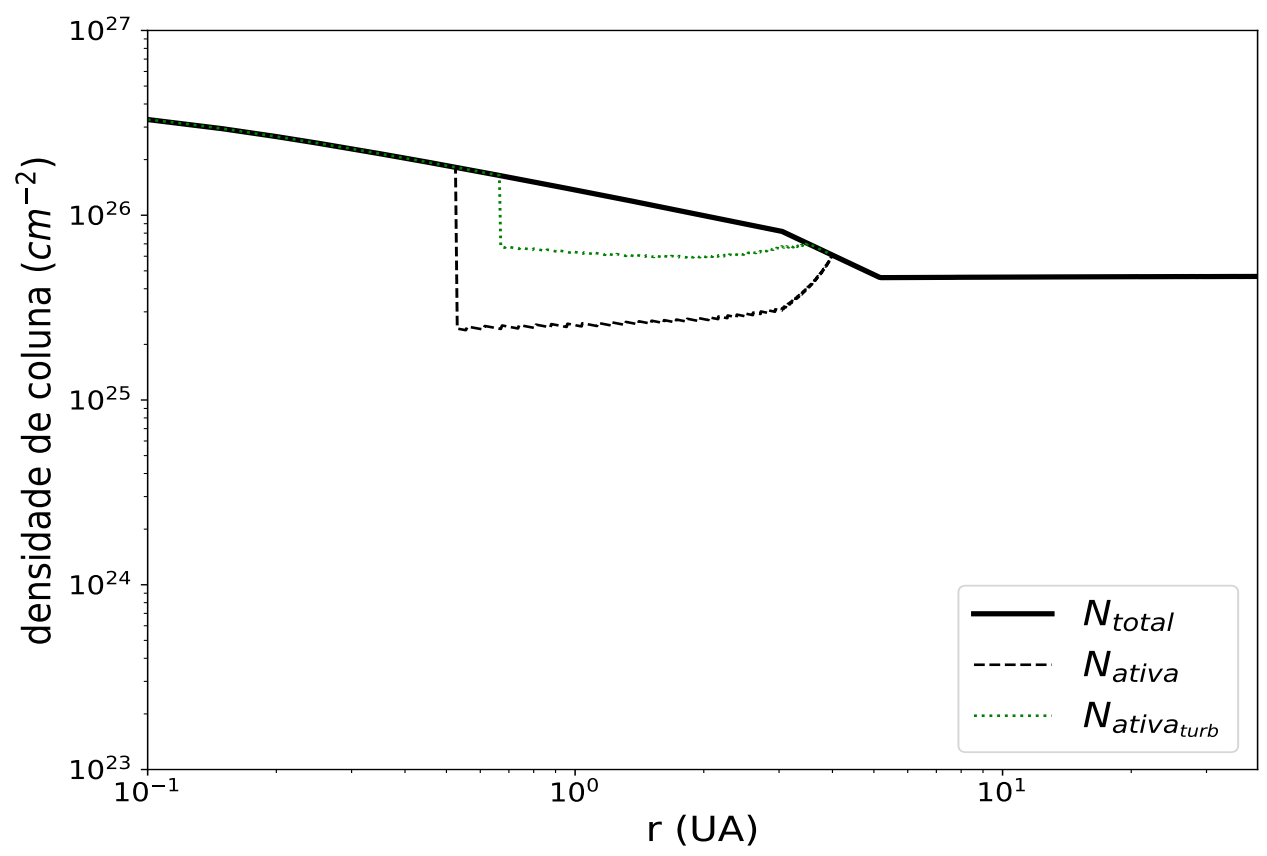

(b)

Figura 5.18: O mesmo que a Figura 5.8, mas para $f=0.2$ e $m=400$. Para os parâmetros considerados, os amortecimentos acoplado e turbulento promovem uma redução significativa na extensão da zona morta. 


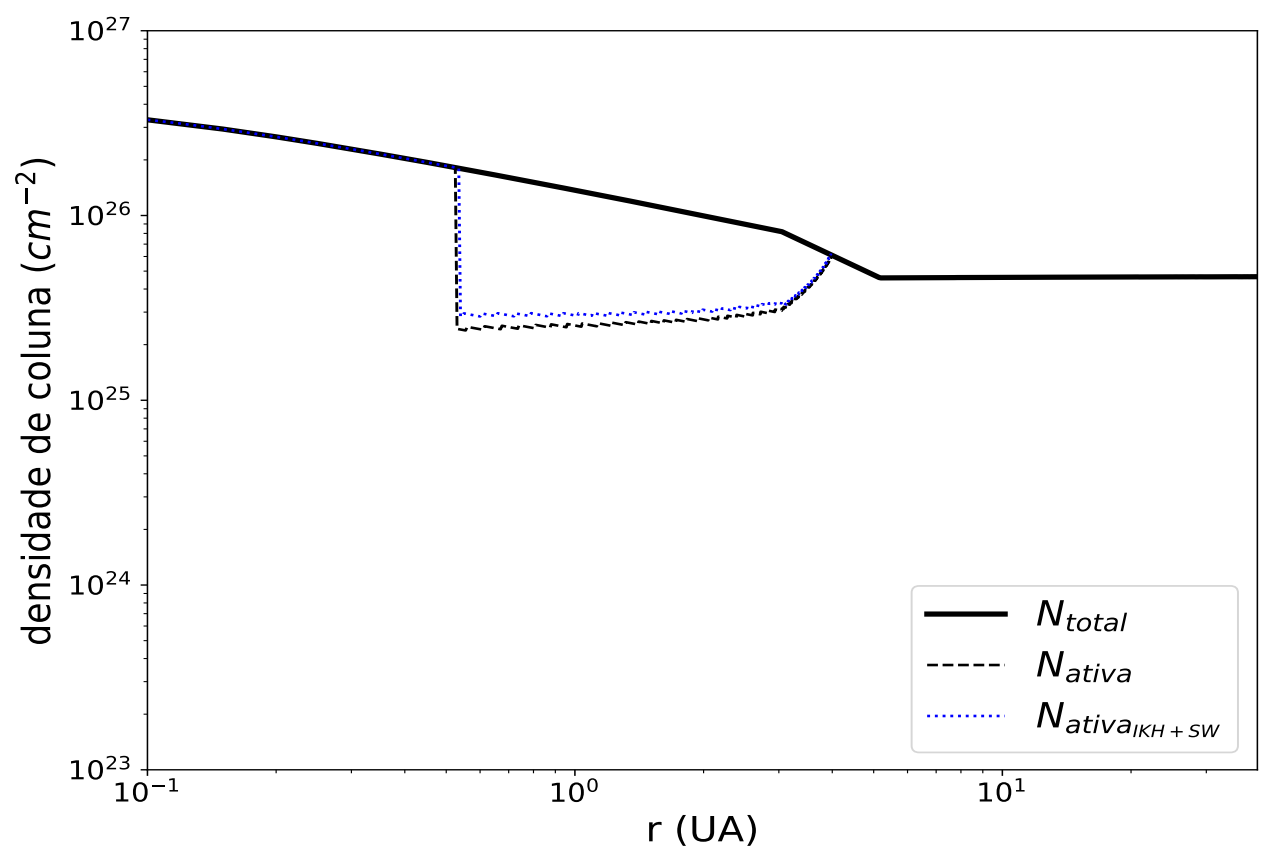

(a)

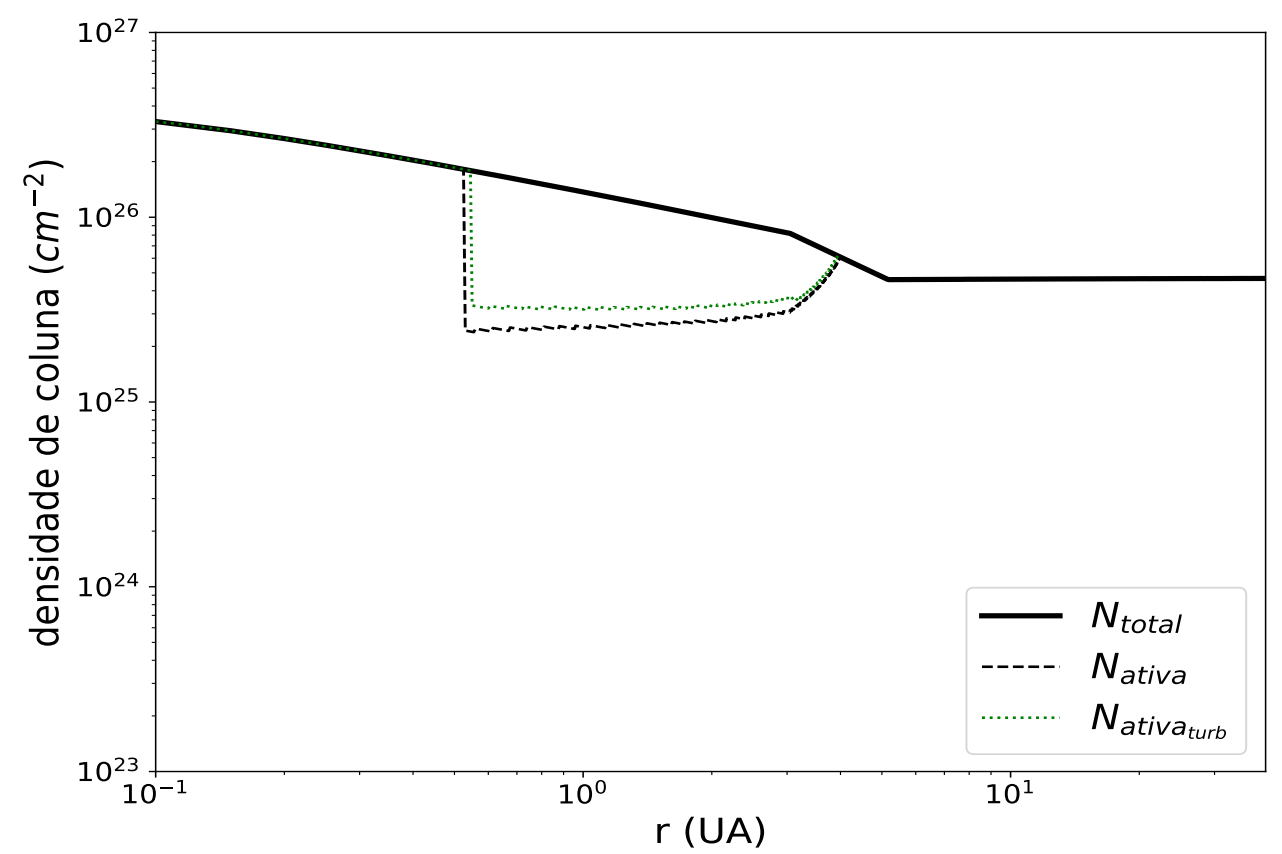

(b)

Figura 5.19: O mesmo que a Figura 5.8, mas para $f=0.2$ e $m=100$. Para os parâmetros considerados, os amortecimentos acoplado e turbulento promovem uma pequena redução na extensão da zona morta. 
vez é diretamente relacionado ao fluxo de ondas, o que faz com que o amortecimento das ondas torne-se mais efetivo conforme mais ondas populem o meio, intensificando, assim, a energia liberada. Logo, esse mecanismo torna-se extremamente ineficiente para fluxos de onda pequenos, ao mesmo tempo em que seus efeitos são potencializados para grandes fluxos. Perceba ainda que o mecanismo que acopla o amortecimento ressonante e turbulento (representado pelas linhas azuis nos gráficos mostrados), apesar de gerar um aumento significativo na temperatura, não é o mais efetivo em aquecer o disco, posição ocupada pelo amortecimento turbulento (tracejado verde). Tal comportamento, embora possa parecer inesperado em um primeiro momento, expressa, de maneira clara, a física por trás do processo de unificação entre os dois mecanismos (Subseção 3.5) e por trás dos mecanismos ressonante e turbulento, individualmente. O amortecimento turbulento nada mais é que um postulado a respeito da maneira com a qual a dissipação ocorrerá. Em outras palavras, tal amortecimento não se preocupa com a origem da energia a ser dissipada; supõe-se apenas que tal energia existe, de forma que o único processo atuante neste mecanismo é a dissipação em si. Já no amortecimento ressonante, a força motriz consiste na interação de duas ondas Alfvén puras, de frequências distintas, $\omega_{A 1}$ e $\omega_{A 2}$, as quais, ao se encontrarem em uma interface, originam uma onda de superfície. Esta onda produto possui, portanto, uma frequência, $\omega$, que estará localizada no contínuo de Alfvén, dado que $\omega_{A 1}>\omega>\omega_{A 2}$. Dessa maneira, a ressonância ocorrerá, culminando no depósito de energia dessa onda na interface. Observe, a absorção ressonante, portanto, está condicionada à ocorrência de dois eventos: o encontro de duas ondas Alfvén, e o subsequente amortecimento e deposição de energia na interface. Logo, ao contrário do amortecimento turbulento, na absorção ressonante não se supõe toda a energia já presente no meio onde a dissipação se dará; ao contrário, o processo-base do amortecimento ressonante pauta-se na geração de uma terceira onda e seu amortecimento para explicar a origem da energia dissipada. Isso pode ser utilizado para explicar por que o mecanismo SW é tão ineficiente em comparação aos demais: o tempo que demora para a dissipação em si ocorrer (tenha em mente que o tempo e a taxa são grandezas inversamente proporcionais) é condicionado ao tempo necessário para o build-up de energia na interface se instaurar, o que aumenta o tempo total necessário para o processo se concretizar como um todo. O mesmo princípio pode ser usado para explicar o por que o mecanismo unificado não é o mais efetivo: apesar de estarmos supondo a IKH como responsável por dissipar as ondas na forma de cascata turbulenta, o que aumenta 
Tabela 5.1 - Resumo dos principais resultados obtidos no presente trabalho. Na primeira coluna, mostramos os valores para o fluxo de ondas Alfvén, $f$, adotados, enquanto na segunda coluna, exibimos os valores utilizados para o número azimutal, $m$. Exibimos também, nas últimas colunas, a redução percentual da zona morta após a aplicação dos mecanismos não-linear, ressonante, turbulento e acoplado, respectivamente.

\begin{tabular}{|c|c|c|c|c|c|}
\hline \multicolumn{2}{|c|}{} & \multicolumn{4}{|c|}{ Redução da zona morta $(\%)$} \\
\hline Fluxo de ondas Alfvén $(f)$ & Número azimutal $(m)$ & NL & SW & Turb & Acoplado \\
\hline 0.01 & 40000 & 0 & 0 & 18.94 & 10.43 \\
0.02 & 4000 & 0 & 0 & 8.32 & 4.39 \\
0.02 & 40000 & 0 & 0 & 57.84 & 35.36 \\
0.1 & 400 & 4.08 & 0 & 18.53 & 10.20 \\
0.2 & 100 & 48.16 & 0 & 8.91 & 4.74 \\
0.2 & 400 & 48.16 & 0 & 56.73 & 34.45 \\
\hline
\end{tabular}

a energia efetiva dissipada, devido ao efeito de agitação das partículas que a turbulência provoca, a atuação da IKH, no mecanismo unificado, também é condicionada à deposição de energia na interface. Logo, o efeito de potenciação da energia liberada visto devido à turbulência, advinda da IKH, no mecanismo turbulento, é retardado, no mecanismo que engloba os amortecimentos ressonante e turbulento, pela necessidade da ocorrência de todos os processos anteriores à ressonância da onda Alfvén de superfície.

Logo, da discussão acima e dos resultados na Tabela 5.1, nota-se que, enquanto o mecanismo ressonante é ineficiente em aquecer o meio quando aplicado à discos de acreção protoestelares, o mecanismo não-linear torna-se extremamente efetivo nos casos onde o fluxo de ondas Alfvén é elevado. Esse comportamento é esperado, uma vez que o mecanismo precursor do amortecimento não-linear é o encontro de duas ondas Alfvén de direções opostas de maneira que, quanto mais populado dessas ondas o ambiente, maior é a probabilidade do encontro entre as ondas, aumentando, assim, a eficácia desse processo. Por outro lado, os amortecimentos turbulento e acoplado, além de dependerem do fluxo de ondas, $f$, apresentam uma forte dependência com a intensidade da perturbação azimutal, $m$. Note que, para os casos onde $f$ é alto, mas $m$ é próximo ao valor crítico $\left(m_{\text {crit }} \sim 90\right.$ no caso considerado), os amortecimentos acoplado e turbulento são bem menos eficientes que o amortecimento não-linear, único dos mecanismos considerados que independe de $m$. Entretanto, a partir do momento em que são utilizados valores para a perturbação azimutal moderados $(m \sim 400)$, o amortecimento turbulento passa a ser o mais efetivo dentre todos. Ademais, pela Tabela 5.1 é possível notar que, de maneira geral, o amortecimento acoplado 
é cerca de $50 \%$ menos efetivo que o amortecimento turbulento.

É possível ainda obter as escalas de tempo associadas a cada um dos mecanismos considerados neste trabalho. Sendo o tempo $(\tau)$ dependente da taxa através da seguinte relação:

$$
\tau \propto \frac{1}{\gamma}
$$

podemos analisar como as escalas de tempo para a ocorrência de cada um dos mecanismos se comparam às escalas de tempo características do disco, como, por exemplo as escalas de tempo viscosa e dinâmica. Para um disco geometricamente fino e estacionário, a escala de tempo viscosa, responsável por ditar o tempo associado à mudanças na estrutura radial do disco, é definida por:

$$
\tau_{v i s} \sim \frac{r^{2}}{\nu}
$$

enquanto a escala de tempo dinâmica assume a forma:

$$
\tau_{\phi} \sim \frac{H}{c s}
$$

Entretanto, para o modelo de disco sob consideração, as escalas de tempo dinâmica e para o equilíbrio hidrostárico vertical, $\tau_{z}$, são equivalentes $\left(\tau_{z} \sim \tau_{\phi}\right)$. Ou seja, para um disco geometricamente fino e estacionário, as mudanças na estrutura vertical do disco também são ditadas pela escala de tempo dinâmica (Frank et al., 2002). Dessa maneira, é possível comparar as escalas de tempo associadas ao amortecimento de ondas Alfvén às escalas de tempo responsáveis pela mudança na estrutura do disco, através das Equações 5.2 , 5.3 e 5.4 .

Na Figura 5.20, apresentamos o comportamento das diferentes escalas de tempo, na direção radial, para a região mais interna do disco. A linha preta espessa denota a escala de tempo viscosa, enquanto a linha preta pontilhada representa a escala de tempo dinâmica do disco. As demais linhas referem-se às escalas de tempo associadas aos diferentes mecanismos de amortecimento considerados neste trabalho: a linha traço-ponto amarela representa o tempo associado ao mecanismo SW, a linha traço-ponto-ponto vermelha denota a escala associada ao amortecimento não-linear, enquanto as linhas pontilhada azul e tracejada verde indicam, respectivamente, as escalas de tempo dos amortecimentos acoplado 
e turbulento. O painel superior à esquerda contém as escalas de tempo obtidas supondo $f=0.01$ e $m=40000$, enquanto o painel superior à direita exibe os comportamentos obtidos para $f=0.02$ e $m=4000$. Nos painéis inferiores, por sua vez, mostramos os tempos associados aos parâmetros $f=0.1$ e $m=400$ (à esquerda) e $f=0.2$ e $m=100$ (à direita). Note que as curvas referentes às escalas de tempo dinâmica e viscosa são as mesmas em todos os gráficos, um vez que elas independem dos mecanismos de aquecimento associados às ondas Alfvén. Pela Figura 5.20, nota-se que as escalas de tempo associadas aos mecanismos turbulento e acoplado são as únicas que, em todas as situações consideradas, são inferiores às escalas de tempo viscosa e dinâmica. Por outro lado, o tempo associado à absorção ressonante é sempre maior que a escala de tempo dinâmica sendo, em alguns casos, até superior à escala de tempo viscosa (no painel inferior à direita, $\tau_{S W}$ torna-se maior que $\tau_{v i s}$ muito próximo à borda interna do disco e continua crescendo de acordo com o aumento da distância radial). O comportamento mais interessante, entretanto, é aquele associado ao amortecimento não-linear: para fluxos de onda baixos (painéis superiores da Figura 5.20 a escala de tempo relacionada à esse mecanismo é superior à escala de tempo dinâmica. Entretanto, quando o fluxo de ondas torna-se grande $(f \geq 0.1$, painéis inferiores da Figura 5.20), o tempo associado ao mecanismo NL torna-se inferior à $\tau_{\text {din }}$. Esse fluxo de ondas crítico é o mesmo a partir do qual o amortecimento não-linear passa a ser efetivo em aquecer o disco e, consequentemente, reduzir a zona morta (veja, por exemplo, a Tabela 5.1). Dessa maneira, é possível relacionar a efetividade dos mecanismos à suas escalas de tempo: o amortecimento de ondas Alfvén só passa a ser eficiente em aquecer o disco quando a escala de tempo para a atuação desse processo é inferior à escala de tempo dinâmica. Os mecanismos acoplado e turbulento, por terem atuação sempre mais rápida que o tempo dinâmico, promovem um aquecimento do disco em todas as situações aqui consideradas, enquanto a absorção ressonante, por atuar em um tempo significativamente maior que $\tau_{\text {din }}$ não consegue promover tal aumento de temperatura. Essa dependência da eficiência dos mecanismos de aquecimento com as escalas de tempo intrínsecas ao disco é esperada: como as escalas de tempo viscosa e dinâmica representam, respectivamente, o tempo necessário para mudanças ocorrerem nas direções radial e vertical, os mecanismos só são efetivos quando conseguem modificar as propriedades do disco mais rapidamente que o tempo necessário para o sistema se rearranjar após algum tipo de perturbação à configuração inicial. 

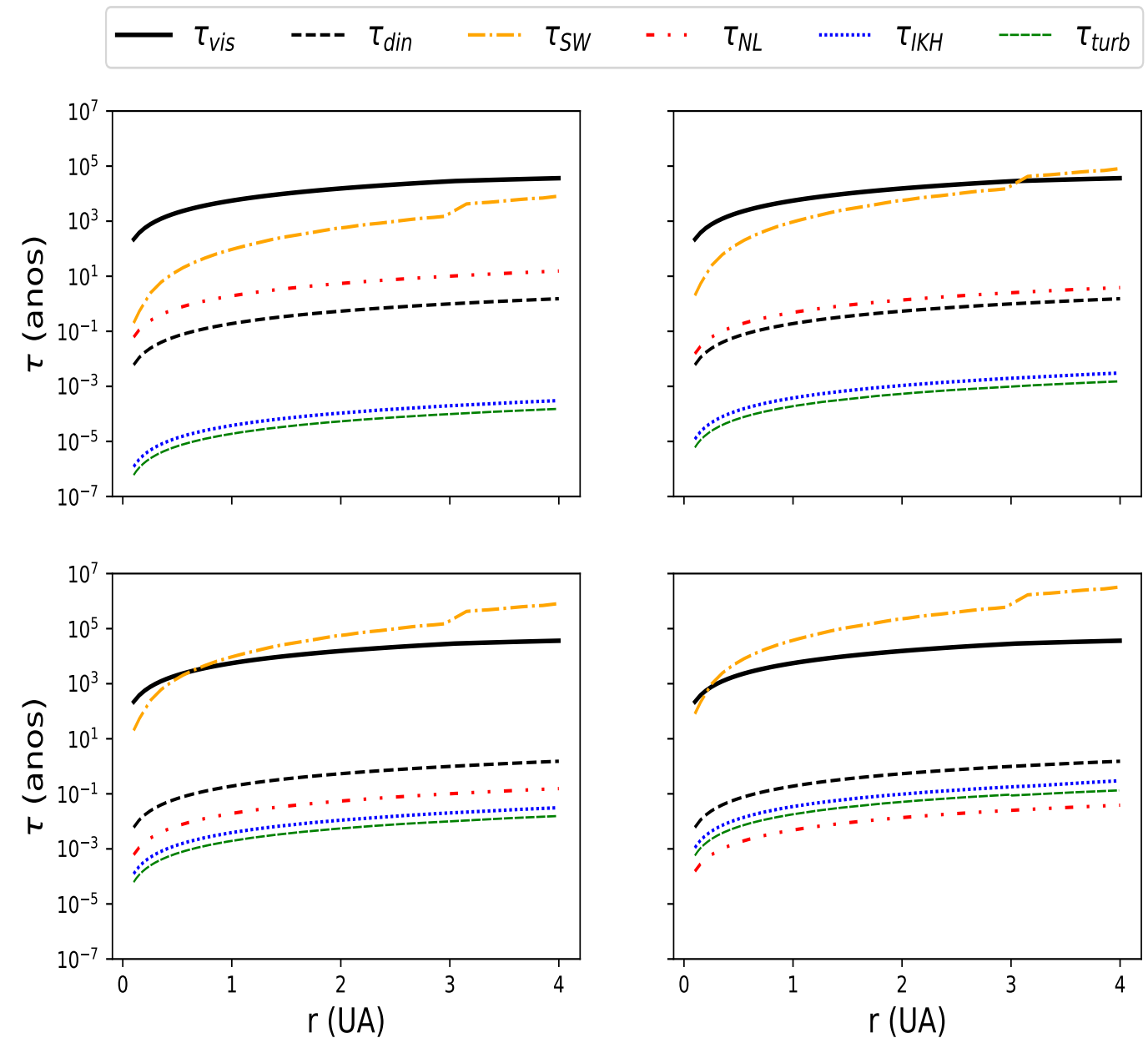

Figura 5.20: Variação radial das escalas de tempo relevantes ao problema. A linha preta espessa representa a escala de tempo viscosa, enquanto a linha preta tracejada denota a escala de tempo dinâmica do disco. As demais linhas referem-se às escalas de tempo associadas aos mecanismos de amortecimento de ondas Alfvén: a linha traço-ponto amarela está associada à absorção ressonante, a linha traço-traço ponto vermelha corresponde ao amortecimento não-linear e as linhas pontilhada azul e tracejada verde reproduzem as escalas de tempo dos amortecimentos acoplado e turbulento, respectivamente. Painéis superiores: escalas de tempo associadas à um fluxo de ondas Alfvén e perturbação azimutal de $f=0.01, m=40000$ (painel à esquerda) e $f=0.02, m=4000$ (painel à direita). Painéis inferiores: escalas de tempo associadas à um fluxo de ondas Alfvén e perturbação azimutal de $f=0.1, m=400$ (painel à esquerda) e $f=0.2, m=100$ (painel à direita). 


\section{Capítulo 6}

\section{Conclusões}

O paradigma atual para estrelas jovens de baixa massa é de que sua evolução é intrinsicamente relacionada ao transporte de momento angular no disco que circunda a protoestrela, responsável por promover a acreção de matéria em direção ao objeto central. Um dos mecanismos mais promissores para o transporte de momento angular em discos associados à estrelas jovens é a IMR, proposta por Balbus e Hawley (1991). Entretanto, devido ao fato da IMR exigir o congelamento das partículas às linhas de campo magnético, essa instabilidade não é atuante em toda a extensão do disco. Na realidade, nas regiões mais internas e próximas ao plano médio do disco, a fração de ionização das partículas é muito baixa, de forma que a IMR passa a ser ineficiente nesse local, configurando a chamada zona morta (Gammie, 1996). Logo, o principal objetivo desse trabalho foi, a partir do modelo de camadas de Gammie (1996) e do modelo $\alpha$-padrão de Shakura e Sunyaev (1973), estudar maneiras de aumentar a fração de ionização nessa região quiescente (i.e. a zona morta), a fim de assegurar a ocorrência da IMR e, assim, propiciar um transporte de momento angular mais efetivo em uma maior porção do disco. Para isso, consideramos o amortecimento de ondas Alfvén como um mecanismo extra de aquecimento do disco, de maneira análoga à realizada por Vasconcelos et al. (2000). Quatro mecanismos de amortecimento foram considerados: o amortecimento não-linear, o turbulento, a absorção ressonante de ondas Alfvén de superfície e o mecanismo acoplado, o qual unifica os efeitos da absorção ressonante e do amortecimento turbulento.

A partir de um modelo de disco 1D+1D, conforme proposto por Ilgner et al. (2004) e utilizado por Ilgner e Nelson (2006), simulamos um disco de acreção ao redor de uma estrela T Tauri, sob a influência de três mecanismos de ionização: a ionização térmica, ionização por raios-X e por raios cósmicos. Tal modelo $1 \mathrm{D}+1 \mathrm{D}$ utiliza-se do fato de que, devido à 
escala de tempo viscosa do disco ser superior à escala de tempo dos demais processos que ocorrem nesse objeto, as direções radial e vertical podem ser desacopladas, diminuindo, dessa maneira, a complexidade numérica do código.

Foram considerados diversos valores para o fluxo de ondas Alfvén, $\Phi$, e para o número azimutal, $m$, o qual controla a intensidade da perturbação aplicada no meio. Obteve-se que, para discos de acreção associados à estrelas T Tauri, a absorção ressonante de ondas Alfvén de superfície é extremamente ineficiente em aquecer o disco, de forma que mesmo para altos valores de fluxo de ondas, nenhuma mudança significativa à estrutura do disco foi observada. Isso ocorre pois a eficácia desse mecanismo é diretamente proporcional à diferença entre a frequência de ondas existentes em meios vizinhos, $\gamma_{s w} \propto \omega_{A e}^{2}-\omega_{A i}^{2}$. No caso de discos como o considerado nesse trabalho, essa diferença é muito pequena, dado que a variação nas propriedades desses objetos ocorre de maneira suave. Assim, $\omega_{A e} \sim \omega_{A i}$, e o efeito da absorção ressonante torna-se desprezível nesses meios.

O amortecimento não-linear, por outro lado, torna-se um mecanismo relevante no aquecimento do disco apenas para fluxos de ondas Alfvén grandes, i.e. $f>0.1$. Conforme explicitado anteriormente, isso ocorre pois esse mecanismo depende fortemente da densidade de energia das ondas, $\gamma_{N L} \propto \epsilon_{A}$. Logo, as ondas tornam-se amortecidas de maneira mais efetiva de acordo com o aumento de $\epsilon_{A}$, o que potencializa a transferência de energia para o meio para altos valores de $f$. De fato, para $f=0.2$, o amortecimento não-linear promove uma redução significativa na extensão da zona morta.

Finalmente, obteve-se que o amortecimento turbulento é o mais efetivo em aquecer o disco, sendo, inclusive, mais eficiente que o mecanismo acoplado devido às razões discutidas na Capítulo 5. Obteve-se que para valores de $m$ ligeiramente acima do valor crítico para a ocorrência da IKH, esses mecanismos promovem um aquecimento significativo do disco, aumentando, assim, as regiões onde a IMR é ativa. Logo, os amortecimentos turbulento e acoplado podem ser mecanismos atuantes no disco, a fim de assegurar a ocorrência da IMR em uma maior região, propiciando um transporte de momento angular mais efetivo nesses meios.

As principais conclusões deste trabalho podem ser resumidas, portanto, da seguinte maneira: quando aplicado à discos de acreção protoestelares, a absorção ressonante é inefetiva em aquecer o meio, enquanto o amortecimento não-linear produz um impacto significativo na diminuição da zona morta apenas para altos valores de fluxo de ondas 
Alfvén, $f>0.1$. Os amortecimentos acoplado e turbulento, por outro lado, propiciam mudanças significativas no disco, mesmo para baixos fluxos de onda, desde que a perturbação azimutal seja suficientemente alta. Entretanto, esses mesmos mecanismos, para fluxos de onda mais elevados $(f \geq 0.1)$, também promovem uma redução substancial na zona morta para valores de $m$ ligeiramente acima do valor crítico. Obtivemos ainda que o amortecimento acoplado, apesar de eficiente, gera temperaturas inferiores ao turbulento, promovendo uma diminuição da zona morta aproximadamente $50 \%$ menor que o mecanismo turbulento, sendo esse último o mais efetivo dentre os mecanismos considerados, na presença de uma perturbação azimutal significativa.

Nesse trabalho, considerou-se apenas a IMR como sendo o mecanismo responsável por promover o transporte de momento angular em discos associados à estrelas T Tauri. Entretanto, a presença de ventos nesses sistemas também pode auxiliar nesse transporte: de fato, nos últimos anos, diversos estudos apontam que a presença de ventos magnetocentrífugos (Blandford e Payne, 1982), responsáveis por extrair momento angular verticalmente em discos, são necessários para explicar a taxa de acreção observada (e.g. Bai, 2011, 2013). Além disso, devido ao fato do gás presente nesses discos ser fracamente ionizado, efeitos MHD não-ideais passam a ser importantes. Esses efeitos influenciam a localização e extensão da zona morta (e.g. Dzyurkevich et al., 2013) e podem diminuir a efetividade da IMR nesses discos (e.g. Fleming et al., 2000; Bai e Stone, 2013; Bai, 2013). Portanto, no futuro, pretende-se aprofundar o estudo do transporte de momento angular em discos, ao incluir, além do amortecimento de ondas Alfvén, os efeitos MHD não-ideais e ventos, tanto de origem estelar, quanto os ventos originários no disco, a fim de promover uma evolução temporal do sistema e inferir as consequências desses processos para a evolução do sistema estrela-disco e para a formação de planetesimais, analisando, inclusive, como a inclusão desses efeitos ajustaria as massas dos planetas que seriam formados no disco. 


\section{Referências}

André P., The Cold Universe. Editions Frontières, 1994

André P., Ward-Thompson D., Barsony M., Submillimeter continuum observations of Rho Ophiuchi A-The candidate protostar VLA 1623 and prestellar clumps, The Astrophysical Journal, 1993, vol. 406, p. 122

Andrews S. M., Williams J. P., Circumstellar dust disks in Taurus-Auriga: the submillimeter perspective, The Astrophysical Journal, 2005, vol. 631, p. 1134

Andrews S. M., Williams J. P., High-resolution submillimeter constraints on circumstellar disk structure, The Astrophysical Journal, 2007, vol. 659, p. 705

Ansdell M., Williams J. P., Trapman L., van Terwisga S. E., Facchini S., Manara C. F., van der Marel N., Miotello A., Tazzari M., Hogerheijde M., Guidi G., Testi L., van Dishoeck E. F., ALMA Survey of Lupus Protoplanetary Disks. II. Gas Disk Radii, ApJ, 2018, vol. 859 , p. 21

Armitage P. J., Dynamics of Protoplanetary Disks, The Annual Review of Astronomy and Astrophysics, 2011, vol. 49

Arregui I., Terradas J., Oliver R., Ballester J., Resonantly damped surface and body MHD waves in a solar coronal slab with oblique propagation, Solar Physics, 2007, vol. 246, p. 213

Avenhaus H., Quanz S. P., Garufi A., Perez S., Casassus S., Pinte C., Bertrang G. H. M., Caceres C., Benisty M., Dominik C., Disks around T Tauri Stars with SPHERE (DARTTS-S). I. SPHERE/IRDIS Polarimetric Imaging of Eight Prominent T Tauri Disks, ApJ, 2018, vol. 863, p. 44 
Bai X.-N., Magnetorotational-instability-driven accretion in protoplanetary disks, ApJ, 2011, vol. 739 , p. 50

Bai X.-N., Wind-driven accretion in protoplanetary disks. II. Radial dependence and global picture, ApJ, 2013, vol. 772, p. 96

Bai X.-N., Global Simulations of the Inner Regions of Protoplanetary Disks with Comprehensive Disk Microphysics, ApJ, 2017, vol. 845, p. 75

Bai X.-N., Stone J. M., Wind-driven accretion in protoplanetary disks. I. Suppression of the magnetorotational instability and launching of the magnetocentrifugal wind, ApJ, 2013, vol. 769 , p. 76

Bai X.-N., Ye J., Goodman J., Yuan F., Magneto-thermal disk winds from protoplanetary disks, ApJ, 2016, vol. 818, p. 152

Balbus S. A., Hawley J. F., A powerful local shear instability in weakly magnetized disks. I-Linear analysis. II-Nonlinear evolution, ApJ, 1991, vol. 376, p. 214

Balbus S. A., Hawley J. F., Solar nebula magnetohydrodynamics, Space Science Reviews, 2000, vol. 92, p. 39

Barranco J. A., Three-dimensional simulations of Kelvin-Helmholtz instability in settled dust layers in protoplanetary disks, The Astrophysical Journal, 2009, vol. 691, p. 907

Belcher J., Davis Jr L., Large-amplitude Alfvén waves in the interplanetary medium, 2, Journal of Geophysical Research, 1971, vol. 76, p. 3534

Bell K., Lin D., Using FU Orionis outbursts to constrain self-regulated protostellar disk models, The Astrophysical Journal, 1994, vol. 427, p. 987

Béthune W., Lesur G., Ferreira J., Global simulations of protoplanetary disks with net magnetic flux. I. Non-ideal MHD case, A\&A, 2017, vol. 600, p. A75

Blandford R., Payne D., Hydromagnetic flows from accretion discs and the production of radio jets, MNRAS, 1982, vol. 199, p. 883 
Bouvier J., Matt S. P., Mohanty S., Scholz A., Stassun K. G., Zanni C., Angular momentum evolution of young low-mass stars and brown dwarfs: observations and theory, Protostars and Planets VI, 2014, vol. 433, p. 94

Browning P., Priest E., Kelvin-Helmholtz instability of a phased-mixed Alfven wave, Astronomy and Astrophysics, 1984, vol. 131, p. 283

Chandrasekhar S., Hydrodynamic and Hydromagnetic Stability. Oxford University Press, 1961

Cranmer S. R., Turbulence-driven polar winds from T Tauri stars energized by magnetospheric accretion, The Astrophysical Journal, 2008, vol. 689, p. 316

Cranmer S. R., Saar S. H., Testing a predictive theoretical model for the mass loss rates of cool stars, The Astrophysical Journal, 2011, vol. 741, p. 54

Cranmer S. R., Van Ballegooijen A., On the generation, propagation, and reflection of Alfvén waves from the solar photosphere to the distant heliosphere, The Astrophysical Journal Supplement Series, 2005, vol. 156, p. 265

Cranmer S. R., Van Ballegooijen A. A., Edgar R. J., Self-consistent coronal heating and solar wind acceleration from anisotropic magnetohydrodynamic turbulence, The Astrophysical Journal Supplement Series, 2007, vol. 171, p. 520

David V., Galtier S., Spectrum in Kinetic Alfvén Wave Turbulence: Implications for the Solar Wind, The Astrophysical Journal Letters, 2019, vol. 880, p. L10

Dos Santos L., Jatenco-Pereira V., Opher R., Mass loss from Wolf-Rayet stars due to radiation pressure and Alfven waves, The Astrophysical Journal, 1993, vol. 410, p. 732

Downs C., Roussev I. I., van der Holst B., Lugaz N., Sokolov I. V., Gombosi T. I., Toward a realistic thermodynamic magnetohydrodynamic model of the global solar corona, The Astrophysical Journal, 2010, vol. 712, p. 1219

Dudorov A. E., Khaibrakhmanov S. A., Fossil magnetic field of accretion disks of young stars, Ap\&SS, 2014, vol. 352, p. 103

Dzyurkevich N., Turner N. J., Henning T., Kley W., Magnetized accretion and dead zones in protostellar disks, The Astrophysical Journal, 2013, vol. 765, p. 114 
Escande D., Gondret V., Sattin F., Relevant heating of the quiet solar corona by Alfvén waves: a result of adiabaticity breakdown, Scientific reports, 2019, vol. 9, p. 1

Evans R. M., Opher M., Jatenco-Pereira V., Gombosi T. I., Surface Alfvén wave damping in a three-dimensional simulation of the solar wind, The Astrophysical Journal, 2009, vol. 703 , p. 179

Evans R. M., Opher M., Oran R., van der Holst B., Sokolov I., Frazin R., Gombosi T. I., Vásquez A., Coronal heating by surface Alfvén wave damping: Implementation in a global magnetohydrodynamics model of the solar wind, The Astrophysical Journal, 2012, vol. 756 , p. 155

Falceta-Gonçalves D., Jatenco-Pereira V., The effects of Alfvén waves and radiation pressure in dust winds of late-type stars, The Astrophysical Journal, 2002, vol. 576, p. 976

Falceta-Gonçalves D., Lazarian A., Houde M., Damping of Magnetohydrodynamic Turbulence in Partially Ionized Gas and the Observed Difference of Velocities of Neutrals and Ions, The Astrophysical Journal, 2010, vol. 713, p. 1376

Falceta-Gonçalves D., Vidotto A., Jatenco-Pereira V., On the magnetic structure and wind parameter profiles of Alfvén wave driven winds in late-type supergiant stars, Monthly Notices of the Royal Astronomical Society, 2006, vol. 368, p. 1145

Fleming T., Stone J. M., Local magnetohydrodynamic models of layered accretion disks, The Astrophysical Journal, 2003, vol. 585, p. 908

Fleming T. P., Stone J. M., Hawley J. F., The effect of resistivity on the nonlinear stage of the magnetorotational instability in accretion disks, The Astrophysical Journal, 2000, vol. 530 , p. 464

Frank J., King A., Raine D., Accretion Power in Astrophysics. Cambridge University Press, 2002

Fromang S., Terquem C., Balbus S. A., The ionization fraction in $\alpha$ models of protoplanetary discs, Monthly Notices of the Royal Astronomical Society, 2002, vol. 329, p. 18 
Gallet F., Bouvier J., Improved angular momentum evolution model for solar-like stars, A\&A, 2013, vol. 556, p. A36

Gammie C. F., Layered Accretion in T-Tauri Disks, The Astrophysical Journal, 1996, vol. 457

Glassgold A., Najita J., Igea J., X-ray ionization of protoplanetary disks, The Astrophysical Journal, 1997, vol. 480, p. 344

Gonçalves D., Jatenco-Pereira V., Opher R., The possibility of thermal instability in earlytype stars due to Alfven waves, The Astrophysical Journal, 1998, vol. 501, p. 797

Gonçalves D. R., Jatenco-Pereira V., Opher R., Two-Phase Broad-Line Regions in the Presence of Alfven Wave Heating: The Role of Nonlinear and Turbulent Heating, The Astrophysical Journal, 1996, vol. 463, p. 489

Goossens M., Arregui I., Ballester J., Wang T., Analytic approximate seismology of transversely oscillating coronal loops, Astronomy \& Astrophysics, 2008, vol. 484, p. 851

Goossens M., Erdélyi R., Ruderman M. S., Resonant MHD waves in the solar atmosphere, Space science reviews, 2011, vol. 158, p. 289

Goossens M., Hollweg J. V., Sakurai T., Resonant behaviour of MHD waves on magnetic flux tubes, Solar physics, 1992, vol. 138, p. 233

Goossens M., Ruderman M. S., Hollweg J. V., Dissipative MHD solutions for resonant Alfvén waves in 1-dimensional magnetic flux tubes, Solar Physics, 1995, vol. 157, p. 75

Goossens M., Terradas J., Andries J., Arregui I., Ballester J., On the nature of kink MHD waves in magnetic flux tubes, Astronomy \& Astrophysics, 2009, vol. 503, p. 213

Gorti U., Dullemond C., Hollenbach D., Time evolution of viscous circumstellar disks due to photoevaporation by far-ultraviolet, extreme-ultraviolet, and X-ray radiation from the central star, ApJ, 2009, vol. 705, p. 1237

Gorti U., Hollenbach D., Dullemond C., The impact of dust evolution and photoevaporation on disk dispersal, ApJ, 2015, vol. 804, p. 29 
Gressel O., Turner N. J., Nelson R. P., McNally C. P., Global simulations of protoplanetary disks with ohmic resistivity and ambipolar diffusion, The Astrophysical Journal, 2015, vol. 801 , p. 84

Hartmann L., Accretion disks of young stars. In The Nature and Evolution of Disks Around Hot Stars , vol. 337, 2005, p. 3

Hartmann L., Accretion processes in star formation. Cambridge University press, 2009

Hasegawa A., Uberoi C., , 1982 Technical report Alfven wave. DOE Critical Review Series. Department of Energy, Washington, DC (USA). Office of Technical Information

Hawley J. F., Global Magnetohydrodynamical Simulations of Accretion Tori, ApJ, 2000, vol. 528 , p. 462

Hawley J. F., Gammie C. F., Balbus S. A., Local three-dimensional magnetohydrodynamic simulations of accretion disks, The Astrophysical Journal, 1995, vol. 440, p. 742

Hayashi C., Structure of the solar nebula, growth and decay of magnetic fields and effects of magnetic and turbulent viscosities on the nebula, Progress of Theoretical Physics Supplement, 1981, vol. 70, p. 35

Heyvaerts J., Priest E., Coronal heating by phase-mixed shear Alfvén waves, Astronomy and Astrophysics, 1983, vol. 117, p. 220

Hollweg J., Resonances of coronal loops, The Astrophysical Journal, 1984, vol. 277, p. 392

Hollweg J. V., Transition region, corona, and solar wind in coronal holes, Journal of Geophysical Research: Space Physics, 1986, vol. 91, p. 4111

Hollweg J. V., Yang G., Resonance absorption of compressible magnetohydrodynamic waves at thin "surfaces", J. Geophys. Res., 1988, vol. 93, p. 5423

Hoshoudy G., Cavus H., Mahdy A., A viscous magnetohydrodynamic Kelvin-Helmholtz instability in the interface of two fluid layers: Part I. Basic mechanism, Astrophysics and Space Science, 2019, vol. 364, p. 89

Igea J., Glassgold A., X-ray ionization of the disks of young stellar objects, The Astrophysical Journal, 1999, vol. 518, p. 848 
Ilgner M., Henning T., Markwick A., Millar T., Transport processes and chemical evolution in steady accretion disk flows, Astronomy \& Astrophysics, 2004, vol. 415, p. 643

Ilgner M., Nelson R. P., On the ionisation fraction in protoplanetary disks-I. Comparing different reaction networks, Astronomy \& Astrophysics, 2006, vol. 445, p. 205

Ionson J. A., Resonant absorption of Alfvenic surface waves and the heating of solar coronal loops, The Astrophysical Journal, 1978, vol. 226, p. 650

Jatenco-Pereira V., Damping of Alfvén waves as a heating source in protostellar accretion discs, Monthly Notices of the Royal Astronomical Society, 2013, vol. 431, p. 3150

Jatenco-Pereira V., The dead zone size limits in a proto-stellar accretion disc model heated by the damping of Alfvén waves, Astrophysics and Space Science, 2015, vol. 357, p. 81

Jatenco-Pereira V., Opher R., Observational limits on the coronal hole flow geometry in an Alfvén wave-driven solar wind, The Astrophysical Journal, 1989a, vol. 344, p. 513

Jatenco-Pereira V., Opher R., Effect of diverging magnetic fields on mass loss in late-type giant stars, Astronomy and Astrophysics, 1989b, vol. 209, p. 327

Jatenco-Pereira V., Opher R., Alfvén-driven protostellar winds, Monthly Notices of the Royal Astronomical Society, 1989c, vol. 236, p. 1

Khaibrakhmanov S. A., Dudorov A. E., Parfenov S. Y., Sobolev A. M., Large-scale magnetic field in the accretion discs of young stars: the influence of magnetic diffusion, buoyancy and Hall effect, Monthly Notices of the Royal Astronomical Society, 2017, vol. 464 , p. 586

Krall N. A., Trivelpiece A. W., Principles of plasma physics, 1973

Lada C. J., Star formation: from OB associations to protostars. In SymposiumInternational Astronomical Union, vol. 115, 1987, p. 1

Lagage P., Cesarsky C., The maximum energy of cosmic rays accelerated by supernova shocks, Astronomy and Astrophysics, 1983, vol. 125, p. 249

Larson R. B., Turbulence and star formation in molecular clouds, Monthly Notices of the Royal Astronomical Society, 1981, vol. 194, p. 809 
Lee M., Roberts B., On the behavior of hydromagnetic surface waves, The Astrophysical Journal, 1986, vol. 301, p. 430

Lee M. A., Völk H. J., Damping and nonlinear wave-particle interactions of Alfvén-waves in the solar wind, Astrophysics and Space Science, 1973, vol. 24, p. 31

Lesur G., Kunz M. W., Fromang S., Thanatology in protoplanetary discs. The combined influence of Ohmic, Hall, and ambipolar diffusion on dead zones, A\&A, 2014, vol. 566, p. A56

Li L.-X., Narayan R., Quasi-periodic oscillations from Rayleigh-Taylor and KelvinHelmholtz instability at a disk-magnetosphere interface, The Astrophysical Journal, 2004, vol. 601, p. 414

Lovelace R., Romanova M., Newman W., Kelvin-Helmholtz instability of the magnetopause of disc-accreting stars, Monthly Notices of the Royal Astronomical Society, 2010, vol. 402, p. 2575

Lynden-Bell D., Pringle J. E., The evolution of viscous discs and the origin of nebular variables, The Astrophysical Journal, 1974, vol. 552

McKee C. F., Ostriker E. C., Theory of star formation, Annu. Rev. Astron. Astrophys., 2007, vol. 45 , p. 565

Manners H., Masters A., First Evidence for Multiple-Harmonic Standing Alfvén Waves in Jupiter's Equatorial Plasma Sheet, Geophysical Research Letters, 2019

Martin R. G., Lubow S. H., Livio M., Pringle J., Dead zones around young stellar objects: dependence on physical parameters, Monthly Notices of the Royal Astronomical Society, 2012, vol. 420, p. 3139

Matt S., Pudritz R. E., Accretion-powered stellar winds as a solution to the stellar angular momentum problem, ApJ Letters, 2005, vol. 632, p. L135

Maucó K., Hernández J., Calvet N., Ballesteros-Paredes J., Briceño C., McClure M., D'Alessio P., Anderson K., Ali B., A Herschel View of Protoplanetary Disks in the $\sigma$ Ori Cluster, ApJ, 2016, vol. 829, p. 38 
Mignone A., The Magneto-Rotational Instability (MRI), Plasma Physics Course, University of Torino, 2016, p. 2

Murcia M. A. P., Study of the formation of Kelvin-Helmholtz instability and shocks in coronal mass ejections, IAG-USP, 2018, Tese de Doutorado

Najita J. R., Bergin E. A., Protoplanetary Disk Sizes and Angular Momentum Transport, ApJ, 2018, vol. 864, p. 168

Oppenheimer M., Dalgarno A., The fractional ionization in dense interstellar clouds, The Astrophysical Journal, 1974, vol. 192, p. 29

Ostriker E. C., Shu F. H., Magnetocentrifugally driven flows from young stars and disks. IV. The accretion funnel and dead zone, The Astrophysical Journal, 1995, vol. 447, p. 813

Perez-Becker D., Chiang E., Surface layer accretion in conventional and transitional disks driven by far-ultraviolet ionization, ApJ, 2011, vol. 735, p. 8

Press W. H., Teukolsky S. A., Vetterling W. T., Flannery B. P., Numerical recipes 2nd edition: The art of scientific computing. Cambridge university press, 1992

Pringle J. E., Accretion Discs in Astrophysics, The Annual Review of Astronomy and Astrophysics, 1981, vol. 19

Romanova M. M., Owocki S. P., Accretion, outflows, and winds of magnetized stars, Space Science Reviews, 2015, vol. 191, p. 339

Ruderman M., Roberts B., The damping of coronal loop oscillations, The Astrophysical Journal, 2002, vol. 577, p. 475

Sakurai T., Goossens M., Hollweg J. V., Resonant behaviour of MHD waves on magnetic flux tubes, Solar Physics, 1991, vol. 133, p. 227

Santos-Silva T., Gregorio-Hetem J., Montmerle T., Fernandes B., Stelzer B., Star formation history of Canis Major OB1-II. A bimodal X-ray population revealed by XMM-Newton, Astronomy \& Astrophysics, 2018, vol. 609, p. A127 
Schulz N. S., From dust to stars: studies of the formation and early evolution of stars. Springer-Verlag Berlin Heidelberg, 2005

Shaikh Z. I., Raghav A., Vichare G., Coexistence of a planar magnetic structure and an Alfvén wave in the shock-sheath of an interplanetary coronal mass ejection, Monthly Notices of the Royal Astronomical Society, 2019, vol. 490, p. 1638

Shakura N. I., Sunyaev R. A., Black holes in binary systems. Observational appearance., Astronomy and Astrophysics, 1973, vol. 24, p. 337

Soler R., Terradas J., Oliver R., Ballester J., Goossens M., Kelvin-Helmholtz instability in coronal magnetic flux tubes due to azimuthal shear flows, The Astrophysical Journal, 2010, vol. 712 , p. 875

Spitzer Jr L., Tomasko M. G., Heating of H i regions by energetic particles, The Astrophysical Journal, 1968, vol. 152, p. 971

Telleschi A., Güdel M., Briggs K. R., Audard M., Palla F., X-ray emission from T Tauri stars and the role of accretion: inferences from the XMM-Newton extended survey of the Taurus molecular cloud, Astronomy \& Astrophysics, 2007, vol. 468, p. 425

Turner N., Sano T., Dziourkevitch N., Turbulent mixing and the dead zone in protostellar disks, The Astrophysical Journal, 2007, vol. 659, p. 729

Turner N. J., Sano T., Dead zone accretion flows in protostellar disks, The American Astronomical Society, 2008, vol. 679

Umebayashi T., Nakano T., . Ionization State and Magnetic Fields in the Solar Nebula, Progress of Theoretical Physics Supplement, 1988, vol. 96, p. 151

Van Ballegooijen A., Asgari-Targhi M., Cranmer S., DeLuca E., Heating of the solar chromosphere and corona by Alfvén wave turbulence, The Astrophysical Journal, 2011, vol. 736, p. 3

Vasconcelos M., Jatenco-Pereira V., Opher R., Alfvénic heating of protostellar accretion disks, The Astrophysical Journal, 2000, vol. 534, p. 967 
Vasconcelos M., Jatenco-Pereira V., Opher R., The Role of Damped Alfvén Waves in Magnetospheric Accretion Models of Young Stars, The Astrophysical Journal, 2002, vol. 574, p. 847

Vasconcelos M. J., Aquecimento Alfvênico em Discos e Colunas de Acresção de Estrelas T Tauri, IAG-USP, 2000, Tese de Doutorado

Verdini A., Grappin R., Velli M., Coronal heating in coupled photosphere-chromospherecoronal systems: turbulence and leakage, Astronomy \& Astrophysics, 2012, vol. 538, p. A70

Völk H. J., Cesarsky C. J., Nonlinear Landau Damping of Alfvén Waves in a High $\beta$ Plasma, Zeitschrift für Naturforschung A, 1982, vol. 37, p. 809

Wentzel D. G., Coronal heating by Alfven waves, Solar Physics, 1974, vol. 39, p. 129

Xin-Jie M., Acceleration by Magnetic Mirrors and Alfven Waves in Molecular Outflows, Astrophysics and space science, 1998, vol. 260, p. 397

Yasuda Y., Suzuki T. K., Kozasa T., Alfvén Wave-driven Wind from RGB and AGB Stars, The Astrophysical Journal, 2019, vol. 879, p. 77

Zaqarashvili T., Vörös Z., Zhelyazkov I., Kelvin-Helmholtz instability of twisted magnetic flux tubes in the solar wind, Astronomy \& Astrophysics, 2014, vol. 561, p. A62

Zhao J., Voitenko Y., Guo Y., Su J., Wu D., Nonlinear Damping of Alfvén Waves in the Solar Corona Below 1.5 Solar Radii, The Astrophysical Journal, 2015, vol. 811, p. 88 
Apêndice 



\section{Apêndice A}

\section{As equações que regem o disco}

\section{A.1 A equação de conservação de momento angular}

Conforme descrito na Seção 2.1, a conservação de momento angular é descrita através de:

$$
\rho \frac{D \vec{v}}{D t}=-\rho \vec{\nabla} \Phi-\vec{\nabla} P+\vec{\nabla} \cdot \vec{\Pi}
$$

onde $\Phi$ denota o potencial gravitacional, $P$ a pressão total e $\vec{\Pi}$ representa o tensor de stress viscoso, definido em A.2. Sendo $D$ uma derivada material, temos que, pela definição:

$$
\frac{D \vec{u}}{D t}=\frac{\partial \vec{u}}{\partial t}+\vec{v} \cdot \nabla \vec{u}
$$

onde $\vec{v}$ refere-se à velocidade do fluido. Em coordenadas cilíndricas, a equação acima passa a ser escrita como:

$$
\frac{D \vec{u}}{D t}=\frac{\partial \vec{u}}{\partial t}+\frac{d r}{d t} \frac{\partial \vec{u}}{\partial r}+\frac{d \phi}{d t} \frac{\partial \vec{u}}{\partial \phi}+\frac{d z}{d t} \frac{\partial \vec{u}}{\partial z} .
$$

Logo, a expressão à esquerda da igualdade na Equação A.1 assume a seguinte forma:

$$
\rho \frac{D \vec{v}}{D t}=\rho\left[\frac{\partial \vec{v}}{\partial t}+\frac{d r}{d t} \frac{\partial \vec{v}}{\partial r}+\frac{d \phi}{d t} \frac{\partial \vec{v}}{\partial \phi}+\frac{d z}{d t} \frac{\partial \vec{v}}{\partial z}\right]
$$

Sendo os vetores unitários, em coordenadas cilíndricas, definidos como: 


$$
\begin{aligned}
& \hat{r}=\hat{x} \cos \phi+\hat{y} \sin \phi \\
& \hat{\phi}=-\hat{x} \sin \phi+\hat{y} \cos \phi \\
& \hat{z}=\hat{z}
\end{aligned}
$$

é trivial obtermos as derivadas dos vetores unitários. A saber:

$$
\begin{array}{lll}
\frac{\partial \hat{r}}{\partial r}=0 & \frac{\partial \hat{\phi}}{\partial r}=0 & \frac{\partial \hat{z}}{\partial r}=0 \\
\frac{\partial \hat{r}}{\partial \phi}=-\sin \phi \hat{x}+\cos \phi \hat{y}=\hat{\phi} & \frac{\partial \hat{\phi}}{\partial \phi}=-\cos \phi \hat{x}-\sin \phi \hat{y}=-\hat{r} & \frac{\partial \hat{z}}{\partial \phi}=0 \\
\frac{\partial \hat{r}}{\partial z}=0 & \frac{\partial \hat{\phi}}{\partial z}=0 & \frac{\partial \hat{z}}{\partial z}=0 .
\end{array}
$$

Podemos, definir, portanto, cada uma das componentes da derivada material:

\section{(i) Coordenada radial}

$$
\frac{d r}{d t} \frac{\partial \vec{v}}{\partial r}=v_{r}\left[\frac{\partial v_{r}}{\partial r} \hat{r}+v_{r} \frac{\partial \hat{r}}{\partial r}+\frac{\partial v_{\phi}}{\partial r} \hat{\phi}+v_{\phi} \frac{\partial \hat{\phi}}{\partial r}+\frac{\partial v_{z}}{\partial r} \hat{z}+v_{z} \frac{\partial \hat{z}}{\partial r}\right]
$$

Como todas as derivadas dos vetores unitaŕios em $r$ são nulas, obtemos:

$$
v_{r} \frac{\partial \vec{v}}{\partial r}=v_{r}\left(\frac{\partial v_{r}}{\partial r} \hat{r}+\frac{\partial v_{\phi}}{\partial r} \hat{\phi}+\frac{\partial v_{z}}{\partial r} \hat{z}\right)
$$

\section{(ii) Coordenada azimutal}

$$
\frac{d \phi}{d t} \frac{\partial \vec{v}}{\partial \phi}=\frac{v_{\phi}}{r}\left[\frac{\partial v_{r}}{\partial \phi} \hat{r}+v_{r} \frac{\partial \hat{r}}{\partial \phi}+\frac{\partial v_{\phi}}{\partial \phi} \hat{\phi}+v_{\phi} \frac{\partial \hat{\phi}}{\partial \phi}+\frac{\partial v_{z}}{\partial \phi} \hat{z}+v_{z} \frac{\partial \hat{z}}{\partial \phi}\right]
$$

Substituindo as derivadas, em $\phi$, dos vetores unitários (Equação A.6), temos:

$$
v_{\phi} \frac{\partial \vec{v}}{\partial \phi}=\frac{v_{\phi}}{r}\left[\left(\frac{\partial v_{r}}{\partial \phi}-v_{\phi}\right) \hat{r}+\left(\frac{\partial v_{\phi}}{\partial \phi}+v_{r}\right) \hat{\phi}+\frac{\partial v_{z}}{\partial \phi} \hat{z}\right]
$$




\section{(iii) Coordenada vertical}

$$
\frac{d z}{d t} \frac{\partial \vec{v}}{\partial z}=v_{z}\left[\frac{\partial v_{r}}{\partial z} \hat{r}+v_{r} \frac{\partial \hat{r}}{\partial z}+\frac{\partial v_{\phi}}{\partial z} \hat{\phi}+v_{\phi} \frac{\partial \hat{\phi}}{\partial z}+\frac{\partial v_{z}}{\partial z} \hat{z}+v_{z} \frac{\partial \hat{z}}{\partial z}\right]
$$

Como todas as derivadas dos vetores unitaŕios em $z$ são nulas, obtemos:

$$
v_{z} \frac{\partial \vec{v}}{\partial z}=v_{z}\left(\frac{\partial v_{r}}{\partial z} \hat{r}+\frac{\partial v_{\phi}}{\partial z} \hat{\phi}+\frac{\partial v_{z}}{\partial z} \hat{z}\right)
$$

Logo, obtemos o set de equações abaixo, responsável por descrever a conservação de momento angular do fluido:

$$
\left\{\begin{array}{l}
\frac{\partial v_{r}}{\partial t}+v_{r} \frac{\partial v_{r}}{\partial r}+\frac{v_{\phi}}{r} \frac{\partial v_{r}}{\partial \phi}-\frac{v_{\phi}^{2}}{r}+v_{z} \frac{\partial v_{r}}{\partial z}=-g_{R}-\frac{1}{\rho} \frac{\partial P}{\partial r}+\frac{1}{\rho}(\nabla \cdot \vec{\Pi})_{r} \\
\frac{\partial v_{\phi}}{\partial t}+v_{r} \frac{\partial v_{\phi}}{\partial r}+\frac{v_{\phi}}{r} v_{r}+\frac{v_{\phi}}{r} \frac{\partial v_{\phi}}{\partial \phi}+v_{z} \frac{\partial v_{\phi}}{\partial z}=-\frac{1}{r} \frac{\partial \Phi}{\partial \phi}-\frac{1}{\rho r} \frac{\partial P}{\partial \phi}+\frac{1}{\rho}(\nabla \cdot \vec{\Pi})_{\phi} \\
\frac{\partial v_{z}}{\partial t}+v_{r} \frac{\partial v_{z}}{\partial r}+\frac{v_{\phi}}{r} \frac{\partial v_{z}}{\partial \phi}+v_{z} \frac{\partial v_{z}}{\partial z}=-\frac{\partial \Phi}{\partial z}-\frac{1}{\rho} \frac{\partial P}{\partial z}+\frac{1}{\rho}(\nabla \cdot \vec{\Pi})_{z} .
\end{array}\right.
$$

\section{A.2 O tensor de stress viscoso}

Conforme descrito na Seção 2.1, o tensor de stress viscoso é definido por:

$$
\Pi_{i k}=\mu\left[\frac{\partial w_{i}}{\partial x_{k}}+\frac{\partial w_{k}}{\partial x_{i}}-\frac{2}{3}(\vec{\nabla} \cdot \vec{v}) \delta_{i k}\right]+\zeta \frac{\partial w_{j}}{\partial x_{j}} \delta_{i k}
$$

onde $\frac{\partial w_{i}}{\partial x_{k}}$ representa uma componente do tensor gradiente de velocidade. Sendo o gradiente de uma grandeza tensorial definido como:

$$
\begin{array}{r}
\nabla U=\hat{r} \hat{r} \frac{\partial U_{r}}{\partial r}+\hat{r} \hat{\phi} \frac{\partial U_{\phi}}{\partial r}+\hat{r} \hat{z} \frac{\partial U_{z}}{\partial r}+\hat{\phi} \hat{r}\left(\frac{1}{r} \frac{\partial U_{r}}{\partial \phi}-\frac{U_{\phi}}{r}\right)+ \\
+\hat{\phi} \hat{\phi}\left(\frac{1}{r} \frac{\partial U_{\phi}}{\partial \phi}+\frac{U_{r}}{r}\right)+\hat{\phi} \hat{z} \frac{1}{r} \frac{\partial U_{z}}{\partial \phi}+\hat{z} \hat{r} \frac{\partial U_{r}}{\partial z}+\hat{z} \hat{\phi} \frac{\partial U_{\phi}}{\partial z}+\hat{z} \hat{z} \frac{\partial U_{z}}{\partial z}
\end{array}
$$

e tomando $\zeta \equiv 0$, as componentes do stress viscoso passam a ser descritas através de: 


$$
\begin{array}{ll}
\Pi_{r r}=\mu\left[2 \frac{\partial v_{r}}{\partial r}-\frac{2}{3}(\vec{\nabla} \cdot \vec{v})\right] & \Pi_{\phi \phi}=\mu\left[2\left(\frac{1}{r} \frac{\partial v_{\phi}}{\partial \phi}+\frac{v_{r}}{r}\right)-\frac{2}{3}(\vec{\nabla} \cdot \vec{v})\right] \\
\Pi_{z z}=\mu\left[2 \frac{\partial v_{z}}{\partial z}-\frac{2}{3}(\vec{\nabla} \cdot \vec{v})\right] & \Pi_{r \phi}=\Pi_{\phi r}=\mu\left[\frac{1}{r} \frac{\partial v_{r}}{\partial \phi}+r \frac{\partial}{\partial r}\left(\frac{v_{\phi}}{r}\right)\right] \\
\Pi_{r z}=\Pi_{z r}=\mu\left[\frac{\partial v_{z}}{\partial r}+\frac{\partial v_{r}}{\partial z}\right] & \Pi_{\phi z}=\Pi_{z \phi}=\mu\left[\frac{1}{r} \frac{\partial v_{z}}{\partial \phi}+\frac{\partial v_{\phi}}{\partial z}\right],
\end{array}
$$

onde o gradiente $(\vec{\nabla} \cdot \vec{v})$ é determinado, em coordenadas cilíndricas, por:

$$
\vec{\nabla} \cdot \vec{v}=\frac{1}{r} \frac{\partial}{\partial r}\left(r v_{r}\right)+\frac{1}{r} \frac{\partial v_{\phi}}{\partial \phi}+\frac{\partial v_{z}}{\partial z}
$$

\section{A.3 A aproximação de disco geometricamente fino}

A suposição de disco fino acarreta em algumas simplificações às equações que regem a dinâmica do disco. Considerando um sistema com simetria axial $\left(\frac{\partial}{\partial \phi}=0\right)$, de dimensão vertical muito menor que a distância radial $(H / r \ll 1)$ e com movimento confinado ao plano do disco $\left(v_{z}=0\right.$ e $\left.\frac{\partial v_{i}}{\partial z}=0\right)$, a componente azimutal do momento angular (Equação 2.7) reduz-se a:

$$
\rho\left(\frac{\partial v_{\phi}}{\partial t}+v_{r} \frac{\partial v_{\phi}}{\partial r}+\frac{v_{\phi} v_{r}}{r}\right)=(\vec{\nabla} \cdot \vec{\Pi})_{\phi}
$$

Sendo o divergente de um tensor descrito por:

$$
\begin{aligned}
\vec{\nabla} \cdot \vec{A}= & \left(\frac{\partial A_{r r}}{\partial r}+\frac{1}{r} \frac{\partial A_{r \phi}}{\partial \phi}+\frac{\partial A_{r z}}{\partial z}+\frac{A_{r r}-A_{\phi \phi}}{r}\right) \hat{r} \\
+ & \left(\frac{\partial A_{\phi r}}{\partial r}+\frac{1}{r} \frac{\partial A_{\phi \phi}}{\partial \phi}+\frac{\partial A_{\phi z}}{\partial z}+\frac{A_{\phi r}+A_{r \phi}}{r}\right) \hat{\phi} \\
& +\left(\frac{\partial A_{z r}}{\partial r}+\frac{A_{z r}}{r}+\frac{1}{r} \frac{\partial A_{z \phi}}{\partial \phi}+\frac{\partial A_{z z}}{\partial z}\right) \hat{z}
\end{aligned}
$$

a componente $\phi$ do divergente do tensor de stress viscoso é definida através de: 


$$
\begin{array}{r}
(\vec{\nabla} \cdot \vec{\Pi})_{\phi}=\frac{\partial}{\partial r}\left(\mu\left[\frac{1}{r} \frac{\partial v_{r}}{\partial \phi}+r \frac{\partial}{\partial r}\left(\frac{v_{\phi}}{r}\right)\right]\right) \\
+\frac{1}{r} \frac{\partial}{\partial \phi}\left(2 \mu\left[\frac{1}{r} \frac{\partial v_{\phi}}{\partial \phi}+\frac{v_{r}}{r}-\frac{2}{3}(\vec{\nabla} \cdot \vec{v})\right]\right) \\
+\frac{\partial}{\partial z}\left(\mu\left[2 \frac{\partial v_{z}}{\partial z}-\frac{2}{3}(\vec{\nabla} \cdot \vec{v})\right]\right) \\
+2 \frac{\mu}{r}\left[\frac{1}{r} \frac{\partial v_{r}}{\partial \phi}+r \frac{\partial}{\partial r}\left(\frac{v_{\phi}}{r}\right)\right] .
\end{array}
$$

Aplicando as aproximações de disco fino, a Equação A.19 reduz-se a:

$$
(\vec{\nabla} \cdot \vec{\Pi})_{\phi}=\frac{\partial}{\partial r}\left[\mu r \frac{\partial}{\partial r}\left(\frac{v_{\phi}}{r}\right)\right]+2 \frac{\mu}{r} r \frac{\partial}{\partial r}\left(\frac{v_{\phi}}{r}\right)
$$

a qual, após a substituição $v_{\phi}=\Omega r$ resulta, por fim, em:

$$
(\vec{\nabla} \cdot \vec{\Pi})_{\phi}=\frac{\partial}{\partial r}\left[\mu r \frac{\partial \Omega}{\partial r}\right]+2 \mu \frac{\partial \Omega}{\partial r} .
$$

Logo, obtemos a seguinte expressão para a componente azimutal da equação do momento angular:

$$
\rho\left(\frac{\partial v_{\phi}}{\partial t}+v_{r} \frac{\partial v_{\phi}}{\partial r}+\frac{v_{\phi}}{r} v_{r}\right)=\frac{\partial}{\partial r}\left[\mu r \frac{\partial \Omega}{\partial r}\right]+2 \mu \frac{\partial \Omega}{\partial r} .
$$

Substituindo $v_{\phi}$ e $\mu=\nu \rho$ :

$$
\frac{\partial(\rho \Omega r)}{\partial t}+\frac{\partial\left(\rho v_{r} \Omega r\right)}{\partial r}+\rho \Omega v_{r}=\frac{\partial}{\partial r}\left[\nu \rho r \frac{\partial \Omega}{\partial r}\right]+2 \nu \rho \frac{\partial \Omega}{\partial r}
$$

e integrando a equação em $z$ e multiplicando por $r$ :

$$
r \frac{\partial(\Sigma \Omega r)}{\partial t}+r \frac{\partial\left(\Omega r \Sigma v_{r}\right)}{\partial r}+r \Sigma \Omega v_{r}=r \frac{\partial}{\partial r}\left[\nu \Sigma r \frac{\partial \Omega}{\partial r}\right]+2 r \nu \Sigma \frac{\partial \Omega}{\partial r}
$$

Realizando as derivadas parciais, a equação acima torna-se: 


$$
\begin{aligned}
& r\left[\frac{\partial \Sigma}{\partial t} \Omega r+\Sigma\left(\frac{\partial \Omega}{\partial t} r+\Omega v_{r}\right)\right]+r\left[\frac{\partial \Sigma}{\partial r} \Omega r v_{r}+\Sigma\left(\frac{\partial v_{r}}{\partial r} r \Omega+v_{r} \Omega+v_{r} r \frac{\partial \Omega}{\partial r}\right)\right] \\
& +r \Omega \Sigma v_{r}=r\left[\frac{\partial \Sigma}{\partial r} \nu r \frac{\partial \Omega}{\partial r}+\Sigma\left(\frac{\partial \nu}{\partial r} r \frac{\partial \Omega}{\partial r}+\nu \frac{\partial \Omega}{\partial r}+\nu r \frac{\partial}{\partial r} \frac{\partial \Omega}{\partial r}\right)\right]+2 r \nu \Sigma \frac{\partial \Omega}{\partial r}
\end{aligned}
$$

Agrupando os termos e tomando $\frac{\partial \Omega}{\partial t}=0$, obtemos:

$$
\begin{aligned}
& \frac{\partial \Sigma}{\partial t} \Omega r^{2}+3 r \Sigma \Omega v_{r}+r^{2} \frac{\partial \Sigma}{\partial r} \Omega v_{r}+\Sigma r^{2} \frac{\partial v_{r}}{\partial r} \Omega+\Sigma r^{2} v_{r} \frac{\partial \Omega}{\partial r} \\
& =\frac{\partial \Sigma}{\partial r} \nu r^{2} \frac{\partial \Omega}{\partial r}+\Sigma r^{2} \frac{\partial \nu}{\partial r} \frac{\partial \Omega}{\partial r}+3 \nu r \frac{\partial \Omega}{\partial r} \Sigma+\Sigma \nu r^{2} \frac{\partial}{\partial r} \frac{\partial \Omega}{\partial r}
\end{aligned}
$$

Sabendo que:

$$
\frac{1}{r} \frac{\partial}{\partial r}\left(\Sigma \Omega r^{3} v_{r}\right)=\frac{\partial \Sigma}{\partial r} \Omega r^{2} v_{r}+\Sigma r^{2} \Omega \frac{\partial v_{r}}{\partial r}+3 \Sigma v_{r} r \Omega+\Sigma v_{r} r^{2} \frac{\partial \Omega}{\partial r}
$$

e

$$
\frac{1}{r} \frac{\partial}{\partial r}\left(\nu \Sigma r^{3} \frac{\partial \Omega}{\partial r}\right)=\frac{\partial \Sigma}{\partial r} \nu r^{2} \frac{\partial \Omega}{\partial r}+\Sigma r^{2} \frac{\partial \nu}{\partial r} \frac{\partial \Omega}{\partial r}+3 \nu r \frac{\partial \Omega}{\partial r} \Sigma+\Sigma \nu r^{2} \frac{\partial}{\partial r} \frac{\partial \Omega}{\partial r}
$$

a equação de conservação de momento angular, na direção azimutal, assume a forma:

$$
\frac{\partial \Sigma}{\partial t} \Omega r^{2}+\frac{1}{r} \frac{\partial}{\partial r}\left(\Sigma \Omega r^{3} v_{r}\right)=\frac{1}{r} \frac{\partial}{\partial r}\left(\nu \Sigma r^{3} \frac{\partial \Omega}{\partial r}\right)
$$

Substituindo a equação de continuidade (Equação A.30,

$$
\frac{\partial \Sigma}{\partial t}=-\frac{1}{r} \frac{\partial}{\partial r}\left(r v_{r} \Sigma\right)
$$

na Equação A.29, obtemos:

$$
-\frac{\Omega r^{2}}{r} \frac{\partial}{\partial r}\left(r v_{r} \Sigma\right)+\frac{1}{r} \frac{\partial}{\partial r}\left(\Sigma \Omega r^{3} v_{r}\right)=\frac{1}{r} \frac{\partial G}{\partial r}
$$


onde $G=\nu \Sigma r^{3} \partial \Omega / \partial r$ denota o torque atuando sobre o disco. Realizando as derivadas parciais e rearranjando os termos da Equação A.31, chega-se a:

$$
\Sigma v_{r} r \frac{\partial}{\partial r}\left(\Omega r^{2}\right)=\frac{\partial G}{\partial r}
$$

Isolando a velocidade radial na Equação A.32.

$$
v_{r}=\frac{\partial G / \partial r}{\Sigma r\left[\partial\left(\Omega r^{2}\right) / \partial r\right]}
$$

e substituindo na equação de continuidade (Equação A.30 obtemos, finalmente, a equação que rege a evolução da densidade superficial no disco:

$$
\begin{gathered}
\frac{\partial \Sigma}{\partial t}=-\frac{1}{r} \frac{\partial}{\partial r}\left[r \Sigma \frac{\partial G / \partial r}{r \Sigma \partial\left(\Omega r^{2}\right) / \partial r}\right] \\
\frac{\partial \Sigma}{\partial t}=-\frac{1}{r} \frac{\partial}{\partial r}\left[\frac{\partial G / \partial r}{\partial\left(\Omega r^{2}\right) / \partial r}\right] .
\end{gathered}
$$

Se assumirmos que a velocidade angular do disco é dada pela velocidade Kepleriana, $\Omega=$ $\left(G M / r^{3}\right)^{1 / 2}$, a equação que governa a evolução temporal da densidade superficial, para discos Keplerianos, assume a forma:

$$
\frac{\partial \Sigma}{\partial t}=\frac{3}{r} \frac{\partial}{\partial r}\left[r^{1 / 2} \frac{\partial}{\partial r}\left(\nu \Sigma r^{1 / 2}\right)\right]
$$

\section{A.4 A aproximação do disco geometricamente fino, opticamente espesso e estacionário}

Aplicando as restrições impostas pelo fato do disco considerado ser geometricamente fino, estacionário e possuir simetria axial, a saber, $v_{z}=0, \partial v_{i} / \partial z=0, \partial / \partial \phi=0$ e $\partial / \partial t=0$, na componente radial da equação de momento, obtemos:

$$
v_{r} \frac{\partial v_{r}}{\partial r}-\frac{v_{\phi}^{2}}{r}=-g_{R}-\frac{1}{\rho} \frac{\partial P}{\partial r}+\frac{1}{\rho}(\nabla \cdot \vec{\Pi})_{r},
$$

onde $(\nabla \cdot \vec{\Pi})_{r}$ é dado por: 


$$
\begin{array}{r}
(\vec{\nabla} \cdot \vec{\Pi})_{r}=\left(\frac{\partial \Pi_{r r}}{\partial r}+\frac{1}{r} \frac{\partial \Pi_{r \phi}}{\partial \phi}+\frac{\partial \Pi_{r z}}{\partial z}+\frac{\Pi_{r r}-\Pi_{\phi \phi}}{r}\right) \\
(\vec{\nabla} \cdot \vec{\Pi})_{r}=\left(\frac{\partial \Pi_{r r}}{\partial r}+\frac{\Pi_{r r}-\Pi_{\phi \phi}}{r}\right)
\end{array}
$$

onde aplicamos o divergente tensorial (Equação A.18) e empregamos as restrições supracitadas. Substituindo as componentes do stress viscoso (Equação A.15), com as aproximações apropriadas, obtemos:

$$
(\vec{\nabla} \cdot \vec{\Pi})_{r}=\frac{\partial}{\partial r}\left[2 \mu \frac{\partial v_{r}}{\partial r}-\frac{2}{3} \mu(\vec{\nabla} \cdot \vec{v})\right]+\frac{2 \mu}{r} \frac{\partial v_{r}}{\partial r}-\frac{2 \mu v_{r}}{r^{2}}
$$

onde $(\vec{\nabla} \cdot \vec{v})$ reduz-se à:

$$
(\vec{\nabla} \cdot \vec{v})_{r}=\frac{1}{r} \frac{\partial}{\partial r}\left(r v_{r}\right)
$$

Logo,

$$
\begin{array}{r}
(\vec{\nabla} \cdot \vec{\Pi})_{r}=\frac{\partial}{\partial r}\left[2 \mu \frac{\partial v_{r}}{\partial r}-\frac{2}{3} \frac{\mu}{r} \frac{\partial}{\partial r}\left(r v_{r}\right)\right]+\frac{2 \mu}{r} \frac{\partial v_{r}}{\partial r}-\frac{2 \mu v_{r}}{r^{2}} \\
(\vec{\nabla} \cdot \vec{\Pi})_{r}=2 \frac{\partial \mu}{\partial r} \frac{\partial v_{r}}{\partial r}+2 \mu \frac{\partial}{\partial r} \frac{\partial v_{r}}{\partial r}-\frac{2}{3}\left[\frac{1}{r} \frac{\partial \mu}{\partial r} \frac{\partial}{\partial r}\left(r v_{r}\right)-\frac{\mu}{r^{2}} \frac{\partial}{\partial r}\left(r v_{r}\right)\right. \\
\left.+\frac{\mu}{r} \frac{\partial}{\partial r} \frac{\partial\left(r v_{r}\right)}{\partial r}\right]+\frac{2 \mu}{r} \frac{\partial v_{r}}{\partial r}-\frac{2 \mu v_{r}}{r^{2}} .
\end{array}
$$

Sendo $\partial / \partial r\left(r v_{r}\right)=v_{r}+r \frac{\partial v_{r}}{\partial r}$ :

$$
\begin{gathered}
(\vec{\nabla} \cdot \vec{\Pi})_{r}=2 \frac{\partial \mu}{\partial r} \frac{\partial v_{r}}{\partial r}+2 \mu \frac{\partial}{\partial r} \frac{\partial v_{r}}{\partial r}-\frac{2}{3 r} \frac{\partial \mu}{\partial r}\left[v_{r}+r \frac{\partial v_{r}}{\partial r}\right] \\
+\frac{2}{3} \frac{\mu}{r^{2}}\left[v_{r}+r \frac{\partial v_{r}}{\partial r}\right]-\frac{2 \mu}{3 r} \frac{\partial}{\partial r}\left[v_{r}+r \frac{\partial v_{r}}{\partial r}\right] \frac{2 \mu}{r} \frac{\partial v_{r}}{\partial r}-\frac{2 \mu v_{r}}{r^{2}} .
\end{gathered}
$$

Realizando as derivadas parciais e eliminando os termos de sinais opostos, obtemos, finalmente:

$$
(\vec{\nabla} \cdot \vec{\Pi})_{r}=\frac{4}{3} \frac{\partial \mu}{\partial r} \frac{\partial v_{r}}{\partial r}+\frac{4}{3} \mu \frac{\partial}{\partial r} \frac{\partial v_{r}}{\partial r}-\frac{2}{3} \frac{\partial \mu}{\partial r} \frac{v_{r}}{r}-\frac{4}{3} \frac{\mu}{r^{2}} v_{r}+\frac{4}{3} \frac{\mu}{r} \frac{\partial v_{r}}{\partial r},
$$


de forma que a componente radial da equação de conservação de momento angular, para um disco geometricamente fino e estacionário, assume a forma:

$$
\begin{aligned}
v_{r} \frac{\partial v_{r}}{\partial r}-\frac{v_{\phi}^{2}}{r}=-g_{R}- & \frac{1}{\rho} \frac{\partial P}{\partial r}+\frac{4}{3 \rho} \frac{\partial \mu}{\partial r} \frac{\partial v_{r}}{\partial r}+\frac{4}{3 \rho} \mu \frac{\partial}{\partial r} \frac{\partial v_{r}}{\partial r} \\
& -\frac{2}{3 \rho} \frac{\partial \mu}{\partial r} \frac{v_{r}}{r}-\frac{4}{3 \rho} \frac{\mu}{r^{2}} v_{r}+\frac{4}{3 \rho} \frac{\mu}{r} \frac{\partial v_{r}}{\partial r}
\end{aligned}
$$

O termo dominante da Equação A.43 pode ser obtido através da análise da ordem de grandeza de cada termo. Aproximando $\partial / \partial r \sim 1 / r$ e assumindo que a velocidade radial, $v_{r}$, é subsônica e que a velocidade circular, $v_{\phi}$, é altamente supersônica (Vasconcelos, 2000), temos:

$$
\frac{v_{r}^{2}}{r}-\frac{v_{\phi}^{2}}{r}=-g_{r}-\frac{1}{\rho} \frac{P}{r}+2 \frac{\mu v_{r}}{\rho r^{2}}
$$

Como a massa do disco é desprezível em relação à massa do objeto central, sua autogravidade pode ser negligenciada, de forma que:

$$
g_{r}=\frac{G M_{*}}{r^{2}}
$$

onde $M_{*}$ representa a massa da estrela. O termo relacionado à pressão, por sua vez, pode ser reescrito como:

$$
\frac{1}{\rho} \frac{P}{r}=\frac{1}{r} c_{s}^{2}
$$

sendo $c_{s}$ a velocidade do som isotérmica. Por fim, o termo relacionado ao stress viscoso pode ser aproximado por:

$$
2 \frac{\mu v_{r}}{\rho r^{2}}=2 \frac{\nu v_{r}}{r^{2}}
$$

onde foi utilizado que $\mu=\nu \rho$. Supondo que a viscosidade segue a prescrição de Shakura e Sunyaev (1973), 


$$
\nu=\alpha c_{s} H
$$

com $H$ sendo a escala de altura do disco, a Equação A.47 é reescrita como:

$$
2 \frac{\nu v_{r}}{r^{2}}=2 \frac{H}{r} \frac{\alpha c_{s} v_{r}}{r}
$$

Como $H / r \ll 1$, devido à aproximação de disco fino, e $\alpha<1$, por definição, temos que:

$$
2 \frac{\nu v_{r}}{r^{2}}<2 \frac{c_{s} v_{r}}{r}<\frac{c_{s}^{2}}{r}
$$

Logo, a Equação A.44 pode ser bem aproximada por:

$$
\begin{gathered}
-\frac{v_{\phi}^{2}}{r}=-g_{r}-\frac{c_{s}^{2}}{r} \\
-\frac{v_{\phi}^{2}}{r}+\frac{c_{s}^{2}}{r}=-g_{r} .
\end{gathered}
$$

Como $v_{\phi}>c_{s}$, temos que:

$$
\frac{v_{\phi}^{2}}{r}=g_{r}
$$

o qual, por sua vez, resulta em:

$$
\begin{aligned}
\frac{v_{\phi}^{2}}{r} & =\frac{G M_{*}}{r^{2}} \\
\Omega^{2} r & =\frac{G M_{*}}{r^{2}} \\
\Omega=\left(\frac{G M_{*}}{r^{3}}\right)^{1 / 2} & =\Omega_{K} .
\end{aligned}
$$

Portanto, para um disco geometricamente fino e estacionário, a velocidade circular será dada pela velocidade Kepleriana.

Integrando a Equação A.30 sobre a área diferencial do disco, $2 \pi 2 d r$, obtemos a taxa de acreção correspondente ao regime estacionário: 


$$
\frac{\partial}{\partial t} \int_{r_{i n}}^{r_{e x t}} \Sigma 2 \pi r d r=-\int_{r_{i n}}^{r_{e x t}}-\frac{1}{r} \frac{\partial}{\partial r}\left(r v_{r} \Sigma\right) 2 \pi r d r
$$

onde $r_{i n}$ e $r_{\text {ext }}$ correspondem aos raios interno e externo do disco, respectivamente. A equação acima pode ser reescrita ainda como:

$$
\frac{\partial}{\partial t}\left[\Sigma \pi\left(r_{e x t}^{2}-r_{i n}^{2}\right)\right]=-\int_{r_{i n}}^{r_{e x t}} 2 \pi \frac{\partial}{\partial r}\left(r v_{r} \Sigma\right) d r
$$

Entretanto, temos que $\Sigma \pi\left(r_{e x t}^{2}-r_{i n}^{2}\right)=M$, onde $M$ equivale à massa total do disco. Logo, chegamos que a taxa de acreção é descrita por:

$$
\dot{M}=2 \pi r \Sigma\left(-v_{r}\right)
$$

onde define-se $\dot{M}=\frac{\partial M}{\partial t}$.

Utilizando a Equação A.29 e aplicando a condição de disco estacionário $(\partial / \partial t=0)$, essa equação reduz-se a:

$$
\frac{1}{r} \frac{\partial}{\partial r}\left(\Omega r^{2} \Sigma r v_{r}\right)=\frac{1}{r} \frac{\partial}{\partial r}\left(\nu \Sigma r^{3} \frac{\partial \Omega}{\partial r}\right)
$$

Agora, utilizando a prescrição dada pela Equação A.54 na Equação A.55, chega-se a:

$$
\frac{\partial}{\partial r}\left(-\Omega r^{2} \dot{M}\right)=2 \pi \frac{\partial}{\partial r}\left(\nu \Sigma r^{3} \frac{\partial \Omega}{\partial r}\right)
$$

Integrando a equação acima em $r$, obtemos:

$$
\Omega r^{2} \dot{M}=-2 \pi r\left(\nu \Sigma r^{2} \frac{\partial \Omega}{\partial r}\right)+J
$$

onde $J$ corresponde à uma constante de integração, a qual depende das condições de contorno do problema e pode ser avaliada se supormos que $\Omega$ atinge seu valor máximo em uma região próxima à interface entre o disco e a estrela (Vasconcelos, 2000), definida por: 


$$
J \sim \dot{M} R_{*}^{2} \Omega\left(R_{*}\right)
$$

sendo $R_{*}$ equivalente ao raio da estrela. Logo, a Equação A.56 torna-se:

$$
\Omega r^{2} \dot{M}-\dot{M} R_{*}^{2} \Omega\left(R_{*}\right)=-2 \pi r\left(\nu \Sigma r^{2} \frac{\partial \Omega}{\partial r}\right)
$$

Dividindo a equação acima por $r^{2}$ e derivando a velocidade Kepleriana, $\Omega$, obtemos:

$$
\dot{M}\left[\Omega-\Omega\left(R_{*}\right)\left(\frac{R_{*}}{r}\right)^{2}\right]=3 \Omega \pi \nu \Sigma .
$$

Agora, se substituírmos as prescrições para $\Omega$ e $\Omega\left(R_{*}\right)$, podemos reescrever a equação acima como:

$$
\begin{aligned}
& \dot{M}\left[\frac{\left(G M_{*}\right)^{1 / 2}}{r^{3 / 2}}-\frac{\left(G M_{*}\right)^{1 / 2}}{R_{*}^{3 / 2}}\left(\frac{R_{*}}{r}\right)^{2}\right]=3 \Sigma \pi \nu \frac{\left(G M_{*}\right)^{1 / 2}}{r^{3 / 2}} \\
& \nu \Sigma=\frac{\dot{M}}{3 \pi}\left[\frac{1}{r^{3 / 2}}-\frac{R_{*}^{1 / 2}}{r^{2}}\right] r^{3 / 2} \\
& \nu \Sigma=\frac{\dot{M}}{3 \pi}\left[1-\left(\frac{R_{*}}{r}\right)^{1 / 2}\right],
\end{aligned}
$$

que corresponde à evolução radial da densidade superficial do disco.

Sendo a componente vertical da equação de conservação de momento descrita por:

$$
\frac{\partial v_{z}}{\partial t}+v_{r} \frac{\partial v_{z}}{\partial r}+\frac{v_{\phi}}{r} \frac{\partial v_{z}}{\partial \phi}+v_{z} \frac{\partial v_{z}}{\partial z}=-\frac{\partial \Phi}{\partial z}-\frac{1}{\rho} \frac{\partial P}{\partial z}+\frac{1}{\rho}(\nabla \cdot \vec{\Pi})_{z}
$$

obtemos que, após as aproximações relacionadas à hipótese de disco fino e estacionário, essa equação torna-se:

$$
\frac{1}{\rho} \frac{\partial P}{\partial z}=-\frac{\partial \Phi}{\partial z}
$$

Sendo o potencial gravitacional definido por: 


$$
\Phi=\frac{G M_{*}}{\left(R^{2}+z^{2}\right)^{1 / 2}}
$$

obtemos que o gradiente da pressão na direção vertical fica definido como:

$$
\frac{\partial P}{\partial z}=\rho \frac{z G M_{*}}{\left(R^{2}+z^{2}\right)^{3 / 2}}
$$

Colocando a distância radial, $r$, em evidência, e fazendo uso do fato de que $z / r \ll 1$ (hipótese de disco geometricamente fino), a Equação A.61 torna-se:

$$
\frac{\partial P}{\partial z}=\rho z \Omega^{2}
$$

Sendo a escala de comprimento típica na direção vertical a escala de altura, $H$, podemos supor que $\frac{\partial P}{\partial z} \sim P / H$ e $z \sim H$. Além disso, sendo a pressão relacionada à densidade por:

$$
c_{s}^{2}=P / \rho,
$$

a Equação A.62 fica sendo definida como:

$$
\frac{\rho c_{s}^{2}}{H}=\rho H \Omega_{K}^{2}
$$

de forma que é possível relacionar a escala de altura do disco à razão entre as velocidades de rotação e do som, na forma:

$$
H=\frac{c_{s}}{\Omega}
$$

A conservação de energia (Equação 2.9), por sua vez, pode ser escrita por:

$$
\begin{aligned}
\rho\left[\frac{\partial \epsilon}{\partial t}+v_{r} \frac{\partial \epsilon}{\partial r}+\frac{v_{\phi}}{r} \frac{\partial \epsilon}{\partial \phi}+v_{z} \frac{\partial \epsilon}{\partial z}\right] & =-P\left[\frac{1}{r} \frac{\partial}{\partial r}\left(r v_{r}\right)+\frac{1}{r} \frac{\partial v_{\phi}}{\partial \phi}+\frac{\partial v_{z}}{\partial z}\right]- \\
& -\left\{\frac{1}{r} \frac{\partial}{\partial r}\left(r F_{r}\right)+\frac{1}{r} \frac{\partial F_{\phi}}{\partial \phi}+\frac{\partial F_{z}}{\partial z}\right\}+\Psi,
\end{aligned}
$$


onde a taxa de dissipação viscosa, $\Psi$, é definido como:

$$
\Psi=\prod_{i k} \frac{\partial w_{i}}{\partial x_{k}}
$$

sendo $\Pi_{i k}$ as componentes do stress viscoso (Equação A.15) e $\frac{\partial w_{i}}{\partial x_{k}}$ as componentes do gradiente do tensor de stress viscoso.

A Equação A.65 pode ser escrita, de maneira mais extensa, como:

$$
\begin{aligned}
\Psi=\Pi_{r r} \frac{\partial w_{r}}{\partial r} & +\Pi_{r \phi}\left(\frac{\partial w_{r}}{\partial \phi}+\frac{\partial w_{\phi}}{\partial r}\right)+\Pi_{r z}\left(\frac{\partial w_{r}}{\partial z}+\frac{\partial w_{z}}{\partial r}\right)+ \\
& +\Pi_{\phi \phi} \frac{\partial w_{\phi}}{\partial \phi}+\Pi_{\phi z}\left(\frac{\partial w_{\phi}}{\partial z}+\frac{\partial w_{z}}{\partial \phi}\right)+\Pi_{z z} \frac{\partial w_{z}}{\partial z}
\end{aligned}
$$

Substituindo as componentes do stress viscoso, definidos pela Equação A.15, e as componentes do gradiente do stress (Equação A.14 na Equação A.66, obtemos a seguinte prescrição para $\Psi$ :

$$
\begin{array}{r}
\Psi=\mu\left\{2\left[\left(\frac{\partial v_{r}}{\partial r}\right)^{2}+\left(\frac{1}{r} \frac{\partial v_{\phi}}{\partial \phi}+\frac{v_{r}}{r}\right)^{2}+\left(\frac{\partial v_{z}}{\partial z}\right)^{2}\right]+\right. \\
\left.+\left[\frac{1}{r} \frac{\partial v_{r}}{\partial \phi}+r \frac{\partial}{\partial r}\left(\frac{v_{\phi}}{r}\right)\right]^{2}+\left(\frac{\partial v_{z}}{\partial r}+\frac{\partial v_{r}}{\partial z}\right)^{2}+\left(\frac{1}{r} \frac{\partial v_{z}}{\partial \phi}+\frac{\partial v_{\phi}}{\partial z}\right)^{2}-\frac{2}{3}(\nabla \cdot \vec{v})^{2}\right\}
\end{array}
$$

Aplicando as aproximações relevantes ao problema sob consideração, a Equação A.67tornase:

$$
\Psi=\mu\left\{2\left[\left(\frac{\partial v_{r}}{\partial r}\right)^{2}+\left(\frac{v_{r}}{r}\right)^{2}\right]+\left[r \frac{\partial}{\partial r}\left(\frac{v_{\phi}}{r}\right)\right]^{2}-\frac{2}{3}\left(\frac{\partial v_{r}}{\partial r}+\frac{v_{r}}{r}\right)^{2}\right\}
$$

Como em discos de acreção a velocidade radial é muito menor que a velocidade de rotação, $v_{r} \ll v_{\phi}$, obtemos que a taxa de dissipação viscosa reduz-se a:

$$
\Psi \sim \mu\left[r \frac{\partial \Omega}{\partial r}\right]^{2}
$$


Dessa forma, a Equação A.64 passa a ser descrita, sob a aproximação de disco fino e estacionário, por:

$$
\rho v_{r} \frac{\partial \epsilon}{\partial r}=-\frac{P}{r} \frac{\partial}{\partial r}\left(r v_{r}\right)-\left\{\frac{1}{r} \frac{\partial}{\partial r}\left(r F_{r}\right)+\frac{\partial F_{z}}{\partial z}\right\}+\mu\left(r \frac{\partial \Omega}{\partial r}\right)^{2}
$$

Espera-se que devido à aproximação de disco fino os gradientes na direção vertical sejam muito maiores que na direção radial (Vasconcelos, 2000). Logo,

$$
\frac{\partial F_{z}}{\partial z}=\mu\left(r \frac{\partial \Omega}{\partial r}\right)^{2}
$$

Dessa forma, obtemos, após a derivação da velocidade Kepleriana, que a variação do fluxo, na direção vertical, é dada por:

$$
\frac{\partial F_{z}}{\partial z}=\frac{9}{4} \nu \rho \frac{G M_{*}}{r^{3}}
$$

onde novamente usamos $\mu=\nu \rho$.

Finalmente, integrando a Equação A.69 na extensão vertical do disco, obtemos a energia

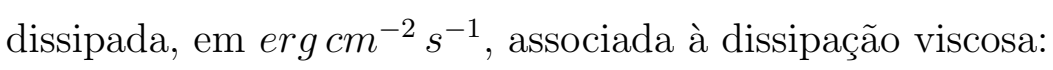

$$
D=\frac{9}{4} \frac{G M_{*}}{r^{3}} \nu \Sigma
$$

Substituindo a prescrição dada pela Equação A.58 na equação acima, chegamos a:

$$
D=\frac{3}{4 \pi} \frac{G M_{*} \dot{M}}{r^{3}}\left[1-\left(\frac{R_{*}}{r}\right)^{1 / 2}\right]
$$

A Equação A.70 refere-se à energia total dissipada pelo disco. Se considerarmos a irradiação associada à apenas uma das faces, obtemos que a energia dissipada, por cada face do disco, é dada por:

$$
D=\frac{3}{8 \pi} \frac{G M_{*} \dot{M}}{r^{3}}\left[1-\left(\frac{R_{*}}{r}\right)^{1 / 2}\right]
$$

